\title{
Effects of Total Dissolved Gas on Chum Salmon Fry Incubating in the Lower Columbia River
}

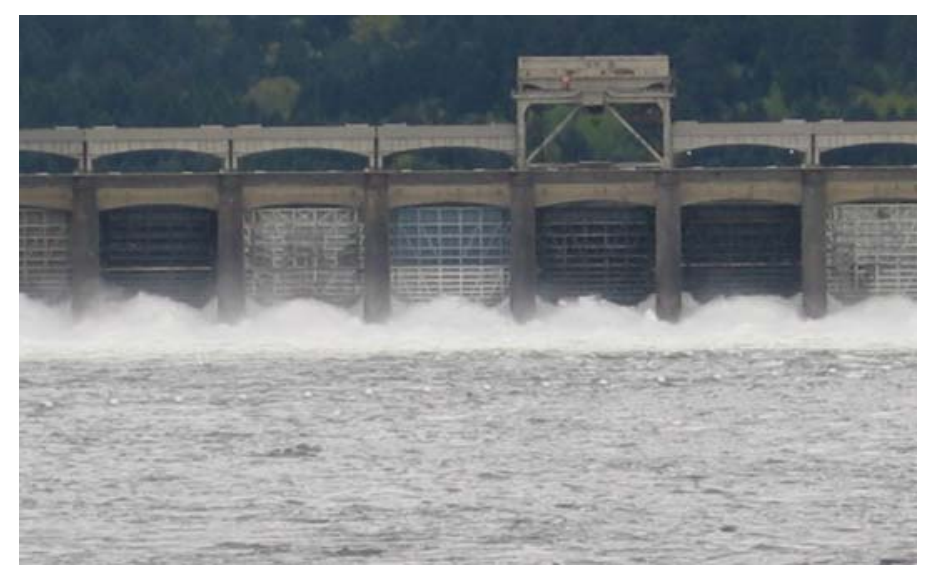
E. V. Arntzen
K. D. Hand
D. R. Geist
K. J. Murray
J. L. Panther
V. I. Cullinan
E. M. Dawley
R. A. Elston

Final Report

January 2008

Prepared for the U.S. Army Corps of Engineers

Portland District, Portland, Oregon under a Related Services Agreement with the U.S. Department of Energy Contract DE-AC05-76RL01830

\section{Pacific Northwest \\ National Laboratory}

Operated by Battelle for the

U.S. Department of Energy 


\title{
DISCLAIMER
}

This report was prepared as an account of work sponsored by an agency of the United States Government. Neither the United States Government nor any agency thereof, nor Battelle Memorial Institute, nor any of their employees, makes any warranty, express or implied, or assumes any legal liability or responsibility for the accuracy, completeness, or usefulness of any information, apparatus, product, or process disclosed, or represents that its use would not infringe privately owned rights. Reference herein to any specific commercial product, process, or service by trade name, trademark, manufacturer, or otherwise does not necessarily constitute or imply its endorsement, recommendation, or favoring by the United States Government or any agency thereof, or Battelle Memorial Institute. The views and opinions of authors expressed herein do not necessarily state or reflect those of the United States Government or any agency thereof.

\author{
PACIFIC NORTHWEST NATIONAL LABORATORY \\ operated by \\ BATTELLE \\ for the \\ UNITED STATES DEPARTMENT OF ENERGY \\ under Contract DE-AC05-76RL01830
}

Printed in the United States of America

\author{
Available to DOE and DOE contactors from the \\ Office of Scientific and Technical Information, \\ P.O. Box 62, Oak Ridge, TN 37831-0062; \\ ph: (865) 576-8401 \\ fax: (865) 576-5728 \\ email: reports@adonis.osti.gov
}

\begin{abstract}
Available to the public from the National Technical Information Service, U.S. Department of Commerce, 5285 Port Royal Rd., Springfield, VA 22161 ph: (800) 553-6847$$
\text { fax: (703) 605-6900 }
$$

email: orders@ntis.fedworld.gov online ordering: http://www.ntis.gov/ordering.htm
\end{abstract}




\section{Effects of Total Dissolved Gas on Chum Salmon Fry Incubating in the Lower Columbia River}
E. V. Arntzen
K. D. Hand
D. R. Geist
K. J. Murray
J. L. Panther
V. I. Cullinan
E. M. Dawley
R. A. Elston

Final Report

January 2008

Prepared for the U.S. Army Corps of Engineers

Portland District, Portland, Oregon

under a Related Services Agreement

with the U.S. Department of Energy

Contract DE-AC05-76RL01830

Pacific Northwest National Laboratory

Richland, Washington 99352 
Incubating in the Lower Columbia River

Cover photo: Bonneville Dam Spillway

Image provided by the project research team, Pacific Northwest National Laboratory. 


\section{Summary}

At the request of the U.S. Army Corps of Engineers (USACE), Portland District, the Pacific Northwest National Laboratory (PNNL) conducted research to measure the concentration of total dissolved gas (TDG) in chum salmon (Oncorhynchus keta) spawning areas downstream of Bonneville Dam. The overall goal of the study was to evaluate potential impacts on chum salmon survival and development from elevated TDG that occurs during spring spill operations at Bonneville Dam.

Spring spill at the dam occurs when chum salmon sac fry are still in the gravel. Prior to this study, no data existed on the concentration of TDG within gravel incubation habitat. Further, little research has been conducted recently on the effects of gas supersaturation on incubating and larval stages of salmonids. The guidance used by hydropower system managers to provide protection for pre-emergent chum salmon fry has been to limit TDG to $105 \%$ after allowing for depth compensation. A previous literature review completed in early 2006 shows that TDG levels as low as 103\% have been documented to cause mortality in sac fry. Our study evaluated whether depth-compensated TDG higher than 103\% occurs within chum spawning habitats and investigated the physiological response of sac fry to TDG levels above $103 \%$.

During 2006, the study involved monitoring the TDG levels at egg pocket depth and in the river at Ives Island and Multnomah Falls chum salmon spawning locations. In 2007, when Columbia River discharge was very different from discharge in 2006, a similar field effort was conducted to provide a more thorough understanding of how egg pocket TDG levels change during different water years. This study used monitoring data from both 2006 and 2007 to estimate exposure of chum salmon redds to TDG each year, respectively. Also during 2007, laboratory toxicity tests were conducted on hatchery chum salmon fry at gas levels likely to occur downstream from Bonneville Dam, and chum salmon sac fry were sampled from natural redds during Bonneville Dam spill operations to determine if there is a physiological response to TDG. These research activities resulted in five key findings:

- Depth-compensated total dissolved gas monitored at sensor locations within the hyporheic zone from March through May 2007 did not exceed 103\% TDG at either Ives Island or Multnomah Falls.

- TDG exposure estimates suggest that some redds constructed at higher elevations than those at which our sensors were emplaced (about half of the redds monitored at Ives Island during incubation year 2007) were exposed to depth-compensated TDG greater than $103 \%$ for 50 to 100 hourssubstantially higher than the estimated 10 hours for incubation year 2006.

- In the laboratory, levels ranging up to $113 \%$ TDG did not influence direct mortality of chum salmon fry exposed to various concentrations of TDG. However, sublethal tissue damage, primarily gill lesions, was measurable at levels of $108 \%$ and $113 \%$ TDG.

- In the laboratory, fry exposed to the $113 \%$ TDG level emerged about four days earlier than those of the control group.

- Few external signs of gas bubble disease were seen in qualitative assessments of sac fry sampled from natural redds in the Ives Island area. However, internal signs of gas bubble disease included inflated swim bladders and bubbles in the intestinal tract. 
Collectively, these results suggest that Ives Island area chum salmon redds are exposed to TDG levels sufficient to cause measurable physiological signs of gas bubble disease. Although acute mortality did not occur in the laboratory study, we observed sublethal physiological effects suggestive of a long-term, chronic impact from TDG downstream of Bonneville Dam. Quantification of mortality and the long-term chronic impacts of TDG exposure to incubating sac fry in natural redds is necessary to conclusively estimate risk to incubating chum salmon sac fry. 


\section{Contents}

Summary

Abbreviations and Acronyms

iii

Overview

Chapter 1 - Assessment of Total Dissolved Gas Within Chum Salmon Spawning Areas in the Columbia River Downstream of Bonneville Dam Introduction

Study Sites

Methods

Water Quality Monitoring at Ives Island and Multnomah Falls Spawning Locations ...

Estimated Exposure of Chum Salmon Redds to Total Dissolved Gas Results

Comparison of PNNL Surface Water TDG Monitoring to Other Columbia River Monitoring Locations.....

Water Quality Monitoring at Ives Island and Multnomah Falls Spawning Locations ...

Estimated Exposure of Chum Salmon Redds to Total Dissolved Gas .

Discussion

Water Quality

Total Dissolved Gas Exposure Estimates

Chapter 2 - Bioassays on the Formation of Gas Bubble Disease in Chum Salmon Fry at Total Dissolved Gas Levels Ranging up to $113 \%$ Saturation.

Introduction

Methods

Egg Source, Egg and Alevin Incubation

Supersaturated Gas and Temperature Control

Alevin Exposure to Supersaturated Gas

Survival and Development

Gross Examination

Necropsy and Histology

Statistical Analysis

Results

Gas and Temperature Levels

Survival and Development

Alevin and Fry Size.

Gross Examination of Gas Bubble Disease.

Histology .....

Post-Treatment Observations

Discussion

Chapter 3 - Sampling of Chum Salmon Embryos from Natural Redds

Introduction

Study Site

Methods
O.1

1.14

1.26

1.34

1.34

1.36

x

1.1

1.2

1.4

1.4

1.11

1.12

2.1

2.1

2.1

2.2

2.2

2.3

2.4

2.5

2.5

2.6

2.7

2.7

2.9

2.11

2.14

2.14

2.18

2.18

3.1

3.1

3.1

3.2 


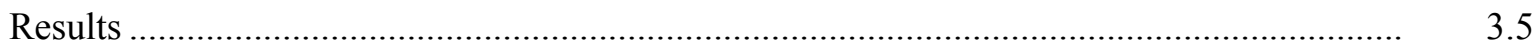

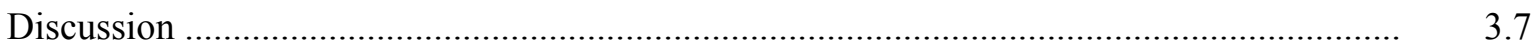

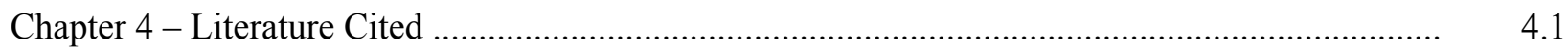

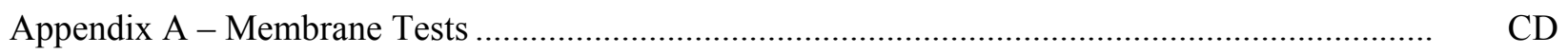

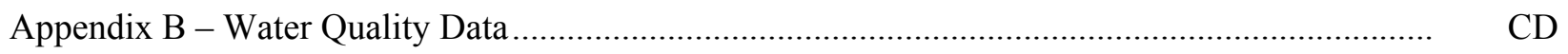

Appendix C - Total Dissolved Gas Exposure Estimates at Ives Island, Spawning Years

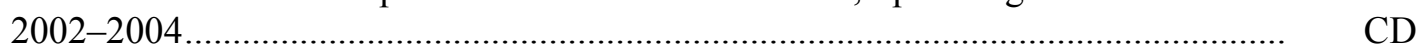

Appendix D - Ives Area Redd Dewatering …................................................................. CD 


\section{Figures}

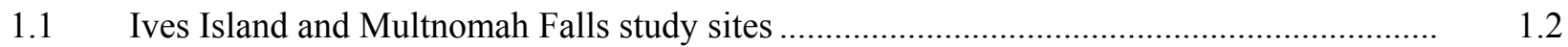

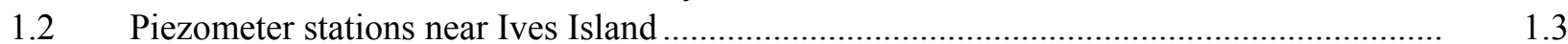

1.3 Piezometer stations near Multnomah Falls ................................................................. 1.4

1.4 Specifications of piezometers screened to the riverbed and river at Ives pair 4, Ives pair 5,

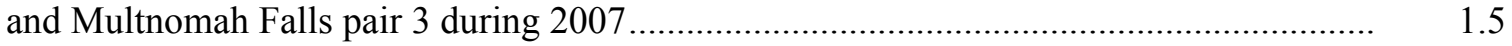

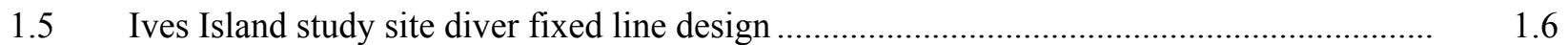

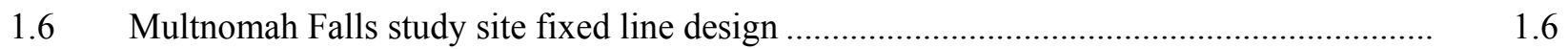

1.7 Examples of functional versus damaged membrane responses during quality assurance

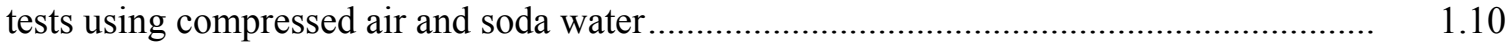

$1.8 \quad$ Total dissolved gas monitoring stations downstream of Bonneville Dam.......................... 1.13

1.9 Comparison of 2007 TDG values obtained at PNNL monitoring stations and USGS

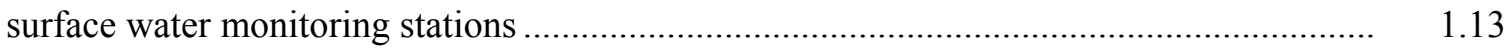

1.10 Deployment periods for water quality sensors in Ives Island area monitoring locations ..... $\quad 1.14$

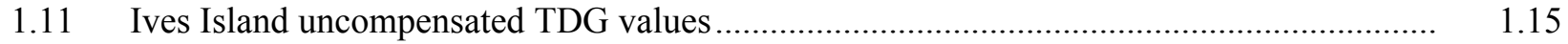

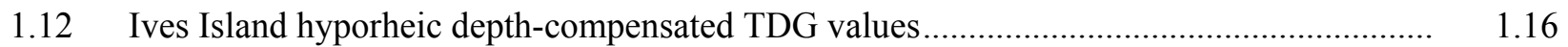

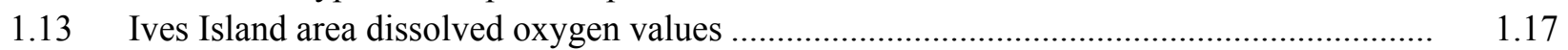

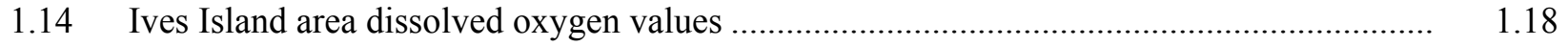

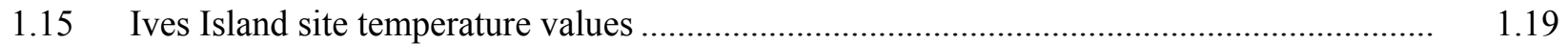

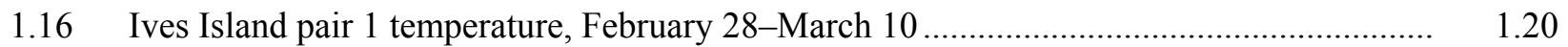

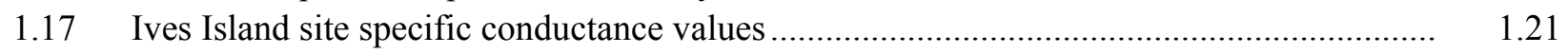

1.18 Ives Island O2/N2 ratios and TDG values at hyporheic piezometers .................................. 1.22

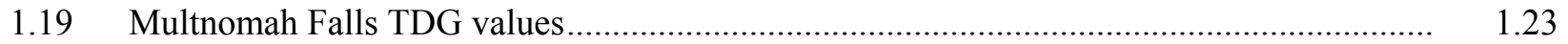

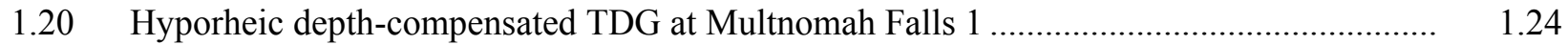

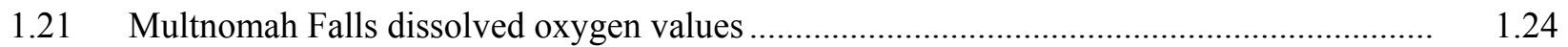

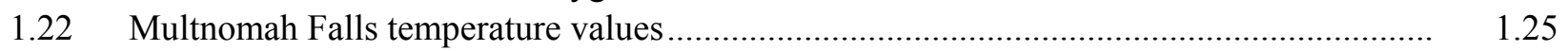

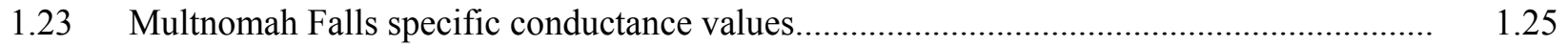

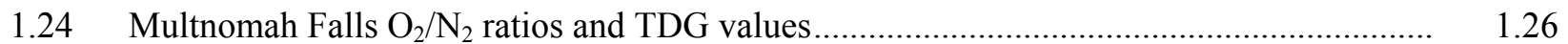

1.25 Ives Island area chum salmon redd locations for spawning years 2000-2006 ................... 1.27

1.26 Multnomah Falls area chum salmon redd locations for spawning years 2003-2006 .......... 1.28

1.27 Estimated TDG exposure to chum salmon sac fry........................................................ 1.29

1.28 Estimated hours of TDG exposure and dewatering to chum salmon sac fry based on hyporheic results from incubation year 2006............................................................... 1.30

1.29 Estimated hours of TDG exposure and dewatering to chum salmon sac fry based on

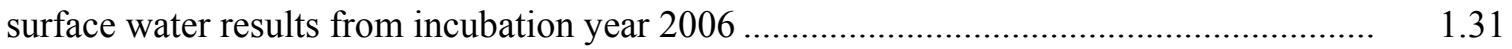

1.30 Estimated TDG exposure to chum salmon sac fry .......................................................... 1.32

1.31 Estimated hours of TDG exposure and dewatering to chum salmon sac fry based on

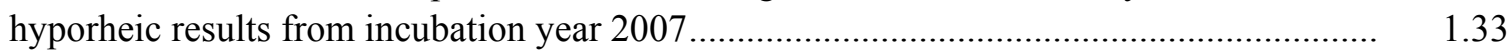

1.32 Estimated hours of TDG exposure and dewatering to chum salmon sac fry based on

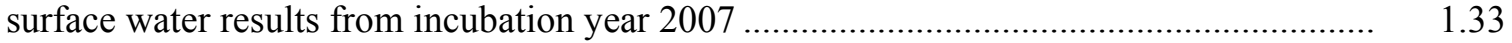

1.33 Water surface elevations during chum emergence for the Ives Island area, 2003-2007 ..... 1.37

1.34 Estimated exposure time of Ives Island site chum salmon redds to depth-compensated total dissolved gas above $103 \%, 2003-2007$

2.1 Total dissolved gas experimental system 
2.2 Total dissolved gas levels throughout exposure period for control, 103\%, 108\%, and $113 \%$ treatments

2.3 Total dissolved gas and temperature on March 13, 2007, during a power outage between 1700 and 1930 hours

2.4 Daily mean temperatures for the study period

2.5 Days to $50 \%$ emergence for each treatment group .....

2.6 Number of days post-hatch that emergence occurred plotted against the control and three treatment levels

2.7 Average daily weight gain from $50 \%$ hatch to $50 \%$ emergence.

2.8 Average daily length gain from $50 \%$ hatch to $50 \%$ emergence.

2.9 The proportion of tissue samples from day 7 and day 19 of the gas exposure that exhibited lesions

2.10 Dose response of the proportion of moderate epithelial hypertrophy in the 19-day sample as a function of total dissolved gas

3.1 Ives Island study site...

3.2 Chum salmon redds flushed in search of chum salmon sac fry

3.3 Flushing of sac fry from redds using pressurized water and sac-fry sampling using aquarium nets.

3.4 Examination of sac fry in the mobile laboratory trailer

3.5 Flow and tailwater levels before, during, and after chum salmon redd flushing.....

3.6 Depth-compensated TDG and water levels above the egg pocket at redds where live chum alevin were collected.

\section{Tables}

1.1 MiniSonde water quality sensor specifications.

1.2 Percentage of chum salmon redds constructed at riverbed elevations higher than Ives Island area monitoring locations for total dissolved gas, 2005 and 2006 spawning years ...

2.1 Total dissolved gas levels used in the exposure experiments and measured in 10-minute increments between March 1 and March 30, 2007.

2.2 Mean daily temperature during the 29-day exposure period

2.3 Mean survival, days post-fertilization, date, and accumulated thermal units at $50 \%$ emergence

2.4 Size of chum salmon sampled at $50 \%$ hatch and at time of transfer to emergence tubes.....

2.5 Size of chum salmon sampled at $50 \%$ emergence ...

2.6 Tissue, yolk, and total dry weights of emergent fry.

2.7 Results of gross examinations of sac fry sampled during the exposure period......................

2.8 Maximum count and proportion occurrence of parasites per nine possible tissue samples per fish

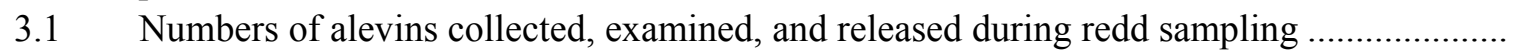




\section{Abbreviations and Acronyms}

\begin{tabular}{|c|c|}
\hline ANOVA & analysis of variance \\
\hline ATU & accumulated thermal unit(s) \\
\hline${ }^{\circ} \mathrm{C}$ & degree(s) centigrade \\
\hline $\mathrm{cm}$ & centimeter(s) \\
\hline $\mathrm{CV}$ & $\begin{array}{l}\text { coefficient of variation; the percentage ratio of the standard deviation (or error) to } \\
\text { the mean }\end{array}$ \\
\hline $\mathrm{d}$ & $\operatorname{day}(\mathrm{s})$ \\
\hline DPF & days past fertilization \\
\hline $\mathrm{EC}$ & effective concentration \\
\hline EPA & U.S. Environmental Protection Agency \\
\hline ESU & environmentally significant unit \\
\hline $\mathrm{ft}$ & foot, feet \\
\hline FY & fiscal year \\
\hline GBD & gas bubble disease \\
\hline GPS & Global Positioning System \\
\hline in. & $\operatorname{inch}(\mathrm{es})$ \\
\hline $\mathrm{k}_{\mathrm{D}}$ & mean development index \\
\hline $\mathrm{L}$ & liter(s) \\
\hline $1 b$ & pound(s) \\
\hline $\mathrm{m}$ & meter(s) \\
\hline $\mathrm{mg}$ & milligram(s) \\
\hline $\mathrm{mm}$ & millimeter(s) \\
\hline $\mathrm{mmHg}$ & millimeters mercury \\
\hline$\mu \mathrm{S}$ & microsiemen(s) \\
\hline MS-222 & tricaine methanesulfonate \\
\hline MSL & mean sea level \\
\hline $\mathrm{N}_{2}$ & dinitrogen \\
\hline$N$ & population size \\
\hline$n$ & subsample size \\
\hline NAS & National Academy of Sciences \\
\hline
\end{tabular}


NAE

$\mathrm{NBF}$

NGVD

NMFS

NOAA

$\mathrm{O}_{2}$

OD

ODFW

$P$

PNNL

psi

PVC

rkm

\pm SE

TDG

USACE

USGS

V
National Academy of Engineering

neutral buffered formalin

national geodetic vertical datum

National Marine Fisheries Service

National Oceanic and Atmospheric Administration

oxygen

outside diameter

Oregon Department of Fish and Wildlife

probability

Pacific Northwest National Laboratory

pounds per square inch

polyvinyl chloride

river kilometer

plus or minus standard error

total dissolved gas

U.S. Army Corps of Engineers

U.S. Geological Survey

$\operatorname{volt}(\mathrm{s})$ 


\section{Overview}

Gas supersaturation caused by spill from dams on the Columbia River was first acknowledged as an environmental concern in the mid 1960s (Ebel and Raymond 1976). Several studies monitored dissolved gas levels and investigated occurrence of gas bubble disease (GBD) in the Columbia River from 1966 through 1969. These studies reported dissolved gas saturation levels ranging from $120 \%$ to $143 \%$ and found significant signs of GBD and associated mortalities for both juvenile and adult salmonids (Ebel 1969; Beiningen and Ebel 1970, 1971; Meekin and Allen 1974). In response, research on the causes and effects of gas supersaturation and resulting modifications to dam structures and operations reduced supersaturated gas levels. A nationwide water quality standard for total dissolved gas (TDG) saturation was set at $110 \%$ by the U.S. Environmental Protection Agency (EPA) in 1972 and remains in effect (NAS/NAE 1973; EPA 1987).

Waivers to the water quality standard were approved beginning in the 1990 s to aid juvenile salmonid downstream migration. Studies reviewed as part of the 1995 and 2000 Biological Opinions (NOAA 1995,2000 ) indicated that TDG saturation levels between $110 \%$ and $120 \%$ had minimal effects on aquatic organisms. Therefore, levels up to $115 \%$ TDG saturation in dam forebays and up to $120 \%$ TDG saturation in dam tailraces have been allowed on a limited basis (NOAA 1995).

The issue of gas supersaturation has once again become a concern regarding, in particular, the chronic effects on incubating embryos and larvae of salmonids downstream from Bonneville Dam (USACE et al. 2004). At the request of the U.S. Army Corps of Engineers (USACE; Portland District), Pacific Northwest National Laboratory (PNNL) undertook a two-part project in 2006 to look further into issues of TDG supersaturation in the lower Columbia River. First, PNNL conducted an extensive review and synthesis of literature related to the impacts of TDG supersaturation on fish species in the lower Columbia River. The product of that effort was a report completed in 2006, Total Dissolved Gas Effects on Fishes of the Lower Columbia River, by K. E McGrath, E. M. Dawley, and D. R. Geist. Second, a field study was initiated to monitor water quality in selected chum salmon (Oncorhynchus keta) spawning habitats downstream from Bonneville Dam. The results of the field study are detailed in a 2007 report, Total Dissolved Gas Monitoring in Chum Salmon Spawning Gravels Below Bonneville Dam, by E. V. Arntzen, J. L. Panther, D. R. Geist, and E. M. Dawley.

Our literature review determined that recent research supports previous findings in regard to migratory juvenile or adult salmonids, that short-term exposure up to $120 \%$ TDG saturation does not produce significant effects when compensating depths are available. During periods of voluntary spill when TDG saturation averaged $120 \%$ or less, monitoring and assessment programs in the Snake and Columbia rivers from 1995 to the early 2000s consistently documented low incidence of significant GBD in migrating juvenile or adult salmonids as well as resident fishes or other taxa (Toner and Dawley 1995; Ryan and Dawley 1998; NMFS 1999; NOAA 2000; Ryan et al. 2000; Backman and Evans 2002; Backman et al. 2002; Weitkamp et al. 2003).

However, our review found that little research has been conducted recently on the effects of gas supersaturation on incubating and larval stages of salmonids. Most recent works focus on post-emergent juveniles and adults, which present a different case because of their mobility within the environment. Methods have advanced since older studies documented incidence of GBD in salmonid sac fry exposed to TDG supersaturation within levels currently authorized (McGrath et al. 2006). In addition, most studies 
conducted on larval fish did not include temperature, exposure duration, or TDG levels relevant to conditions occurring downstream from Bonneville Dam. Therefore, the effects of supersaturated TDG exposure in hyporheic environments that support incubating life stages of salmonids warrant additional study.

Recommendations from the literature review and preliminary analysis of data from the 2006 field study led to the development of a more comprehensive research proposal. For fiscal year (FY) 2007, three objectives were proposed. The first objective was to repeat the field effort to collect empirical data on TDG from the Ives Island and Multnomah Falls study sites. These data provide a more thorough understanding of TDG levels during different river stage scenarios (i.e., high-water year versus low-water year). The second objective was to conduct laboratory toxicity tests on hatchery chum salmon fry at gas levels likely to occur downstream from Bonneville Dam. Findings of effects to fish at different TDG concentrations, in conjunction with field data, can be used by managers when deciding on spill levels. The third objective was to sample chum salmon sac fry during Bonneville Dam spill operations to determine if there is a physiological response to TDG levels. The measured response provides a snapshot of fish health at a given place and time to use in comparison with the results from the other two tasks.

This report summarizes the tasks conducted and results obtained in pursuit of the three objectives. Chapter 1 discusses the field monitoring, Chapter 2 reports the findings of the laboratory toxicity tests, and Chapter 3 describes the field-sampling task. Each chapter contains an objective-specific introduction, description of the study site and methods, results of research, and discussion of findings. Literature cited throughout this report is listed in Chapter 4. Additional details on the study methodology and results are provided in Appendixes A through D included on the compact disc bound inside the back cover of the printed version of this report. 


\title{
Chapter 1
}

\section{Assessment of Total Dissolved Gas Within Chum Salmon Spawning Areas in the Columbia River Downstream of Bonneville Dam}

\author{
E. V. Arntzen, K. J. Murray, J. L. Panther, D. R. Geist, E. M. Dawley
}

\section{Introduction}

Chum salmon that spawn and incubate downstream from Bonneville Dam near Ives Island and an associated site near Multnomah Falls collectively represent one of two remaining populations of the Lower Columbia River evolutionarily significant unit (ESU) listed under the Endangered Species Act. Spring spill from Bonneville Dam is initiated each year to assist downstream migrating juvenile salmonids. Spring spill produces supersaturated gas conditions, which may be causing negative impacts to chum salmon incubating within these reaches. The guidance that managers have used to provide protection for pre-emergent chum salmon fry has been to limit total dissolved gas (TDG) to $105 \%$ after allowing for depth compensation. However, signs of GBD have been found in sac fry at levels of 103\% TDG (Fidler and Miller 1997). Prior to 2006, no data were available on the TDG levels in incubation habitats downstream of Bonneville Dam.

During 2006, Pacific Northwest National Laboratory (PNNL) initiated research to determine whether TDG concentrations are elevated in chum salmon redds during spring spill operations at Bonneville Dam. Water quality was monitored at egg pocket depth and in the river at two chum salmon spawning locations downstream from Bonneville Dam. Three pair of piezometers (hyporheic and river) were installed in the Ives Island study area. One pair and a single hyporheic piezometer were installed in the Multnomah Falls study area. Water quality sensors measured TDG, dissolved oxygen, temperature, specific conductance, and water depth at each location.

Results from 2006 (Arntzen et al. 2007a) showed that groundwater-surface water interaction differed between the Ives Island and Multnomah Falls locations. Egg pocket concentrations of TDG, dissolved oxygen, and temperature remained stable at Multnomah Falls despite significant fluctuations in river depth. In contrast, water quality in the egg pocket fluctuated widely at Ives Island, suggesting that spawning gravels in this area are in much closer contact with river water. No statistical differences were found in TDG levels between periods of voluntary and involuntary spill. Depth-compensated TDG values remained less than $103 \%$ at all monitored sites from the initiation of spring spill through the completion of chum emergence. However, chum salmon redds were constructed at relatively low elevations during the 2005 spawning season, and water levels during spring spill 2006 were relatively high. Consequently, TDG was generally depth-compensated sufficiently to mitigate negative impacts to sac fry during 2006. Uncompensated TDG levels at the Ives Island hyporheic stations did exceed 103\% for short periods and ranged up to $118.2 \%$ (Arntzen et al. 2007a). These levels, combined with waterlevel data for other years, suggested TDG could negatively affect chum sac fry during lower-water years when compensation depths were not available. 
The first objective in the FY 2007 study was to repeat the field effort to collect empirical data on TDG from the Ives Island and Multnomah Falls study sites to provide a more thorough understanding of TDG levels during different water years. This chapter presents monitoring results for TDG, dissolved oxygen, temperature, and specific conductance from FY 2007 in these locations. These data are compared to FY 2006 monitoring results from similar locations, and the data from both study years are used to estimate the exposure of Ives area chum salmon redds to TDG.

\section{Study Sites}

Two major chum salmon spawning areas were selected for monitoring. One site was a side channel downstream from Bonneville Dam on the right bank, north of Ives Island at river kilometer (rkm) 230, which is $4.3 \mathrm{~km}$ downstream from Bonneville Dam. The other site was on the left bank near Multnomah Falls at rkm 220, $14.8 \mathrm{~km}$ downstream from Bonneville Dam (Figure 1.1).

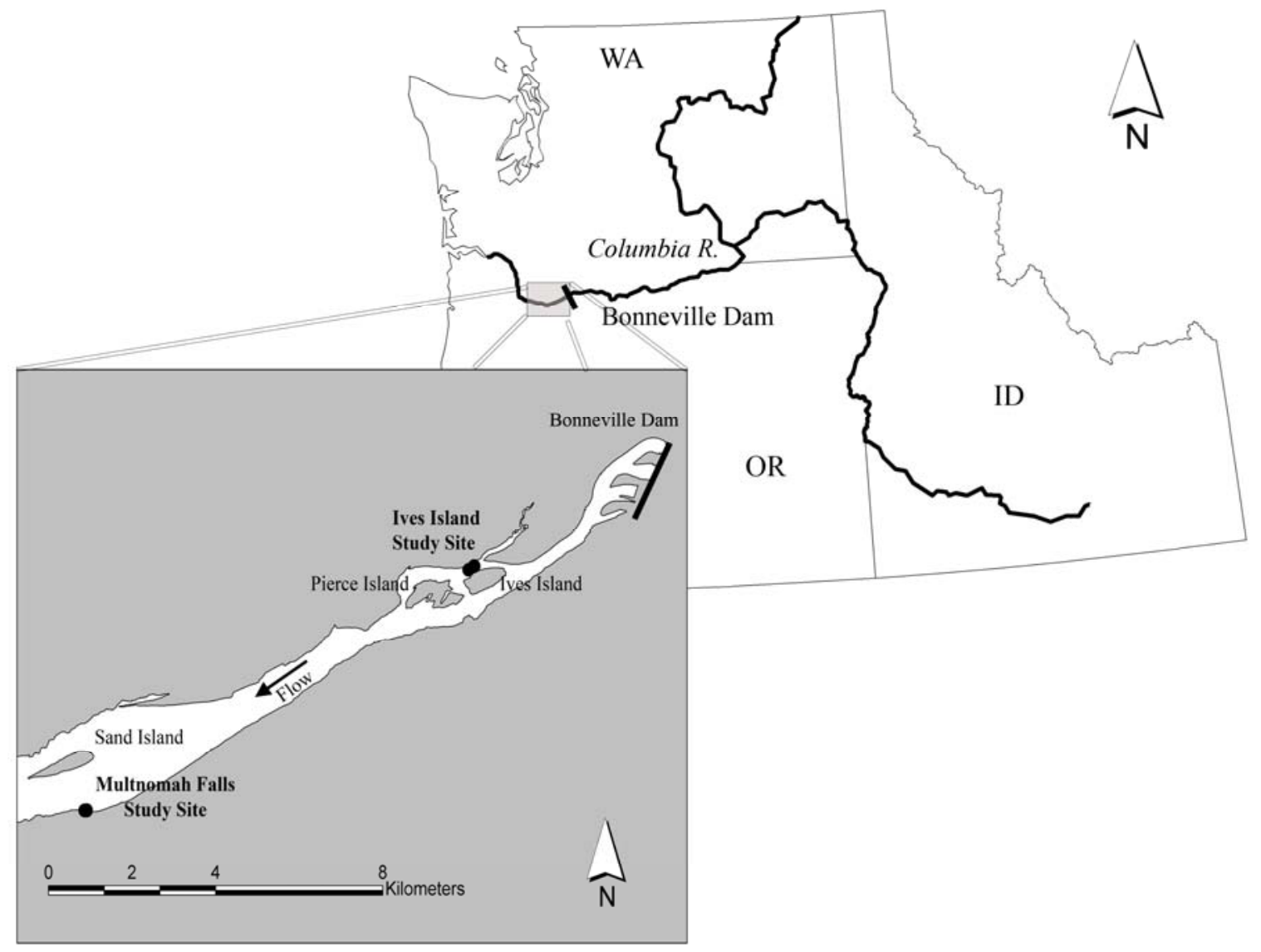

Figure 1.1. Ives Island and Multnomah Falls study sites

At the Ives Island site, we utilized three pairs of piezometers that had been installed during February of 2006 (Arntzen et al. 2007a). Each pair of piezometers consisted of one river and one hyporheic piezometer. The first pair of piezometers (Ives 1) was installed close to the middle of the side channel on the right bank. The second pair (Ives 2) was installed approximately $8 \mathrm{~m}$ farther away from the right bank 
and in shallower water than that at Ives 1 . The third pair (Ives 3) was installed approximately $150 \mathrm{~m}$ downstream of Ives 2 on the left bank of the bar (Figure 1.2). Ives 3 was installed where the river was expected to form an eddy during high flows so that dive operations could continue and data could be collected if water velocities were too high to sample at the other locations.

During February 2007, we installed two additional pairs of piezometers at Ives Island (pair 4 and pair 5; Figure 1.2). Ives pair 4 is on the same transect as Ives 1 and 2, approximately $14 \mathrm{~m}$ closer toward the right bank than Ives pair 1 and much closer to the channel thalweg. Ives pair 5 was approximately $75 \mathrm{~m}$ downstream of Ives 4.

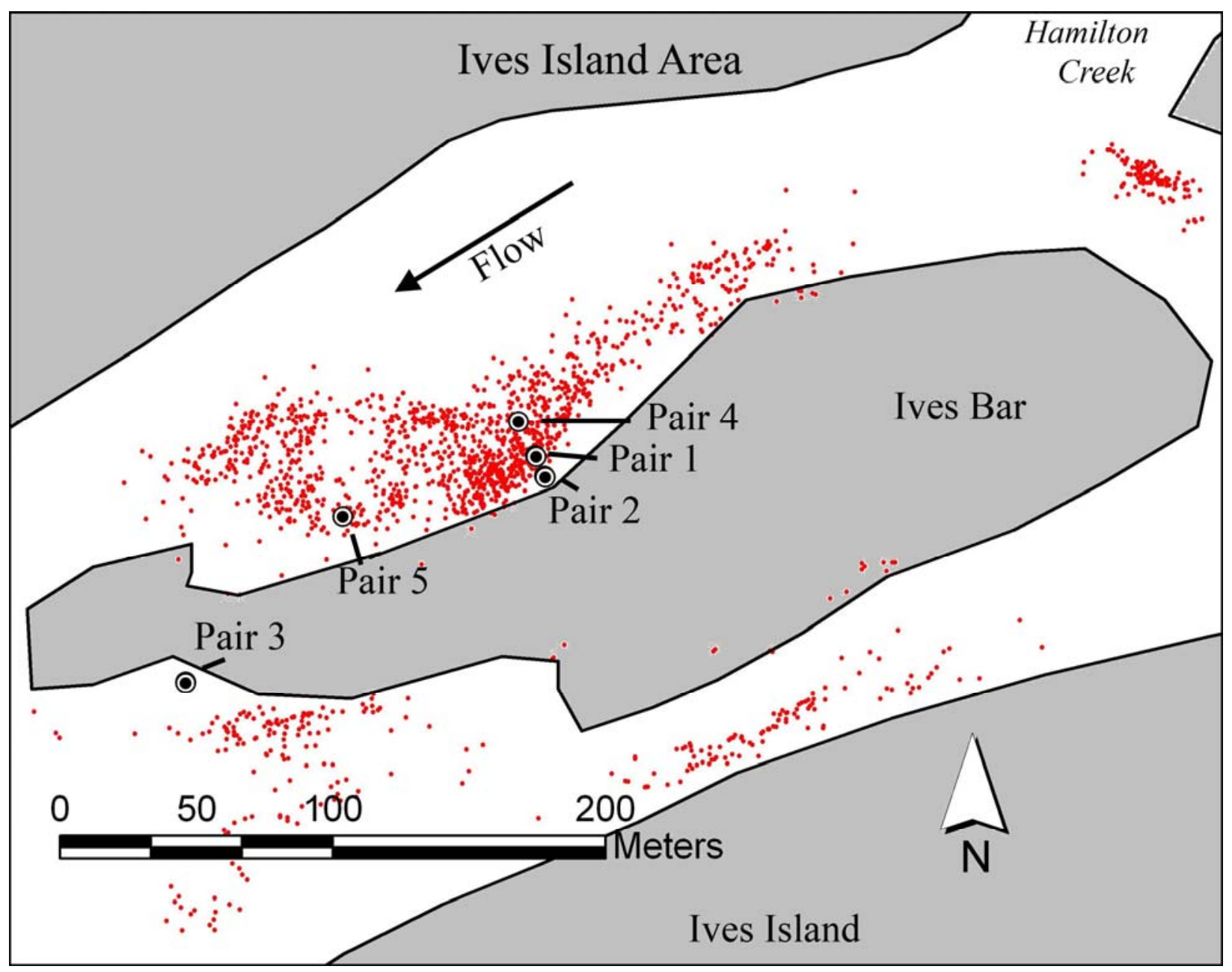

Figure 1.2. Piezometer stations (black and white circles) near Ives Island. Red circles represent chum salmon redds marked from spawning years 2000 through 2006.

At Multnomah Falls, we used two hyporheic piezometers (at pair 1 and pair 2) and one river piezometer (at pair 1) that had been installed during February 2006. During February 2007, we installed an additional river piezometer at pair 2 and an additional river/hyporheic piezometer (pair 3; Figure 1.3). Pair 3 was sited approximately $150 \mathrm{~m}$ downstream from pair 1 (Figure 1.3). Pairs 1 and 3 were used during the sampling period; pair 2 was considered an alternate location during 2007 and was not used. 


\section{Multnomah Falls}

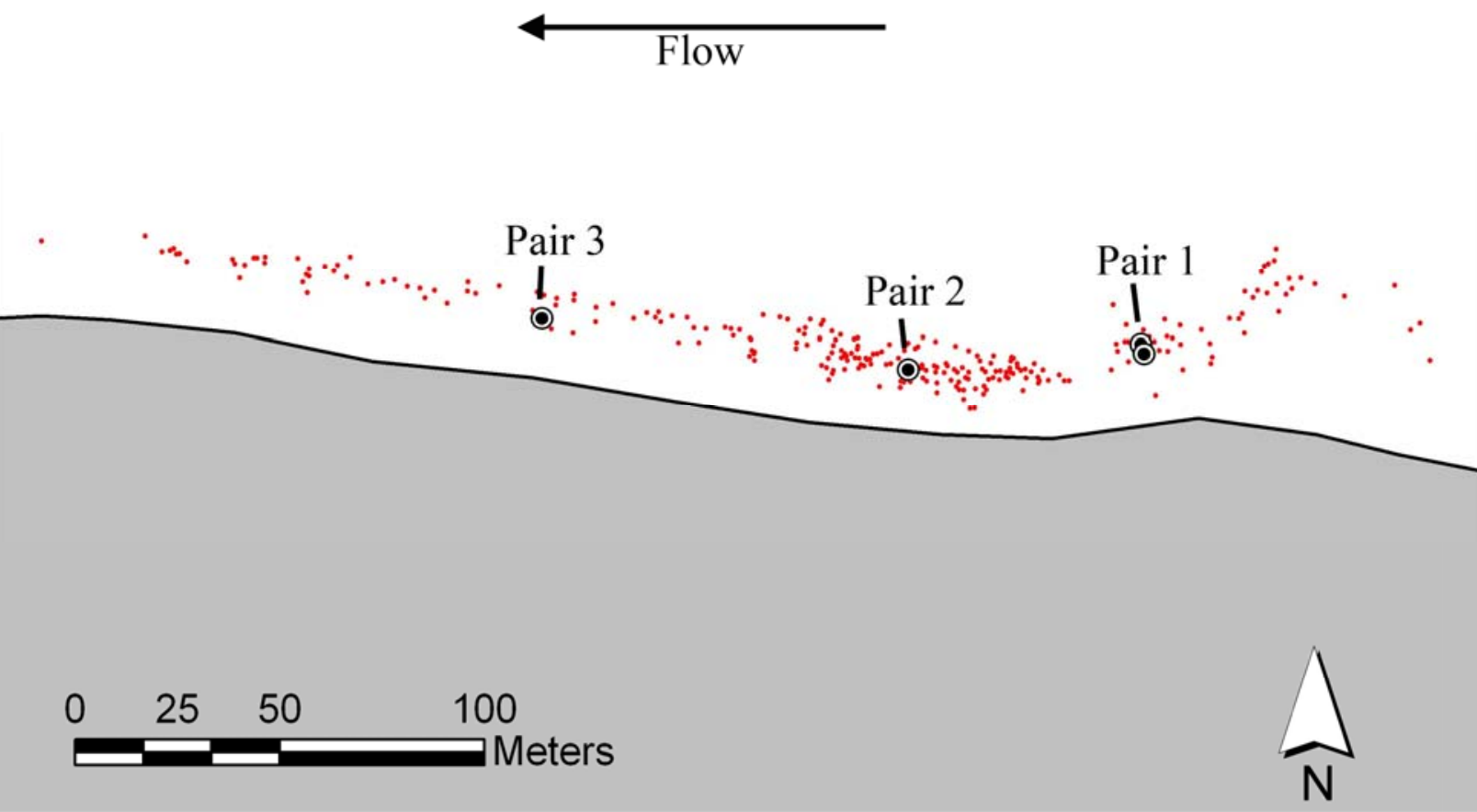

Figure 1.3. Piezometer stations (black and white circles) near Multnomah Falls. Red circles represent chum salmon redds marked from spawning years 2003 through 2006.

\section{Methods}

\section{Water Quality Monitoring at Ives Island and Multnomah Falls Spawning Locations}

During 2007, the design of the river piezometers was similar to that used in 2006 (Arntzen et al. 2007a). We made some slight modifications to the hyporheic piezometer design, primarily to facilitate installation ease. The new hyporheic piezometers were constructed from a 136-cm-long galvanized pipe (Figure 1.4), negating the need for the coupler and riser used during the previous monitoring season. All piezometers consisted of 5.08-cm-diameter galvanized pipe with a built-in 30-cm-long screen to allow water to flow through. At any given time, we used three piezometer pairs at Ives Island and two piezometer pairs at Multnomah Falls.

We used a gasoline-powered jackhammer to drive the piezometers into the riverbed (Geist et al. 1998). A 6-cm segment of $2.5-\mathrm{cm}$ cold-rolled steel was placed in the drive point tip to absorb the impact of the internal drive rod and prevent the drive rod from becoming lodged inside the tip of the piezometer. The drive rod consisted of a $183-\mathrm{cm}$ length of $2.5-\mathrm{cm}-\mathrm{OD}$ cold-rolled steel. River piezometers were driven until the bottom of the screen was approximately $10 \mathrm{~cm}$ above the riverbed and the screen was exposed to the river. Hyporheic piezometers were driven until the top of the screen was approximately $10-20 \mathrm{~cm}$ below the riverbed and the screen was exposed at egg pocket depth. After piezometers were installed, they were developed by removing fines with a hand pump. 
(A)

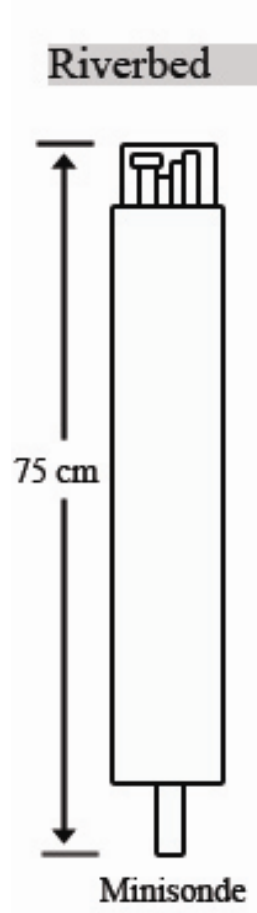

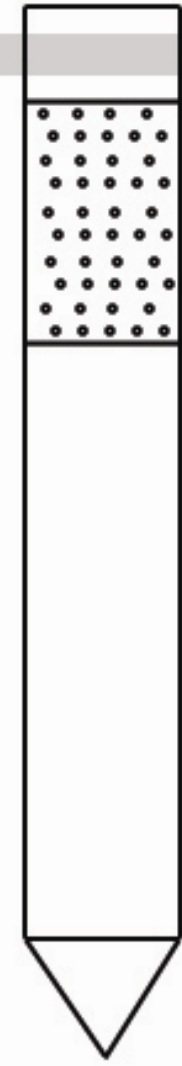

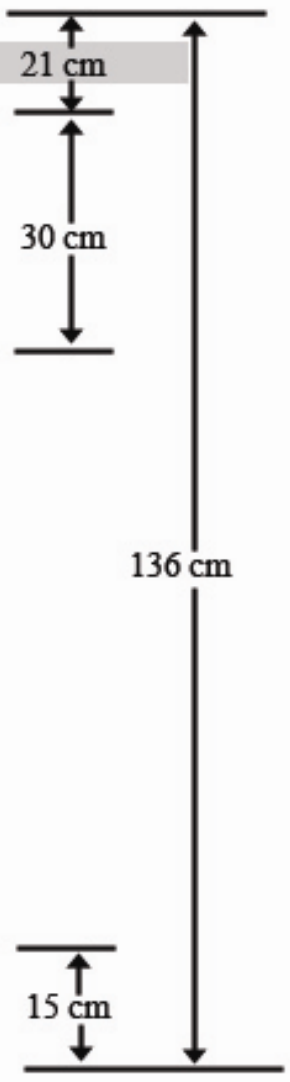

(B)

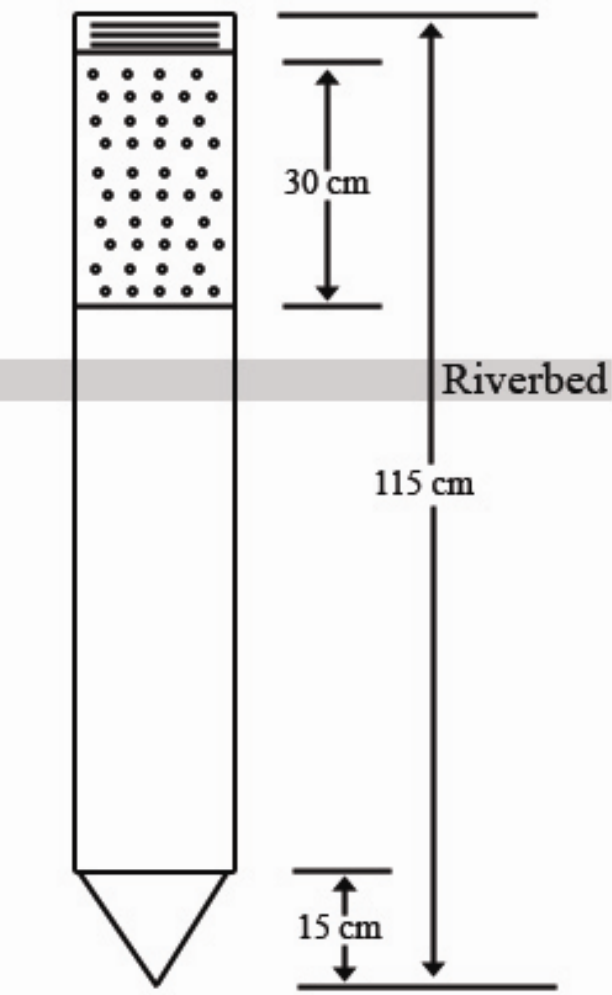

Figure 1.4. Specifications of piezometers screened to the (A) riverbed and (B) river at Ives pair 4, Ives pair 5, and Multnomah Falls pair 3 during 2007. Total dissolved gas sensors were placed at the center of the screens.

The locations of the piezometers were recorded with a Trimble Pro XR Global Positioning System (GPS) receiver (Trimble Navigation Limited, Sunnyvale, California). Caps were placed on all piezometers to prevent sediment from accumulating in them prior to the installation of TDG sensors.

To aid in recovering the sensors during 2007, we installed a fixed diver line at both the Ives Island site (Figure 1.5) and Multnomah Falls site (Figure 1.6). At Ives Island, the line was crucial in terms of maximizing access to the sensors and minimizing the length of time required for each dive operation. For pairs 4, 1, and 2, we installed a surface buoy at the top of Ives Bar anchored with two 70-lb weights and a piezometer driven into the riverbed. The surface buoy had a 5-m section of 1.27-cm Duraplex rope attached to it at the surface with a smaller crab buoy that the divers could use to locate the end of the line. 


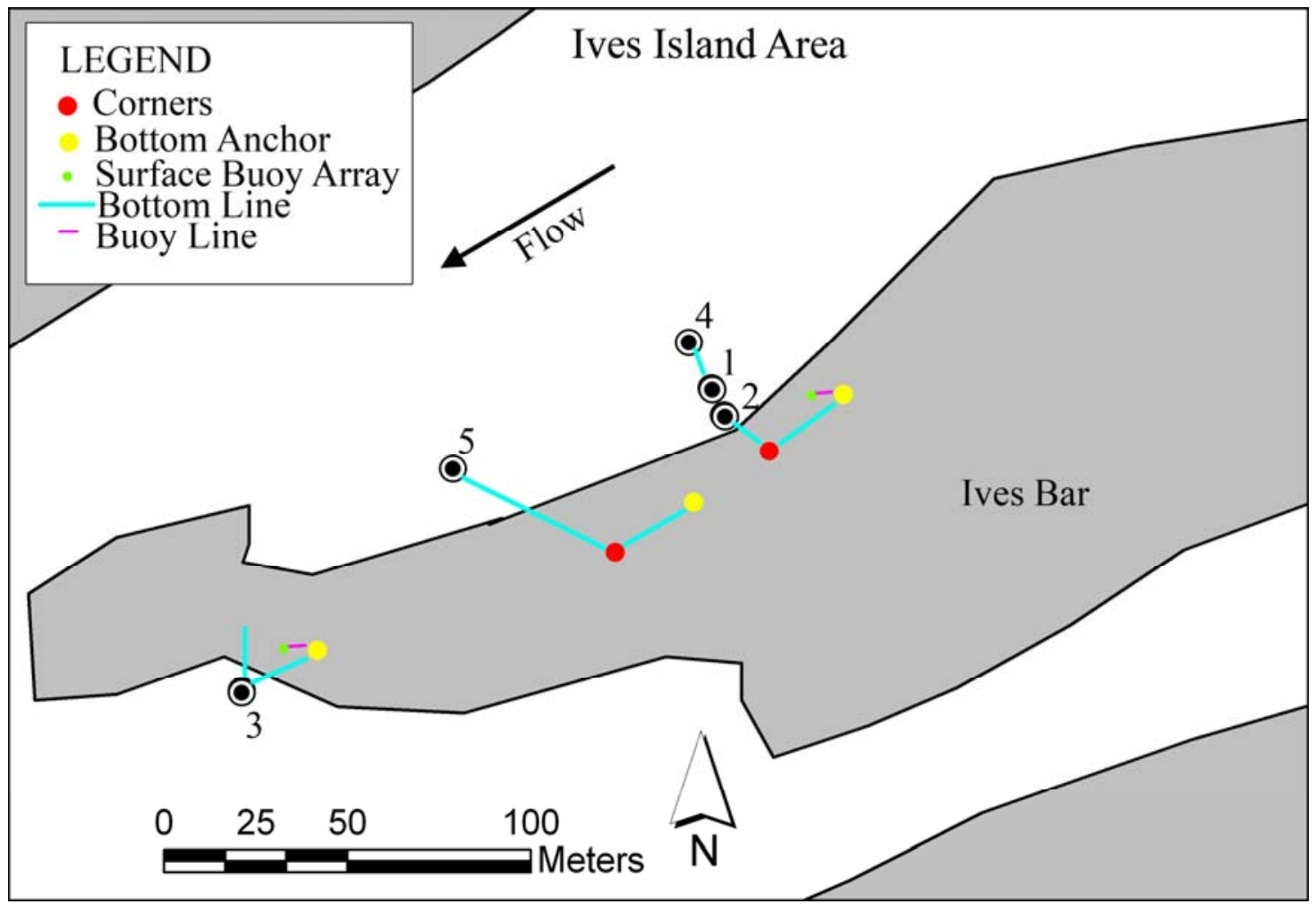

Figure 1.5. Ives Island study site diver fixed line design

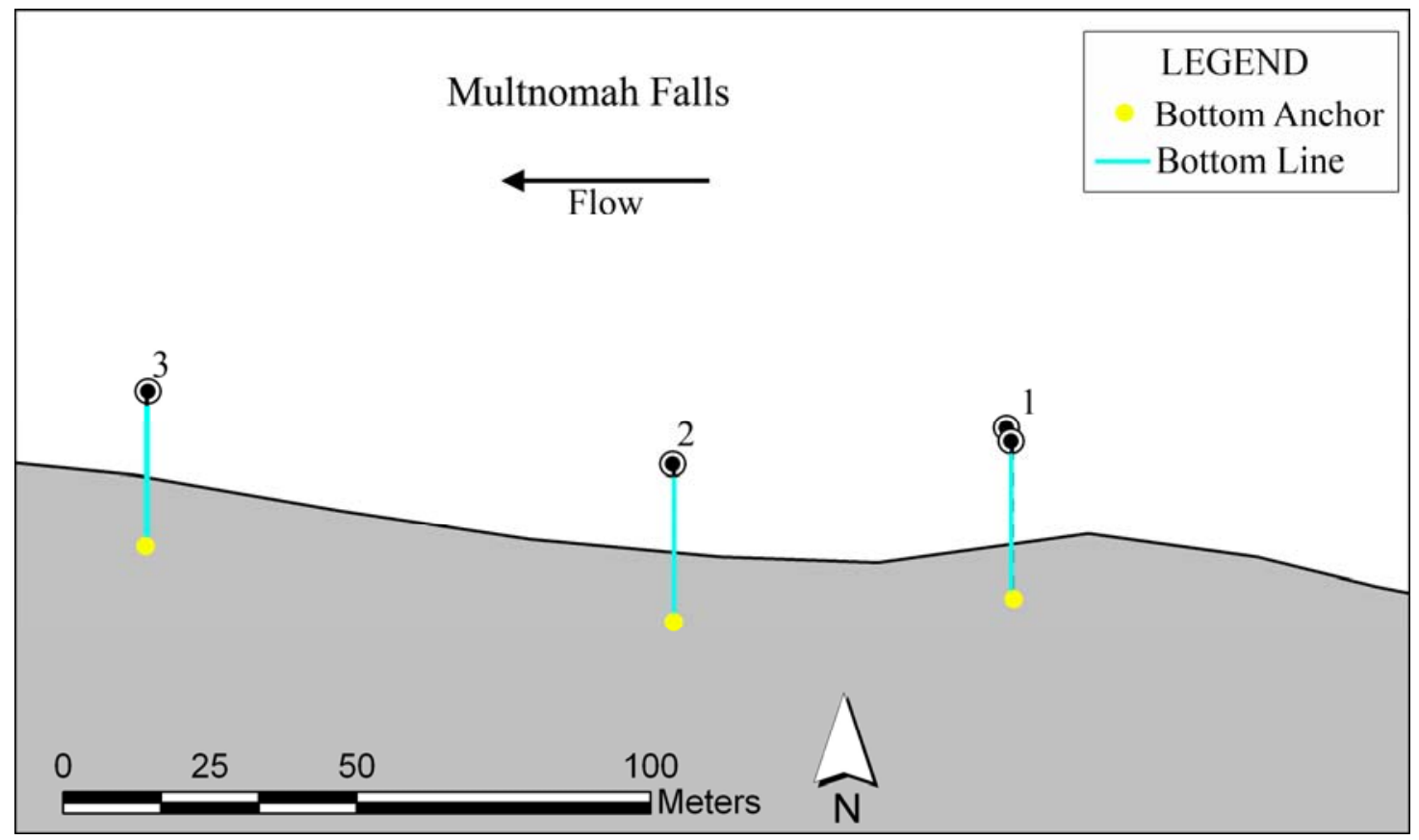

Figure 1.6. Multnomah Falls study site fixed line design 
By holding onto the surface line, the divers were able to reach the bottom line when pulled under by the current. From the piezometer anchor at the bottom, we installed 1.27-cm Duraplex rope that was sturdy enough to hold a diver in strong current for a length of $25 \mathrm{~m}$ going directly downstream. At this point (hereafter termed the corner), the rope made a bend at an angle approximately $60-70^{\circ}$ to the current (where upstream $=0^{\circ}$ ). The rope continued on at this angle until it reached the piezometer pairs. For pair 5 , we did not install a surface buoy. We installed the anchor and piezometer approximately $25 \mathrm{~m}$ upstream of the corner and ran the bottom line parallel to the current. Once the line reached the corner, it changed direction toward pair 5, where it was attached. Pair 3 is very close to a surface water eddy during high flows. For this reason, it was relatively easy for divers to conduct searches on the river bottom. We installed two ropes that converged at pair 3 (and diverged upstream of pair 3) to facilitate finding that location (Figure 1.5). At pair 3, we employed a surface buoy and surface line that could be used to pull the divers down if necessary. All bottom line was anchored approximately every $2 \mathrm{~m}$ using 0.6-m-long by $1.27-\mathrm{cm}$-diameter metal stakes pounded into the riverbed. Stainless steel washers and stainless steel anchor shackles were used to secure the rope to the metal stakes driven into the riverbed. The washers were $0.60 \mathrm{~cm}$ to $0.66 \mathrm{~cm}$ thick and had an outside diameter of $4.13 \mathrm{~cm}$. The $0.95-\mathrm{cm}$ anchor shackles had a screw pin design. The line was kept as taut as possible to prolong the time the rope would last in the river. Knots were tied in the bottom line to maximize the divers' grip on the rope.

At Multnomah Falls, currents are slower; here, the fixed diver line was to reduce time spent searching for piezometers. We installed a line from each pair, perpendicular to river flow, to a point high enough on the bank that it could be located during high water (Figure 1.6). A piezometer was driven in at that location, and a rope was fixed to it. Flagging was installed above the high-water mark to aid in locating the ends of the fixed line. The bottom line was anchored using riverbed stakes spaced approximately every $5 \mathrm{~m}$.

Twelve Hydrolab MiniSondes (Hach Environmental, Loveland, Colorado) were used to monitor water quality. Each MiniSonde weighed $1.3 \mathrm{~kg}$ and measured $74.9 \mathrm{~cm}$ long with a 4.4-cm OD. Eleven MiniSondes were Model 5 (MS5), and one was a Model 4a (MS4a). Each MS5 included sensors to monitor dissolved oxygen, specific conductance, depth, TDG, and temperature. MS5 sensors employed luminescent dissolved oxygen sensors, while the MS4a measured dissolved oxygen with a membrane. Detailed specifications, including accuracies and resolutions of the sensors, are listed in Table 1.1 for both models.

Table 1.1. MiniSonde water quality sensor specifications (Hach Environmental 2006)

\begin{tabular}{|c|c|c|c|}
\hline Sensor & Range & Stated Accuracy & Resolution \\
\hline Total dissolved gas & 400 to $1300 \mathrm{mmHg}$ & $\pm 0.1 \%$ of the span & $1.0 \mathrm{mmHg}$ \\
\hline Luminescent dissolved oxygen & 0 to $20 \mathrm{mg} / \mathrm{L}$ & $\begin{array}{c}0.1 \mathrm{mg} / \mathrm{L} \text { at }<8 \mathrm{mg} / \mathrm{L} \text { and } \\
\pm 0.2 \mathrm{mg} / \mathrm{L} \text { at }>8 \mathrm{mg} / \mathrm{L}\end{array}$ & $0.01 \mathrm{mg} / \mathrm{L}$ \\
\hline Specific conductance & 0 to $50 \mu \mathrm{S} / \mathrm{cm}$ & $\begin{array}{c} \pm 0.5 \% \text { of reading or } \\
\quad \pm 0.001 \mu \mathrm{S} / \mathrm{cm}\end{array}$ & 4 digits \\
\hline Depth & $\begin{array}{c}0 \text { to } 25 \mathrm{~m} \text { (MiniSonde } 5 \text { ) } \\
0 \text { to } 100 \mathrm{~m} \text { (MiniSonde } 4 \mathrm{a})\end{array}$ & $\pm 0.05 \mathrm{~m}$ & $0.01 \mathrm{~m}$ \\
\hline Temperature & -5 to $50^{\circ} \mathrm{C}$ & $\pm 0.10^{\circ} \mathrm{C}$ & $0.01^{\circ} \mathrm{C}$ \\
\hline
\end{tabular}


Most MiniSondes were equipped with stirrers, which were shown to be necessary to remove air bubbles from the TDG sensor during 2006 laboratory testing (Arntzen et al. 2007a). The stirrers consisted of a 1.27-cm-wide revolving plastic blade attached to the MiniSonde next to the TDG sensor. Whenever possible, MiniSondes enabled with stirrers were used in our hyporheic piezometers.

Multnomah Falls pair 3 hyporheic was the only instance in which a hyporheic sensor did not have a stirrer (February 28-April 13). In the river, MiniSondes with stirrers were used at all Ives Island locations. At Multnomah Falls river locations, stirrers were unavailable with the exception of February 28 through April 13 at pair 3. All MiniSondes were powered using eight internal AA batteries.

Each MiniSonde was equipped with a 15.2-cm-long slotted deployment cap. We deployed the MiniSondes by attaching a $0.64-\mathrm{cm}$ eyebolt to the stainless steel end of the deployment cap and attaching a $0.32-\mathrm{cm}-O D$ stainless steel cable to the eyebolt. The other end of the cable was attached to an expansion cap, which secured the sensor to the top of the piezometer. The expansion cap consisted of two 5.1-cm-OD plastic discs with threaded holes in the middle of them, surrounded by a rubber gasket. A stainless steel screw and wing nut were used to tighten the two plastic discs together, causing the rubber gasket to expand until it was tightly secured in the piezometer. A metal plate with holes in it was attached to the cap, and the cable was passed through the holes and secured to the cap by clamping it together with U-bolts. MiniSondes were deployed with the sensor tips located in the center of the piezometer screen, pointed upward (Figure 1.4).

Prior to deployment, fully charged AA batteries were installed in all MiniSondes. We programmed each MiniSonde to log parameters including depth, temperature, total dissolved gas, dissolved oxygen, and specific conductance. One measurement was recorded for each parameter every hour until the batteries were spent. The MiniSondes were given a 3-minute sensor warm-up and a 1-minute stirrer warm-up. Every two to three weeks from February 28 through June 14, 2007, the MiniSondes were recovered, downloaded, maintained, and redeployed. After the final deployment in June, the MiniSondes were left logging data in the piezometers until they were recovered during lower river discharge in July. During a typical deployment, power lasted approximately 20 days. When the battery life of a MiniSonde dropped below approximately $4.3 \mathrm{~V}$, zero values were recorded by some sensors. Zero values recorded due to low power were omitted from the data analysis.

Immediately upon recovery, the batteries inside each MiniSonde were exchanged and the data were transferred to a laptop computer. MiniSondes were then immediately reprogrammed for a side-by-side deployment adjacent to a laboratory-calibrated MiniSonde to help evaluate the accuracy of TDG readings. To collect the side-by-side data, we placed the laboratory-calibrated MiniSonde and the recovered MiniSondes in the river at an approximate depth of 90 to $105 \mathrm{~cm}$. For side-by-side deployments, we logged depth, temperature, TDG, dissolved oxygen, and specific conductance every 3 minutes for a minimum of 60 minutes. The Minisondes were programmed to have a 1-minute sensor and 1-minute stirrer warm-up prior to sampling. Following side-by-side tests, each TDG membrane was removed and later transported back to PNNL facilities in Richland, Washington, for quality assurance checks. Following membrane removal, we attached the TDG pressure sensor on the Minisonde to a Druck pressure calibrator (certified to 0.0015-psi accuracy) and checked the sensor for accuracy at 0, 100, 200, and $300 \mathrm{mmHg}$. If the pressure reading was off by more than $1 \mathrm{mmHg}$, the unit was recalibrated. A barometric pressure reading was obtained from a laboratory-calibrated Garmin GPS unit and used to reset the pressure sensor. After recalibration, the sensor was checked once more for accuracy at 100, 200, and $300 \mathrm{mmHg}$. We calibrated the dissolved oxygen sensor by attaching a calibration cap filled with $1.3 \mathrm{~cm}$ 
of deionized water to the MiniSonde. The MiniSonde was held upright for the duration of the calibration by a clamping laboratory stand. The specific conductance was also checked. The specific conductance sensor was rinsed three times and then immersed in a calibration cap full of $100 \mu \mathrm{S} / \mathrm{cm}$ at $25^{\circ} \mathrm{C} \mathrm{NaCl}$ standard. As long as the sensor read between 90 and $110 \mu \mathrm{S} / \mathrm{cm}$, we did not recalibrate. The depth sensor was calibrated by holding the sensor out of the water and setting the depth value to zero. Following the first several weeks of the study, we noticed some of the stirrers were attracting magnetic minerals that were accumulating until they interfered with stirrer operation. We incorporated a stirrer check into our standard operating procedure to ensure that the stirrers were functioning correctly and cleaned them if they were not. After all calibrations were completed, a laboratory-tested TDG membrane was attached to the pressure sensor. Each MiniSonde was then given a fully charged set of batteries and reprogrammed for a long-term deployment. All data were backed up using a SanDisk thumb drive (SanDisk Corporation, Milpitas, California).

The membranes brought back to PNNL were tested for functionality before they were reused in the field, as outlined in Tanner and Johnston (2001). First, membranes were attached to the pressure sensor on the MiniSonde and allowed to equilibrate for approximately 15 minutes. Because of the compressed air between the sensor and the membrane, a functional membrane would initially respond by showing an increase in pressure, then gradually decline, eventually approaching barometric pressure. If the membrane was damaged, there would be no initial pressure increase or a severely reduced one, and the return to barometric pressure would be nearly immediate (Figure 1.7). In this case, the air would escape quickly through a hole in the membrane rather than gradually be released through the entire membrane. A second functionality test was performed to check the responsiveness of the membrane by inserting the sensor into a beaker of soda water. If the membrane was functioning properly, the sensor should respond by showing a rapid increase in pressure well above barometric pressure. The removal of the sensor from the beaker should show the pressure drop and gradually return to barometric pressure after equilibrating for 15 to 30 minutes. A damaged membrane would return to barometric pressure almost immediately after being inserted in the soda water (Figure 1.7). All membrane test results are listed in Appendix A.

For quality assurance, we looked at both the membrane test results and the side-by-side data. If either looked questionable, we omitted the data. Ives 3 river piezometer gave very high TDG results during the long-term deployment 4 (April 26-May 10). It failed the membrane test and performed poorly during the side-by-side test. Also during deployment 4, Ives 2 hyporheic was found to have performed poorly during the side-by-side test. Its long term data looked good and it passed the membrane test, but the data were still omitted because they were questionable. After deployment 7 (June 13-July 2), two of the membranes tested badly. Although the side-by-side and the long-term data looked normal, the data from Ives 1 river and Multnomah Falls 3 hyporheic were omitted because they did not pass all of our checks. Finally, we lost the Ives 2 hyporheic Minisonde from deployment 5 (May 10-May 25) during the side-by-side test and consequently have no side-by-side results for that sensor or the membrane test. During periods when TDG data were omitted due to membrane failure, other water quality parameters were retained.

We calibrated the pressure sensor of the laboratory-calibrated Minisonde used for the side-by-side tests before every recovery trip. In the laboratory, the pressure sensor was attached to a certified Druck pressure calibrator and tested for accuracy at 0,100, 200, and $300 \mathrm{mmHg}$. If the pressure reading was off by more than $1 \mathrm{mmHg}$, the unit was recalibrated. We obtained the barometric pressure from the Hanford Meteorological Station (Hanford, Washington) and used it to calibrate the pressure sensor. After calibration, the sensor was checked once more for accuracy at 100, 200, and $300 \mathrm{mmHg}$. We calibrated 

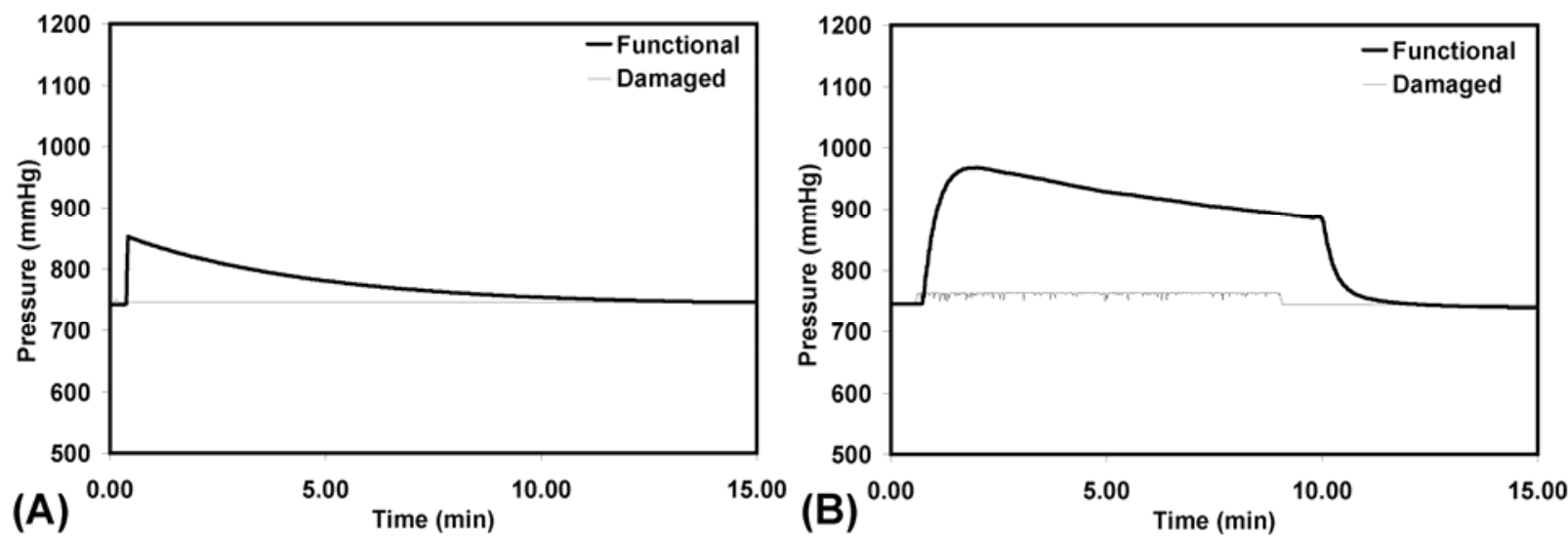

Figure 1.7. Examples of functional versus damaged membrane responses during quality assurance tests using (A) compressed air and (B) soda water

the dissolved oxygen sensor, depth meter, and specific conductance before we went into the field. Before each field trip, the barometric pressure from the Hanford Meteorological Station was used to calibrate the Garmin GPS unit, which was used for field calibrations.

Water depth influences TDG saturation and, therefore, the physiological effects on sac fry. If the water depth is greater than the compensation depth (water depth at which gas is in equilibrium with hydrostatic, barometric, and water vapor pressure, and saturation level is at 100\%), TDG remains in solution and there are no negative impacts to sac fry. We computed the compensation depth using the equation Tanner and Johnston (2001) modified from Colt (1984):

$$
\text { Compensation Depth }(\mathrm{ft})=[\text { TDG Pressure }(\mathrm{mmHg})-\text { Barometric Pressure }(\mathrm{mmHg})] / 23
$$

However, if the water depth is less than the compensation depth and TDG levels are elevated, gas bubbles begin to form, with potential negative impacts to sac fry. When this occurs, there is still a percentage reduction in the effective supersaturation in terms of impact to biota, based on the pressure of the water column, but the effective TDG is not fully reduced to $100 \%$. The extent to which it is reduced (and the potential negative impact to sac fry) is a function of the starting TDG concentration and the depth of the water column. We computed the percentage reduction (compensation) in supersaturation based on the pressure of the water column using an equation from Knittel et al. (1980):

$$
\begin{gathered}
\text { Percentage Compensation }=[\text { Water Depth }(\mathrm{cm}) \times 0.740(\mathrm{mmHg} / \mathrm{cm} \text { water })] \\
\text { 100/Barometric Pressure }(\mathrm{mmHg})
\end{gathered}
$$

We assumed that potential impacts to chum salmon sac fry would occur if the resulting dissolved gas levels were greater than $103 \%$ after the percentage compensation was subtracted from the TDG concentration (McGrath et al. 2006).

Further quality assurance checks were performed by omitting data during periods of dewatering. Whenever the specific conductance values were zero and depth was less than $0.15 \mathrm{~m}$, we assumed that dewatering was imminent and omitted data from all parameters. Although many of these instances occurred at the end of a deployment when we took the MiniSondes out of the water, there were times 
when the MiniSondes became dewatered in the middle of a deployment. When the battery life value was zero, some of the sensor values such as dissolved oxygen also were zero. We omitted any values that appeared incorrect because of low battery life. Data from Ives 5 hyporheic after April 12 were deleted because the results began to look like river water was mixing with the hyporheic water. We think the hyporheic piezometer was disturbed during diver operations and was incorporating more river water. Results were summarized using functions in Microsoft Excel to calculate the mean, standard error, standard deviation, minimum, and maximum values of uncompensated TDG, dissolved oxygen, temperature, and specific conductance. Data were summarized from the start of monitoring until emergence (from February 28 through May 15) excluding the data we omitted.

Fluctuations in hyporheic water quality (e.g., temperature and dissolved oxygen) are known to occur in lower Columbia River chum salmon spawning areas, especially within the Ives Island area (Geist et al. 2002; Arntzen et al. 2007b; Geist et al. in press). To evaluate how these fluctuations affected TDG composition, we used a computer program written by Dawson (1986) that incorporated equations from Bouck (1982) and Colt (1983). The program allowed us to compute the ratio of oxygen to nitrogen, which can affect mortality and symptoms of gas bubble trauma in anadromous sac fry (Nebeker et al. 1979; Krise and Herman 1989). The program required several known quantities to solve for its variables. These included barometric pressure, water temperature, differential dissolved gas pressure, dissolved oxygen, and salinity. Our sensors recorded most of these quantities directly. However, we were required to convert dissolved oxygen from percentage saturation to a concentration per unit volume, and to convert specific conductance to salinity. These conversions were accomplished using the following algorithms provided by the MS5 supplier (Hach Environmental):

$$
\begin{aligned}
& \text { Dissolved Oxygen }(\mathrm{mg} / \mathrm{L})=0.99967(\% \text { Saturation Dissolved Oxygen })(\text { Salinity/Solubility }) \\
& \begin{aligned}
& \text { Salinity }=1- \text { Specific Conductance }\left(0.003439+0.361 /(22.1+\mathrm{t})^{2}\right) \\
& \text { Solubility }=0.0000000072541 \mathrm{t}^{5}-0.00000051387 \mathrm{t}^{4}+0.0000098316 \mathrm{t}^{3} \\
&+
\end{aligned} \\
& 0.00052276 \mathrm{t}^{2}+0.19665 \mathrm{t}+6.8356
\end{aligned}
$$

where $\mathrm{t}=$ water temperature (Celsius).

\section{Estimated Exposure of Chum Salmon Redds to Total Dissolved Gas}

The exposure of chum salmon redds to potentially harmful TDG levels is ultimately controlled by the TDG concentration of water surrounding the egg pocket, the extent to which TDG can be depthcompensated (which depends on the elevation of the redd and the water level of the river), and the length of time embryos are exposed to harmful levels of TDG. Operations at Bonneville Dam and chum salmon seining data from the Oregon Department of Fish and Wildlife (ODFW) suggest that incubating fry could be exposed to elevated TDG between March 1 and May 15. Hourly TDG and water surface elevations for surface water and hyporheic zone during incubation years 2006 and 2007 were taken from this study, previous studies (e.g., Arntzen et al. 2007a,b), or from unpublished data collected as part of other PNNL studies in the Ives Island area. The spatial distribution of chum salmon redds was provided by the ODFW for spawning years 2005 and 2006 (ODFW, unpublished data). To assign vertical elevations to chum salmon redds, we used a bathymetric coverage constructed previously as part of a hydrodynamic model in the Ives Island area (Tiffin et al. 2004). Redd locations were combined with vertical elevations from the bathymetric coverage using ArcMap (Environmental Systems Research Institute, Inc. [ESRI], Redlands, 
California). A benchmark was created to establish vertical control using a Trimble real-time kinematic GPS receiver. The U.S. Fish and Wildlife Service established one vertical control point in the Ives Island area, which subsequently was used as a reference point for the construction of the U.S. Geological Survey bathymetric coverage as well as for completing vertical surveys of PNNL Ives area water level sensors. PNNL re-surveyed this location on October 19, 2007, also using a Trimble real-time kinematic GPS receiver, to confirm the elevation there. The resultant difference in elevation between the two surveys was $2.7 \mathrm{in.}$

We used redd elevations and hourly water surface elevation to estimate the hourly water depth at each redd during incubation years 2006 and 2007. Our goal was to assess the greatest potential risk to chum salmon fry from elevated TDG; thus, for each hour we selected the highest TDG value from a group of sensors simultaneously recording TDG data in the Ives Island area. This TDG value was assumed to be representative of TDG at each redd for that hour and was depth-compensated using the depth of water over each redd. This process was completed first using surface water monitoring TDG sensors, then repeated using hyporheic monitoring TDG sensors. Using both the surface water and hyporheic data on TDG allowed us to determine whether hyporheic water poses an increased risk over surface water for TDG exposure in the Ives Island area. In each case, TDG monitoring results (from either the hyporheic zone or from surface water) were applied to individual redds so that exposure histories over time could be compiled for each redd. The number of hours that depth-compensated TDG exceeded $100 \%, 103 \%$, $105 \%$, and $108 \%$ were tallied for each redd, allowing for comparisons between redd elevation and exposure time at the various depth-compensated TDG concentrations. During periods of redd dewatering, TDG was not counted toward total exposure time for any of the tested levels. Thus, high-elevation redds often showed lower exposure times to given TDG levels due to the increased time they were dewatered.

\section{Results}

\section{Comparison of PNNL Surface Water TDG Monitoring to Other Columbia River Monitoring Locations}

We compared surface water TDG concentrations obtained from our stations near Ives Island and Multnomah Falls to results obtained by the U.S. Geological Survey (USGS) during the same period at Bonneville Dam, Cascades Island, Warrendale, and Camas/Washougal (Figure 1.8). Measurements of TDG at the PNNL and USGS monitoring stations followed similar trends, with the exception of Cascades Island, where TDG values were consistently higher than at other locations (Figure 1.9).

Surface water TDG was generally lower at Bonneville and Ives Island stations compared to that measured at Warrendale and Multnomah Falls. Camas/Washougal was the closest to the average of all the sites (excluding Cascades Island). With the exception of Cascades Island, the data from each site remained within $2 \%$ of the average of all the sites. The TDG records from all of the sites were very highly correlated with one another (correlation coefficient of at least 0.91) except for Cascades Island, which had a correlation coefficient of between 0.80 and 0.88 when compared to the other locations. 


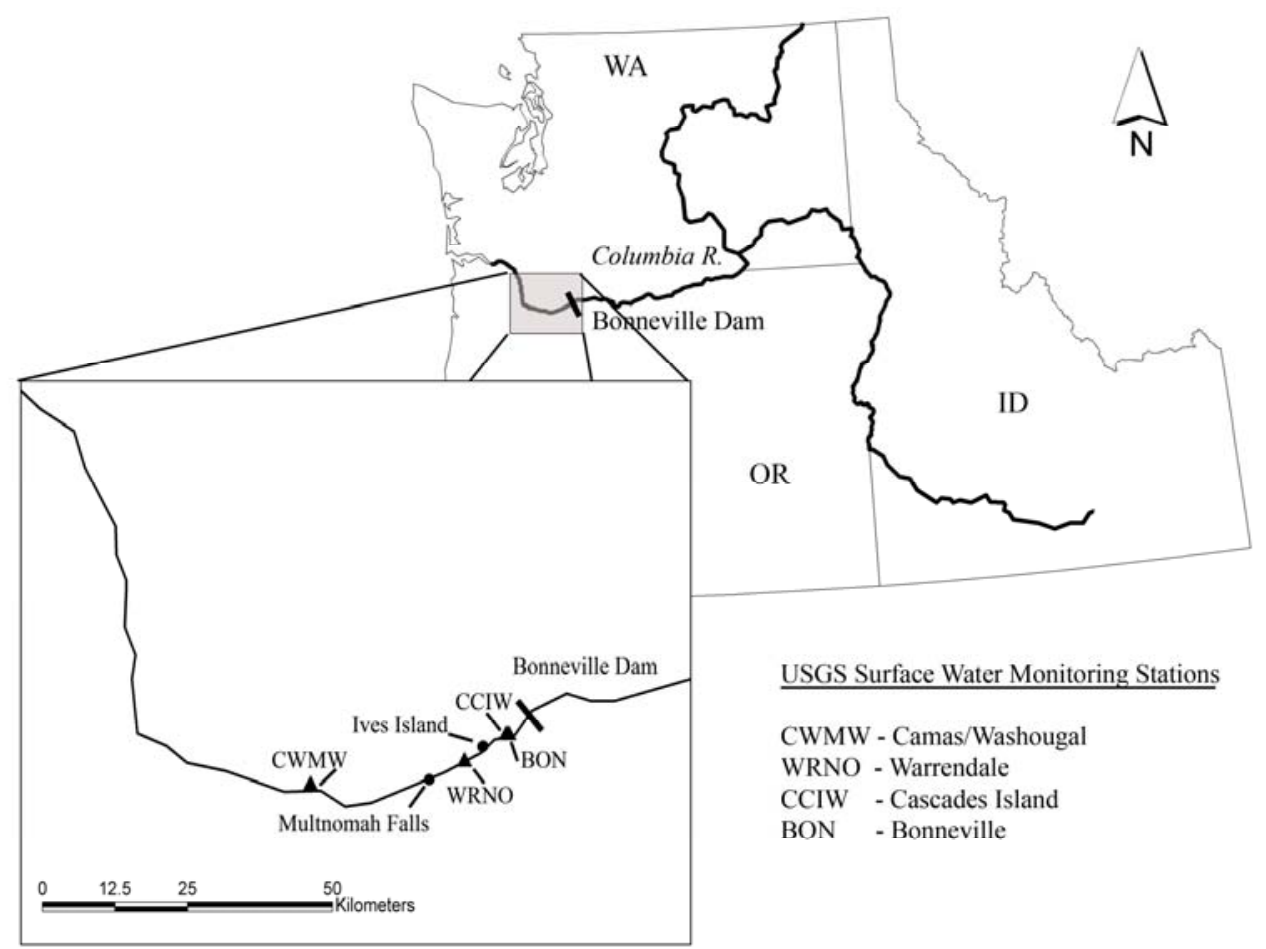

Figure 1.8. Total dissolved gas monitoring stations downstream of Bonneville Dam

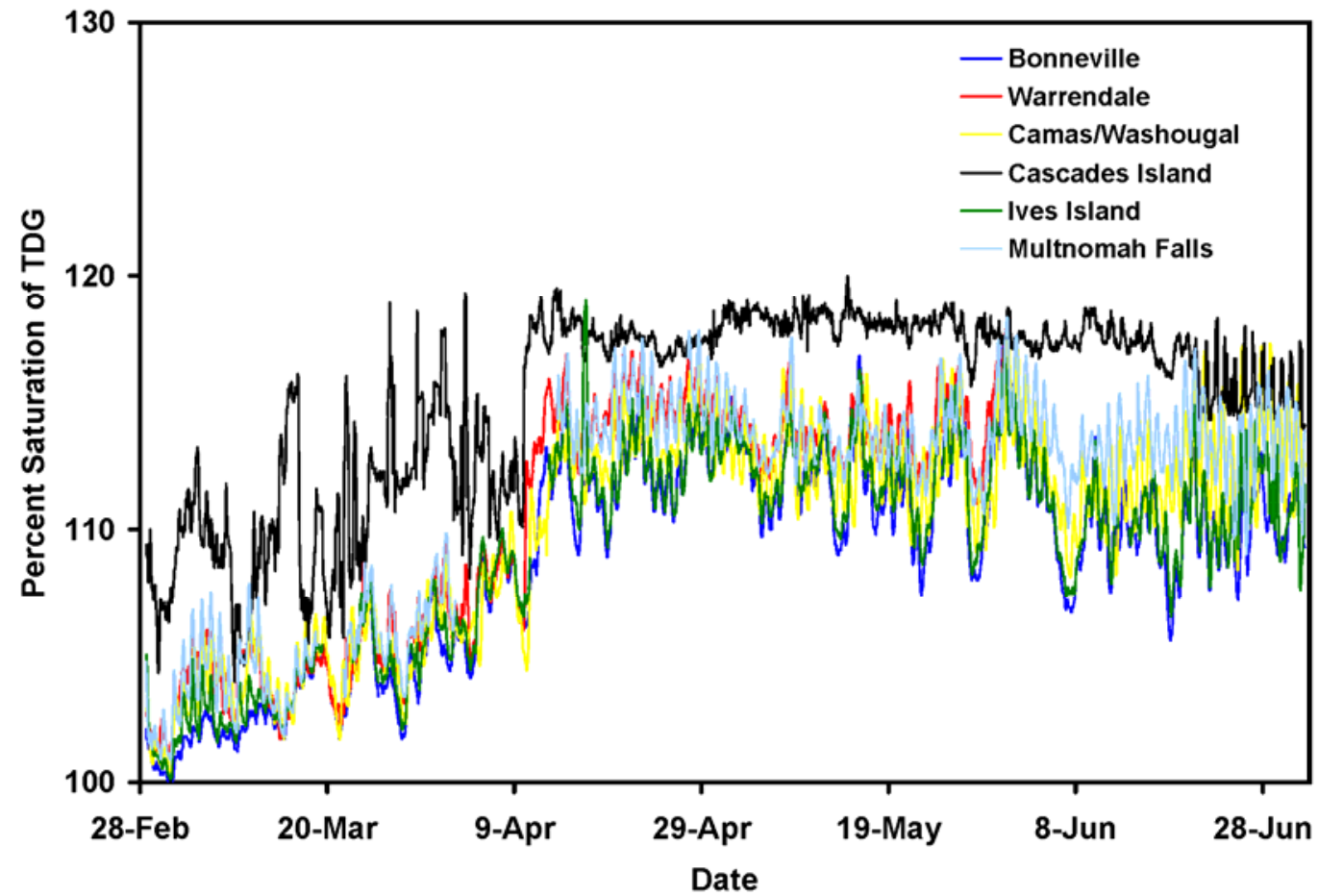

Figure 1.9. Comparison of 2007 TDG values obtained at PNNL monitoring stations and USGS surface water monitoring stations 


\section{Water Quality Monitoring at Ives Island and Multnomah Falls Spawning Locations}

The following sections provide a summary of the water quality data collected at both the Ives Island and Multnomah Falls study sites during the period when spring spill operations occurred while chum sacfry emergence was not completed (March 1 through May 15, 2007). All data collected during the monitoring at both sites are presented in Appendix B.

\section{Ives Island Site}

We monitored water quality including TDG, dissolved oxygen, temperature, specific conductance, and water level at five monitoring stations in the Ives Island area during February 28 through May 15, 2007 (Figure 1.10). Total dissolved gas results for each location are presented in terms of both uncompensated and depth-compensated values at the exact location of each sensor.

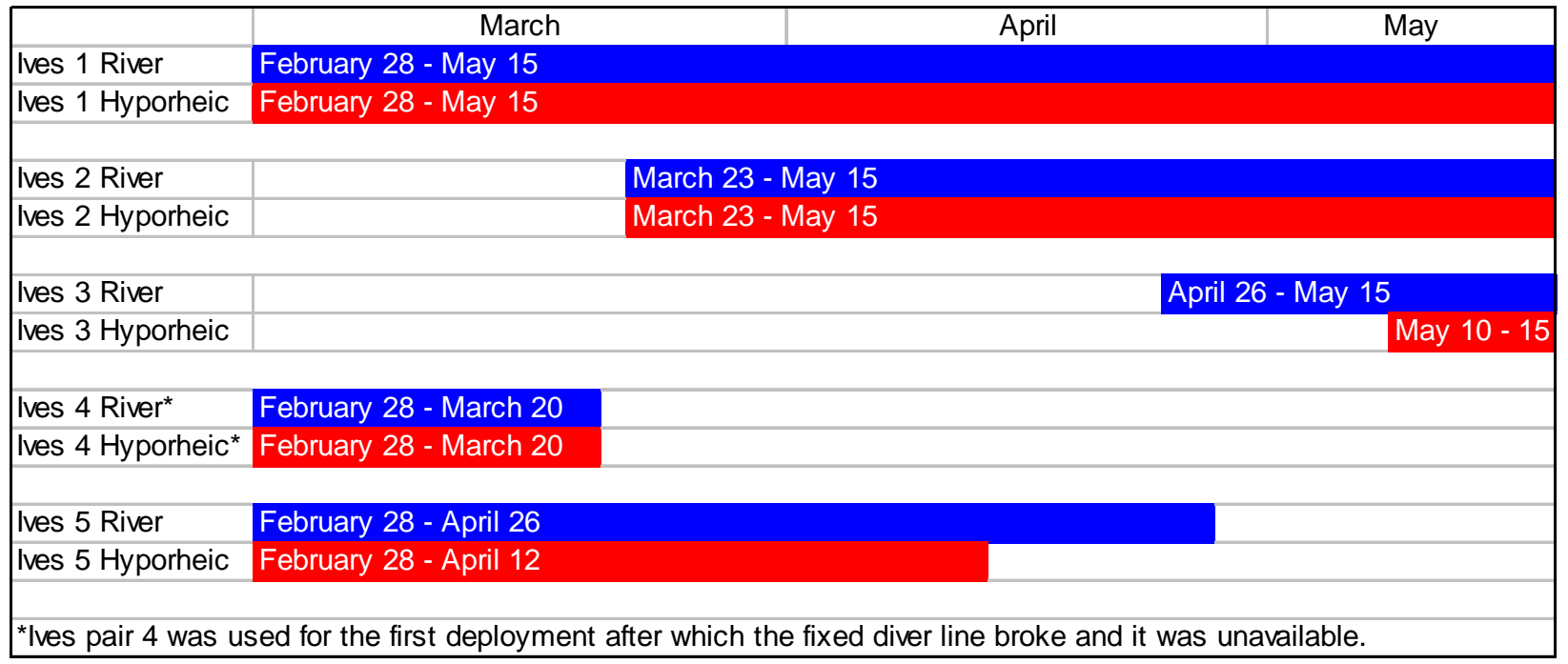

Figure 1.10. Deployment periods for water quality sensors in Ives Island area monitoring locations

\section{Uncompensated Total Dissolved Gas}

Ives Island river TDG levels followed similar trends at all of our sampling pairs (Figure 1.11). The maximum hourly value for TDG was $119.0 \%$ at Ives 1 river. Ives Island hyporheic TDG trends varied between different piezometer locations (Figure 1.11). Ives 2 hyporheic was more stable than the other sites, having a range of $4.2 \%$ compared to $18.3 \%$ and $16.5 \%$ at Ives 1 hyporheic and Ives 5 hyporheic, respectively (Figure 1.11). During the second deployment (March 22-April 13), Ives 1 hyporheic had an average TDG level similar to Ives 2 hyporheic but was more variable. During the third deployment (April 13-April 26), Ives 1 hyporheic increased by approximately 7\%, averaging $( \pm \mathrm{SE}) 108.9 \% \pm 0.15 \%$, while Ives 2 stayed stable. Ives 5 hyporheic TDG values were approximately 106\% for the first week and then decreased to approximately $96 \%$ until the completion of monitoring at that site, while the rest of the sites averaged above 100\% uncompensated TDG the entire time. Ives 1 had the highest hyporheic TDG value, with a maximum hourly value of $115.1 \%$. 
After spring spill started (April 15, 2007), Ives 1 hyporheic average uncompensated TDG percentage saturation values rose (from $103.3 \% \pm 0.11 \%$ to $107.4 \% \pm 0.16 \%$ ); at Ives 2 , hyporheic average TDG values were similar before and after spring spill started $(102.9 \% \pm 0.04 \%$ to $102.4 \% \pm 0.04 \%)$. Ives 1 hyporheic varied more after spill, with a range of $96.8 \%$ to $115.1 \%$ compared to $98.1 \%$ to $112.2 \%$ before spill. Sufficient data were not available for the other hyporheic sites to compare pre-spill TDG to postspill TDG. We recorded no data at Ives 3 hyporheic before spring spill started. Ives 4 hyporheic and Ives 5 hyporheic did not record post-spill data.

(A)

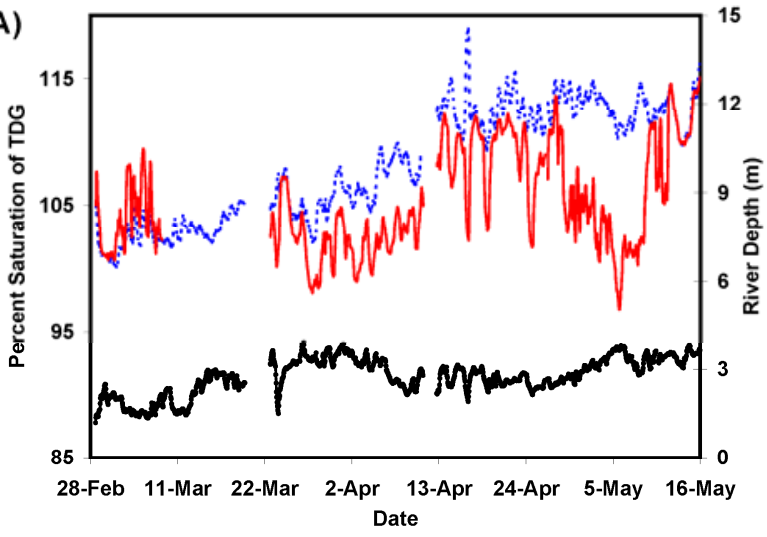

(C)

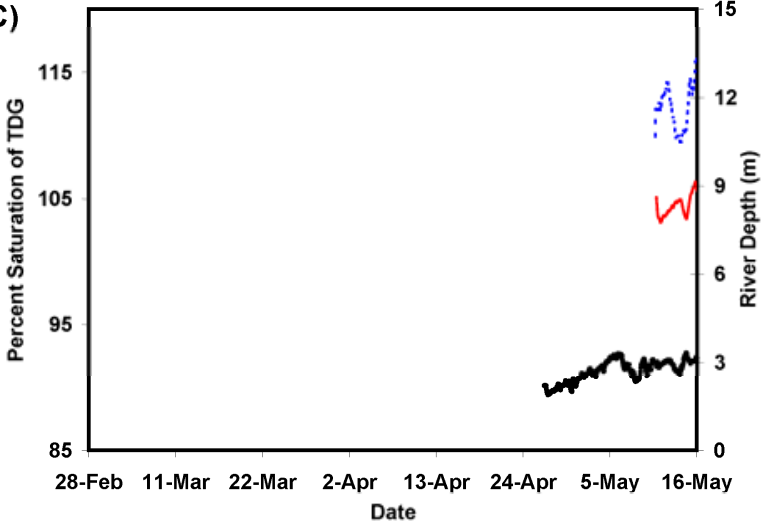

(E)

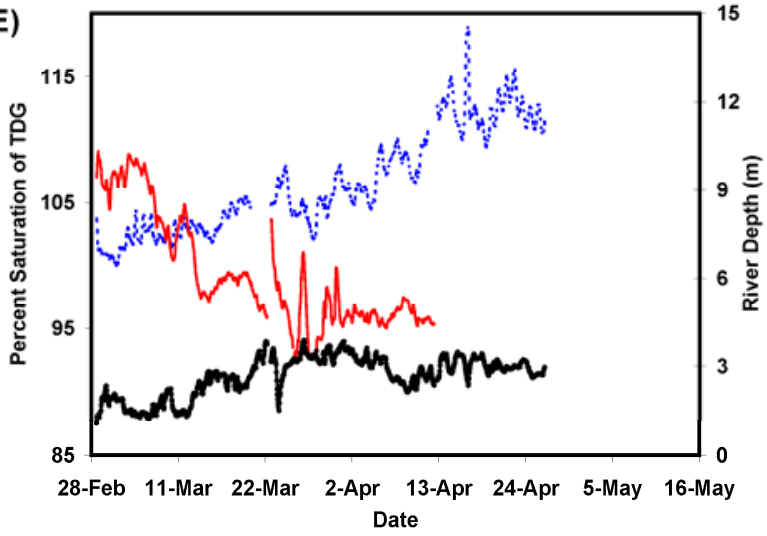

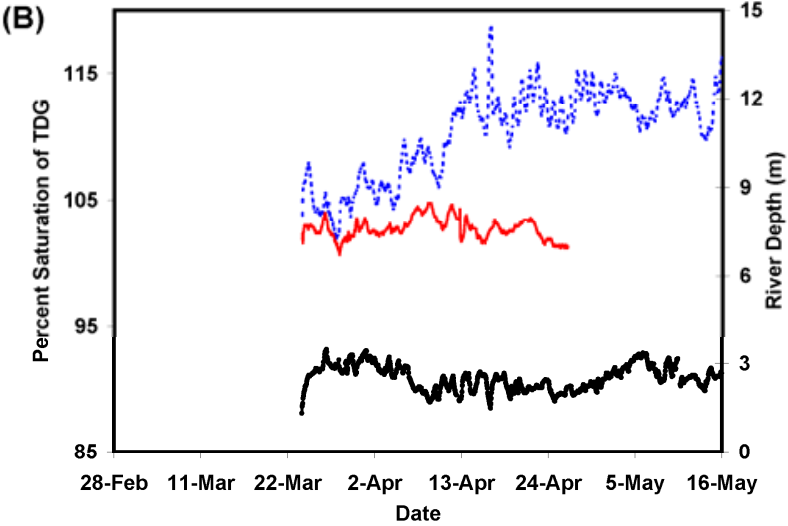

(D)

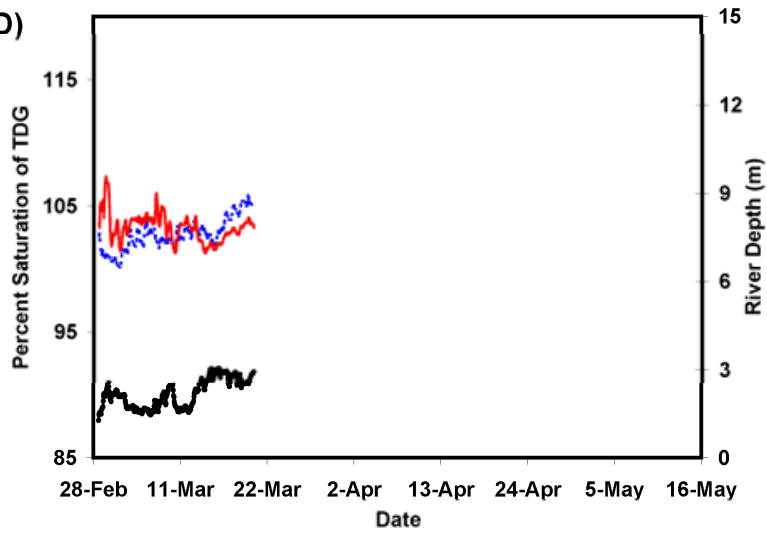

Figure 1.11. Ives Island uncompensated TDG values. (A) Ives pair 1, (B) Ives pair 2, (C) Ives pair 3, (D) Ives pair 4, and (E) Ives pair 5. Solid red lines represent uncompensated TDG values for hyporheic sensors; dashed blue lines represent uncompensated TDG values for river sensors. Solid black lines represent river depth at the hyporheic sensors. 


\section{Depth-Compensated Total Dissolved Gas}

Depth-compensated TDG levels were above $100 \%$ at 3 river sites (Ives 1, Ives 2 , and Ives 5 ) for 6 , 10 and 8 hours, respectively. Depth-compensated TDG levels were above $103 \%$ at 2 river sites (Ives 2 and Ives 5) for 8 and 4 hours, respectively. No other sites, river or hyporheic, had depth-compensated TDG levels greater than $100 \%$. We compared depth compensated TDG from the Ives Island area during the 2007 incubation season to results from the 2006 incubation season to evaluate how changes in river stage between the two years affected depth compensated TDG. Early in the study period, river stage in 2006 and 2007 was similar. From March 13 through April 4, river stage in 2007 was higher, and from April 5 through May 15, river stage in 2006 became higher (Figure 1.12). When the river stage was similar in 2006 and 2007, depth-compensated TDG values were similar. Because depth-compensated TDG is a function of river depth, when the river stage was lower in 2006 than in 2007, depthcompensated TDG values were higher. Data were insufficient to compare long-term TDG records from Ives 3, Ives 4, and Ives 5. However, we were able to compare data from Ives 1 and Ives 2 (Figure 1.12).

(A)

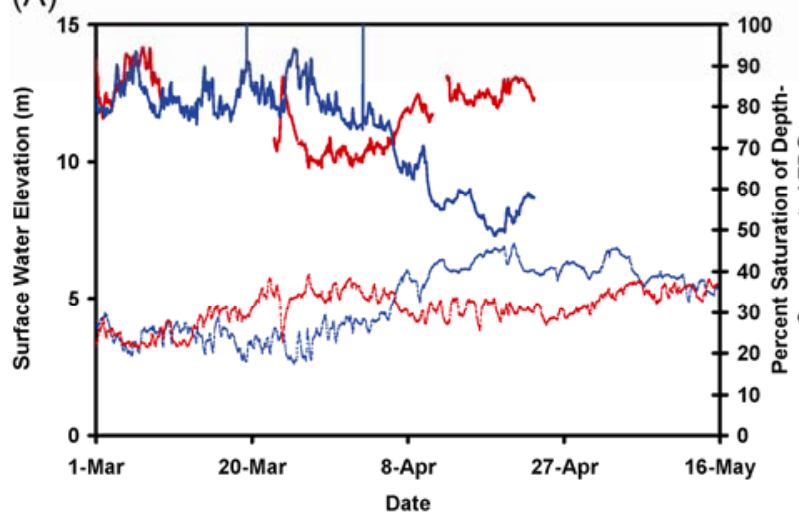

(B)

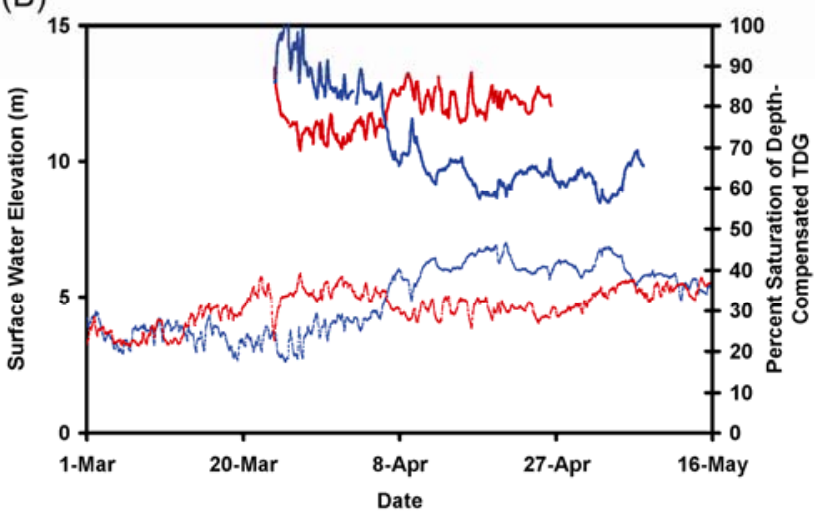

Figure 1.12. Ives Island hyporheic depth-compensated TDG values. (A) Ives 1 and (B) Ives 2 . Solid blue lines represent depth-compensated TDG during incubation year 2006. Dashed blue lines are river elevations during 2006. Solid red lines represent depth-compensated TDG during incubation year 2007. Dashed red lines represent river elevations during 2007.

\section{Dissolved Oxygen}

River dissolved oxygen levels displayed similar trends throughout the season. Values were fairly stable between $100 \%$ and $110 \%$ saturation, with a slight increase occurring when spring spill started. Hyporheic dissolved oxygen levels were almost always lower than river levels (except at Ives 1) and more variable (Figure 1.13). Ives 2 hyporheic was more stable than the other sites and averaged $43.8 \% \pm$ $0.11 \%$. Dissolved oxygen levels were as low as 3.3\% at Ives 5 hyporheic. Despite mean dissolved oxygen being lower in the hyporheic zone than in the overlying river, at a seasonal time scale dissolved oxygen responses at all of the locations (including both river and hyporheic sensors) tend to be inversely correlated with river depth (Figure 1.13). Over shorter time scales (e.g., days to weeks), there appears to be a secondary trend involving the hyporheic response and river stage. During river depth fluctuations at this time scale, hyporheic dissolved oxygen tends to exhibit a positive correlation between river depth and hyporheic dissolved oxygen (Figure 1.14). This likely represents increased mixing of river water with 

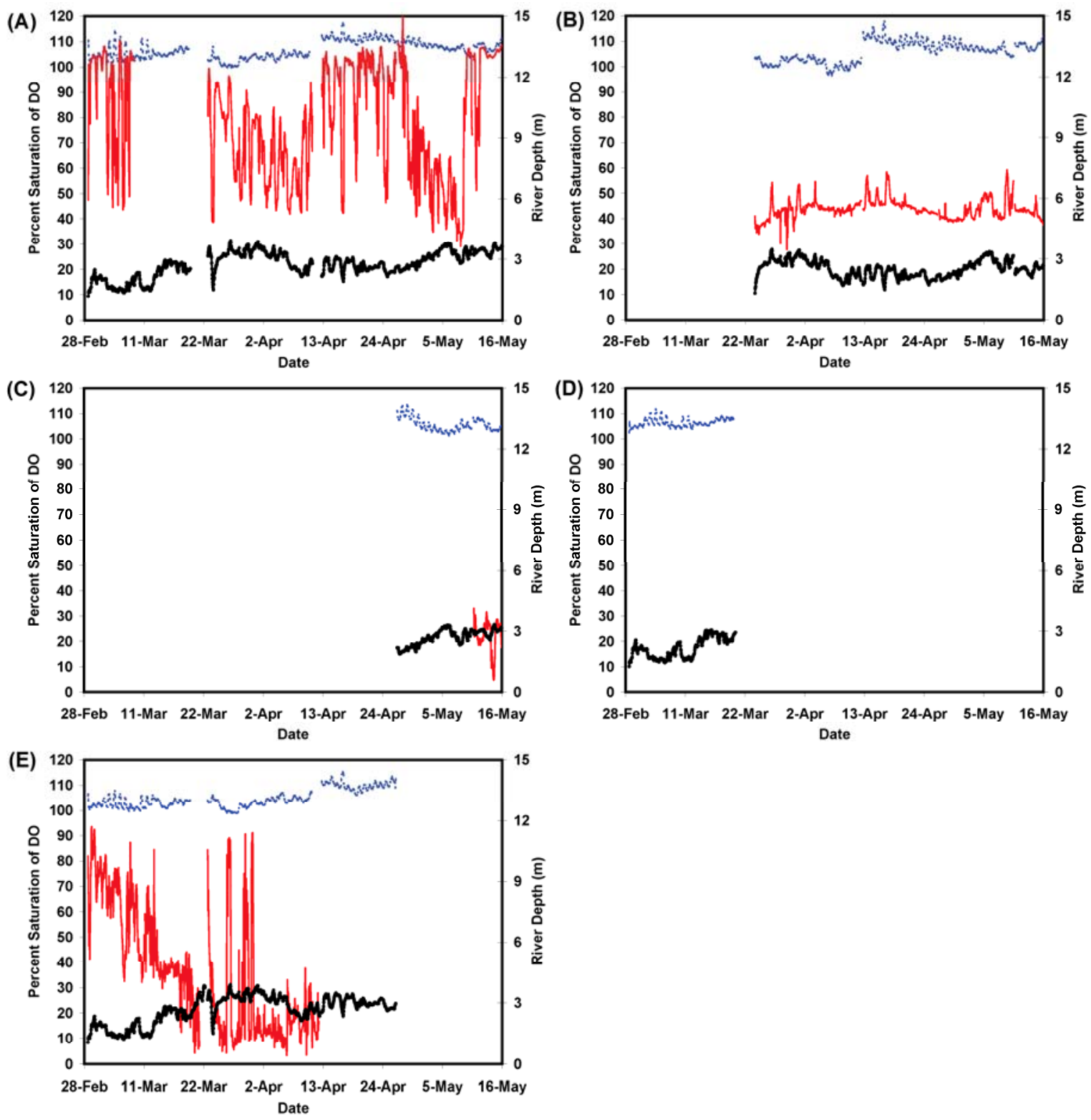

Figure 1.13. Ives Island area dissolved oxygen values. (A) Ives pair 1, (B) Ives pair 2, (C) Ives pair 3, (D) Ives pair 4, and (E) Ives pair 5. Solid red lines represent dissolved oxygen for hyporheic sensors, and dashed blue lines represent dissolved oxygen for river sensors. Solid black lines represent river depth at the hyporheic sensor.

the hyporheic zone when the river stage is higher. Because river dissolved oxygen levels are generally higher than hyporheic levels, when more river water enters the hyporheic zone, dissolved oxygen levels there are increased, becoming more like the river and causing the positive correlation with river stage. These relationships are evident over short time scales (Figure 1.14) but not at the months-long time scale of the entire study period (i.e., February through May). These trends are most evident at monitoring stations Ives 1, 2, and 5, where the most dissolved oxygen data were available (Figure 1.14). 

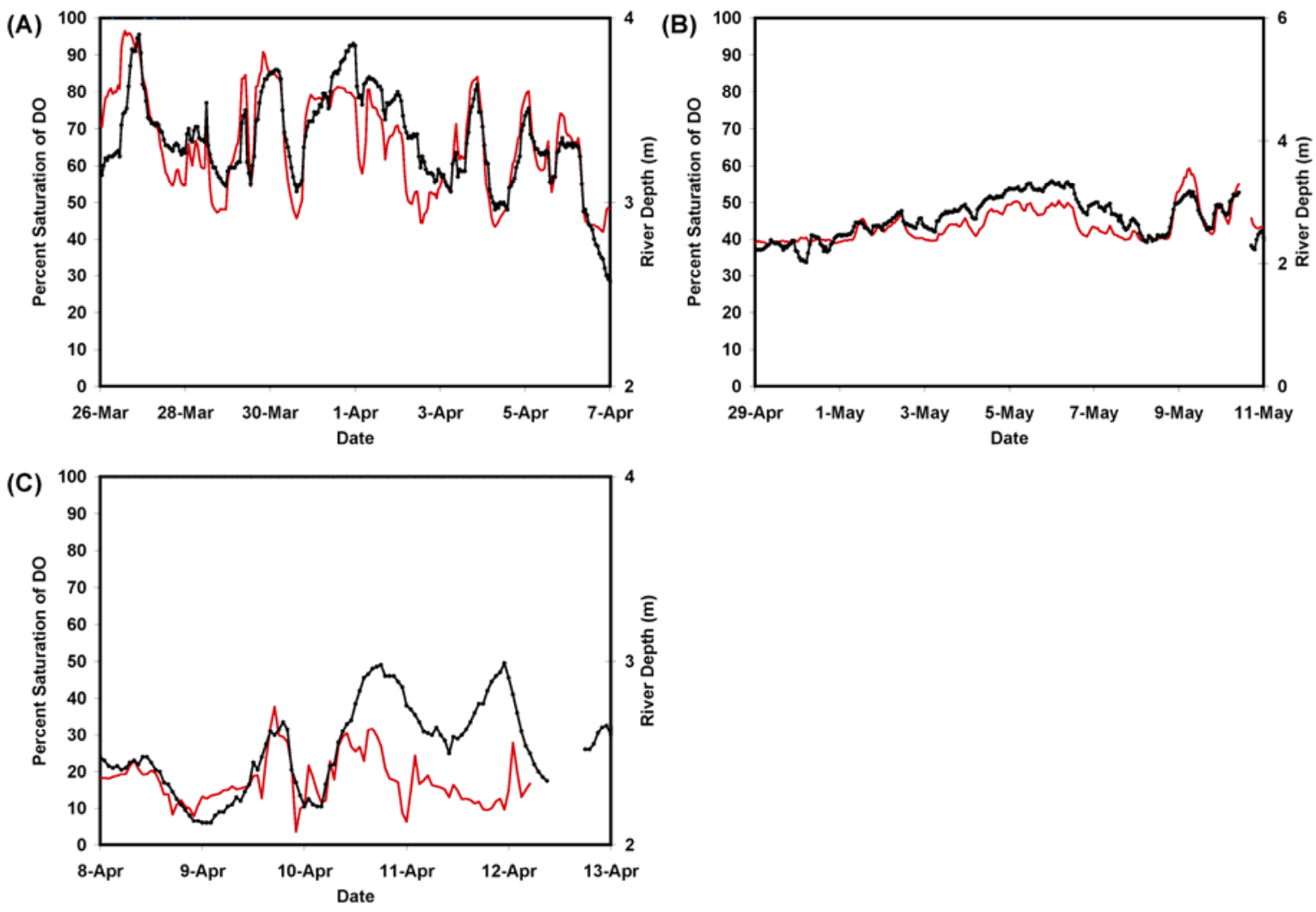

Figure 1.14. Ives Island area dissolved oxygen values. (A) Ives pair 1 (March 26-April 7), (B) Ives pair 2 (April 29-May 11), and (C) Ives pair 5 (April 8-April 13). Solid red lines represent DO for hyporheic sensors. Solid black lines show river depth at the hyporheic sensor.

\section{Temperature}

River temperatures at all five monitoring stations displayed a typical spring warming trend over the sampling period, gradually increasing from February through May, from $4^{\circ} \mathrm{C}$ to $13^{\circ} \mathrm{C}$. All mean hyporheic temperature at Ives 2, 4, and 5 were similar, with hyporheic temperature higher than the river temperature by approximately $4^{\circ} \mathrm{C}$ at the beginning of the record (inferred at Ives 2, where the record began later) and approaching river temperatures as part of seasonal warming trends during mid April (Figure 1.15).

At Ives 1 hyporheic, temperatures exhibited a strong inverse correlation with river depth, especially early during our study period (Figure 1.16). The correlation coefficient for this relationship was -0.92 for the period of February 28 through March 9 and -0.85 from March 22 through April 14. There was a similar but much less prevalent trend in river temperatures early in the record at Ives 1 (Figure 1.15A). These trends continued until seasonal warming negated the difference between hyporheic and river water temperatures, which occurred at approximately the time spring spill was initiated. 

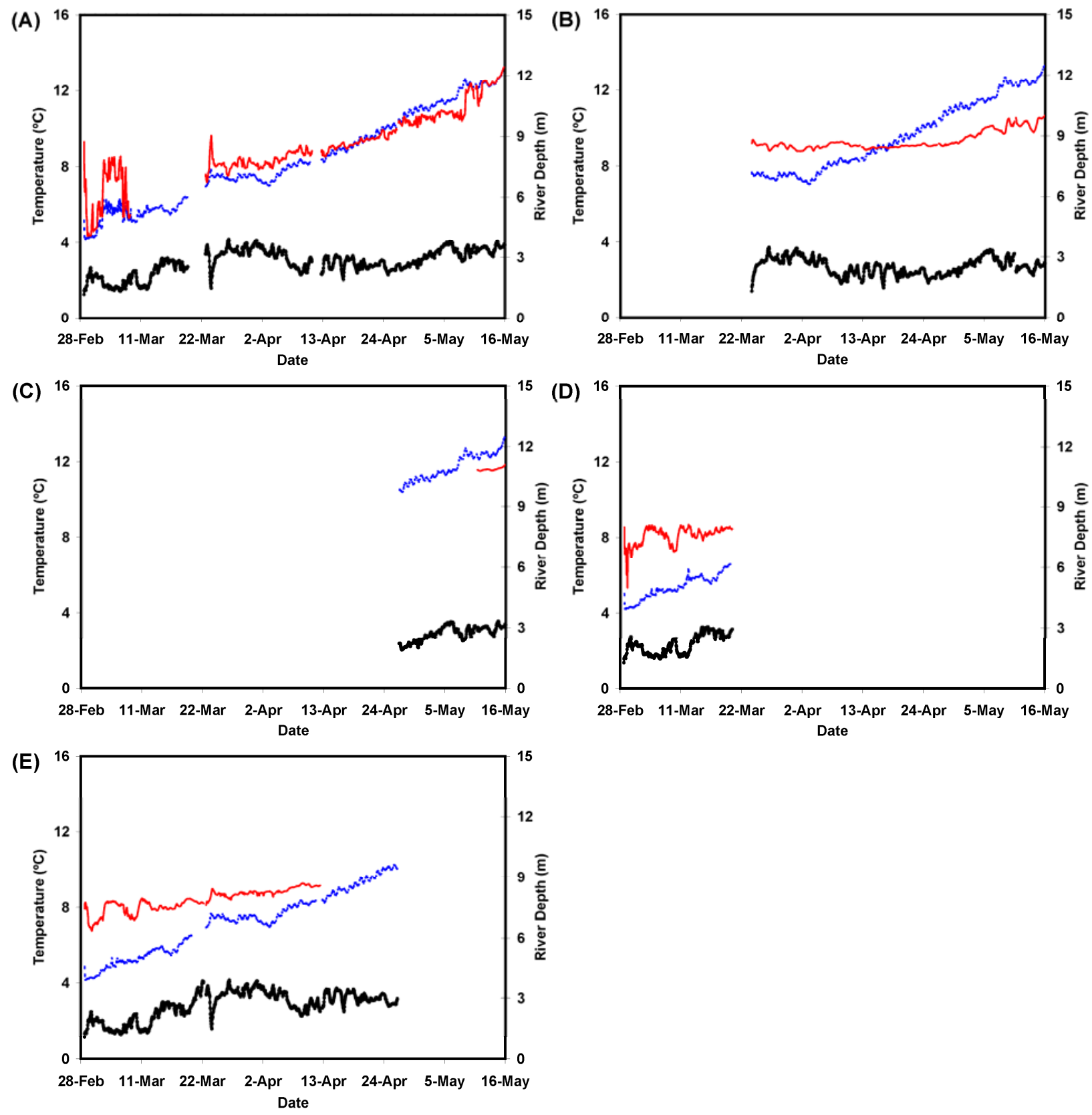

Figure 1.15. Ives Island site temperature values. (A) Ives pair 1, (B) Ives pair 2, (C) Ives pair 3, (D) Ives pair 4, and (E) Ives pair 5. Solid red lines represent temperature for hyporheic sensors, and dashed blue lines represent temperature for river sensors. Solid black lines represent river depth at the hyporheic sensor. 


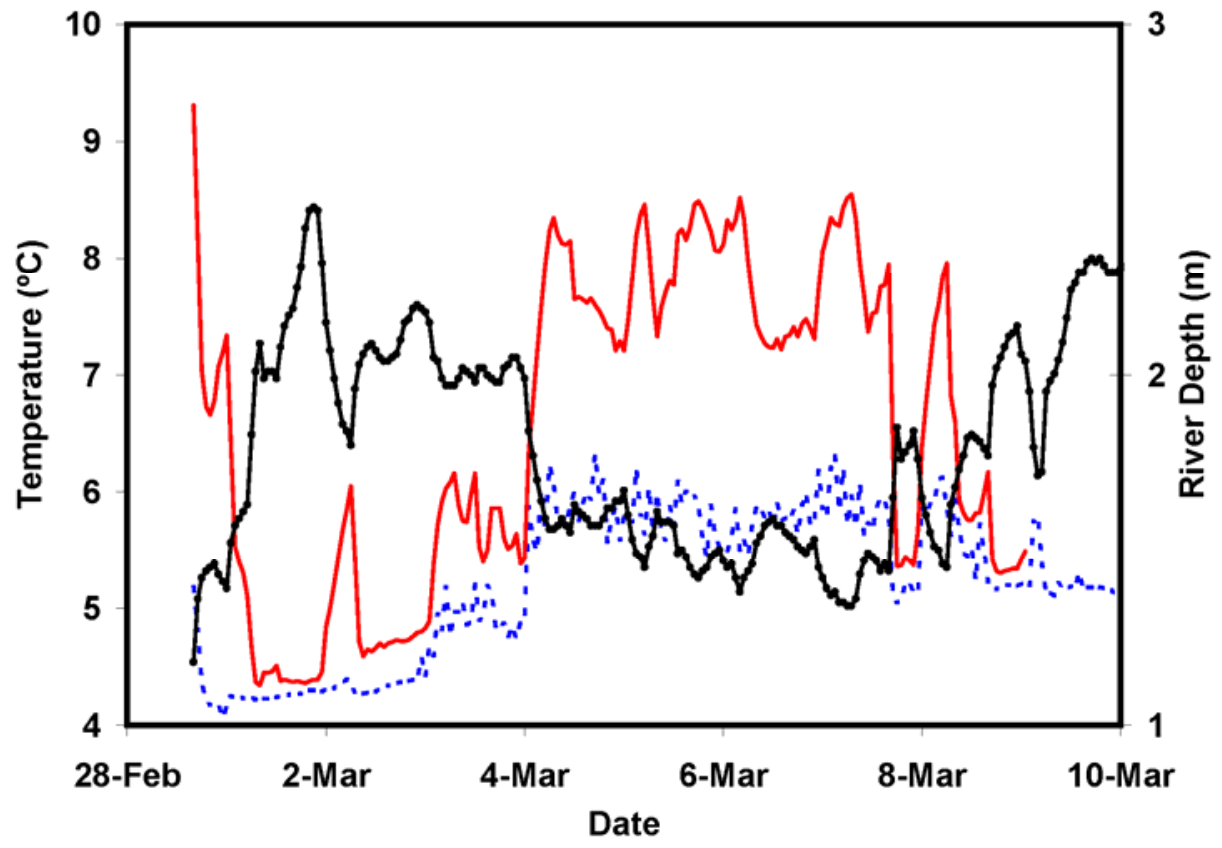

Figure 1.16. Ives Island pair 1 temperature, February 28-March 10. Solid red lines represent temperature for hyporheic sensors, and dashed blue lines represent temperature for river sensors. Solid black lines represent river depth at the hyporheic sensor.

At Ives 2 hyporheic, temperature remained relatively stable at approximately $9^{\circ} \mathrm{C}$, appearing much less affected by fluctuations in river stage than the other Ives site monitoring stations (Figure 1.15B). This could represent a location at which hyporheic discharge to the river remained relatively constant, such that the water quality there was largely not influenced by intruding river water during stage fluctuations.

Ives 4 hyporheic and Ives 5 hyporheic temperature both fluctuated in response to river stage changes early in the record (Figures 1.15D and 1.15E). The early record (February 28-March 13) shows a strong negative correlation between hyporheic temperature and river stage ( -0.53 and -0.71 , respectively).

\section{Specific Conductance}

Overall, the difference between specific conductance in Ives area river sensors and hyporheic sensors was small. The average of the sites ranged from $129.9 \mu \mathrm{S} / \mathrm{cm} \pm 0.11 \mu \mathrm{S} / \mathrm{cm}$ at Ives 3 river to $164.2 \mu \mathrm{S} / \mathrm{cm}$ $\pm 0.38 \mu \mathrm{S} / \mathrm{cm}$ at Ives 4 river. Specific conductance responses in hyporheic sensors generally followed the trend of the river but were more variable (Figure 1.17). This was especially true at Ives pair 1, pair 4, and pair 5 monitoring stations. At pair 2, hyporheic values remained relatively stable and did not appear to be influenced significantly by river water during river stage fluctuation (Figure 1.17B). 

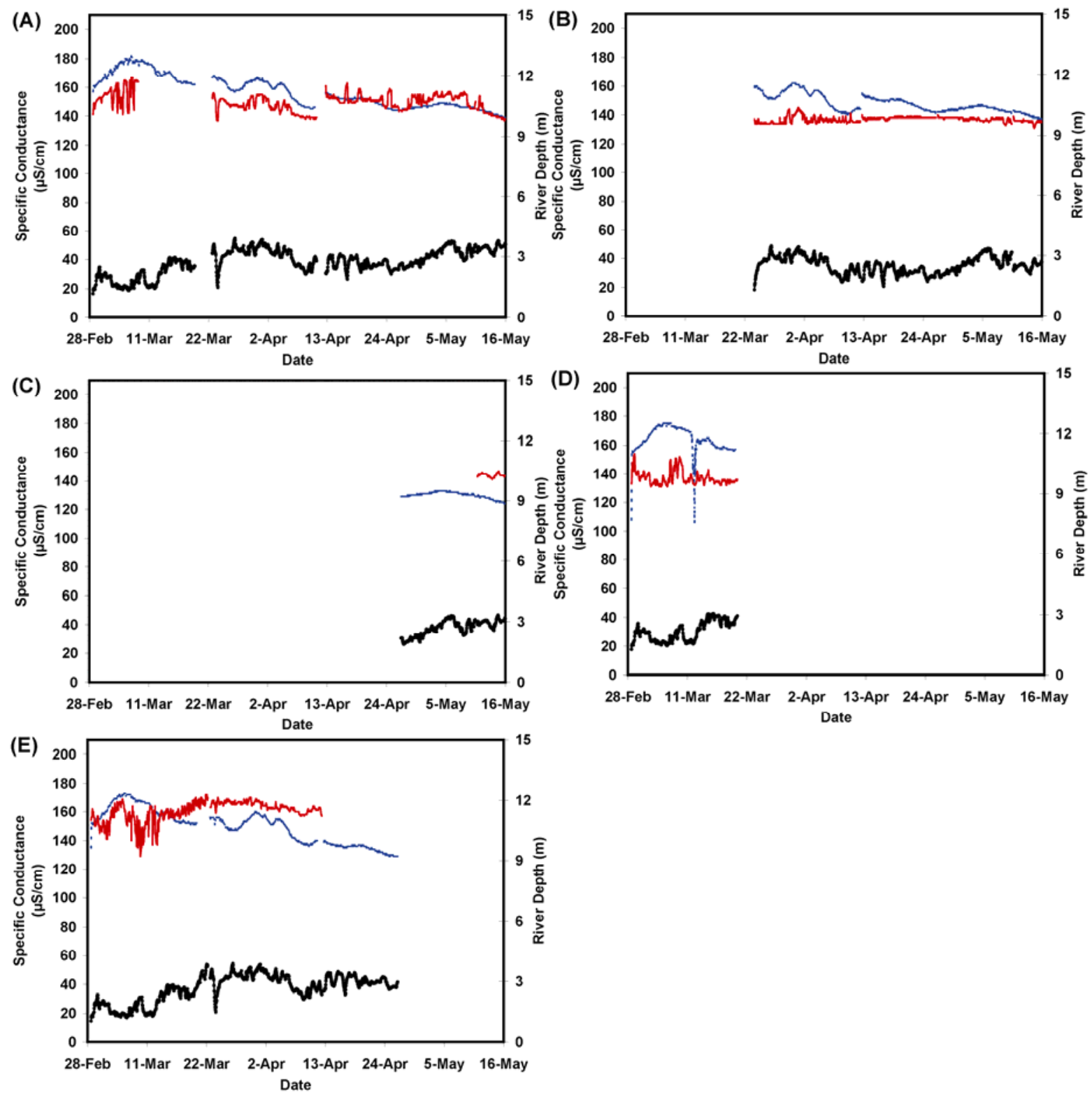

Figure 1.17. Ives Island site specific conductance values. (A) Ives pair 1, (B) Ives pair 2, (C) Ives pair 3 , (D) Ives pair 4, and (E) Ives pair 5. Solid red lines represent specific conductance for hyporheic sensors, and dashed blue lines represent specific conductance for river sensors. Solid black lines represent river depth at the hyporheic sensor.

$\mathrm{O}_{2} / \mathrm{N}_{2}$

Ratios of $\mathrm{O}_{2}$ to $\mathrm{N}_{2}$ were calculated for the Ives Island site hyporheic piezometer locations (Figure 1.18). Ratios ranged from an average of $0.177 \pm 0.005$ at Ives 3 hyporheic to $0.698 \pm 0.006$ at Ives 1 hyporheic. The minimum hourly ratio was at Ives 5 hyporheic at 0.028 , and the maximum hourly ratio was at Ives 1 hyporheic at 1.107. No ratios were computed for Ives 4 because there were no dissolved oxygen data available with which to calculate them. 

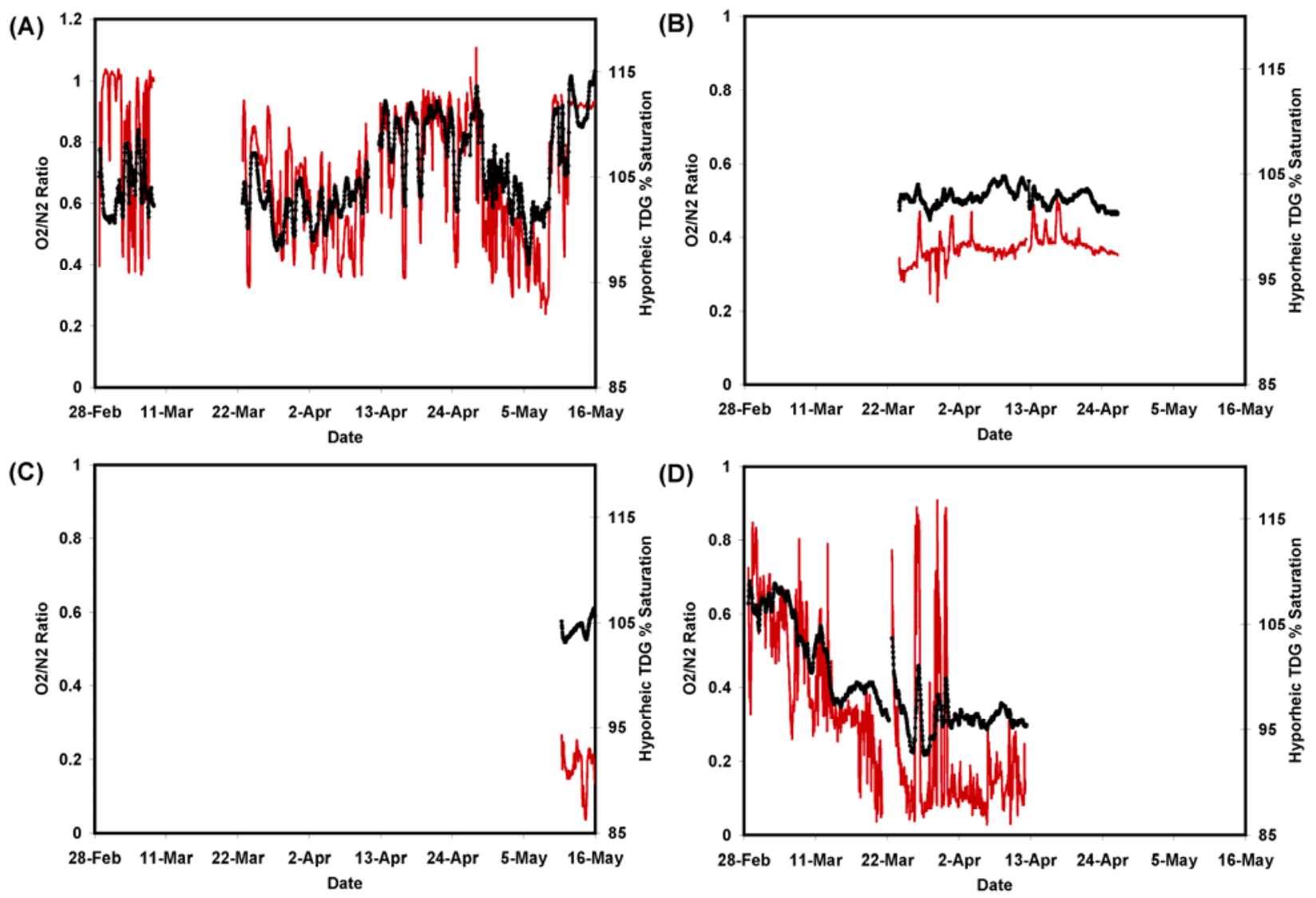

Figure 1.18. Ives Island $\mathrm{O} 2 / \mathrm{N} 2$ ratios and $\mathrm{TDG}$ values at hyporheic piezometers. (A) Ives 1 , (B) Ives 2 , (C) Ives 3, and (D) Ives 5. Solid red lines represent O2/N2 ratios, and black lines represent TDG values.

\section{Multnomah Falls Site}

We monitored water quality parameters at Multnomah Falls pair 1 and Multnomah Falls pair 3 from February 28 through May 15, 2007.

\section{Uncompensated Total Dissolved Gas}

River TDG values for Multnomah Falls 1 and 3 followed similar trends (Figure 1.19). Multnomah Falls 1 river averaged 109.6\% $\pm 0.14 \%$, and Multnomah Falls 3 river averaged $109.7 \% \pm 0.13 \%$. There was approximately a 10\% increase in TDG during the third deployment, when spring spill started (April 15). Hyporheic TDG values for Multnomah Falls 3 were more variable than at Multnomah Falls 1 (Figure 1.19). During the second deployment (March 21-April 12), Multnomah Falls 3 hyporheic averaged approximately 5.35\% higher than Multnomah Falls 1 hyporheic. Values were similar for the rest of the deployments. The Multnomah Falls 3 hyporheic TDG percentage saturation patterns before and after spring spill was initiated were very similar to those of Multnomah Falls 1 hyporheic. However, the average dropped farther than did Multnomah Falls 1 hyporheic. Multnomah Falls 1 hyporheic averaged $99.9 \% \pm 0.03 \%$ before spill and decreased to $97.6 \% \pm 0.03 \%$ post-spill. Multnomah Falls 3 hyporheic decreased from an average of $103.4 \% \pm 0.06 \%$ to $99.2 \% \pm 0.04 \%$. 

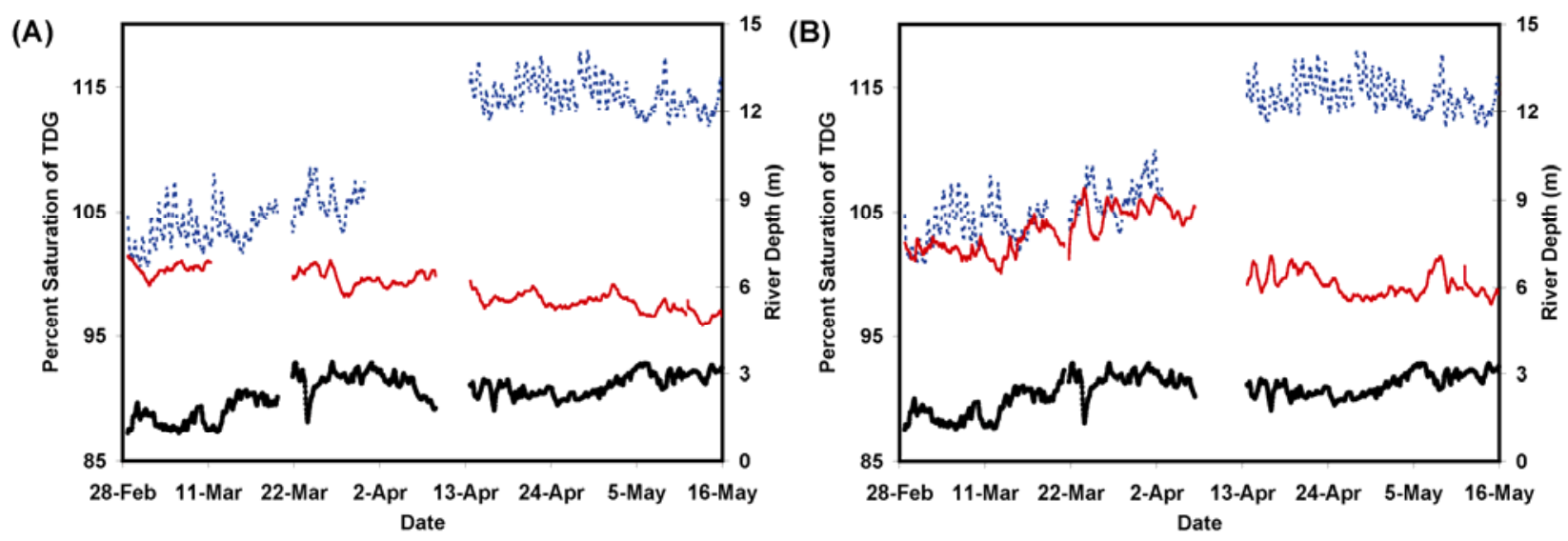

Figure 1.19. Multnomah Falls TDG values. (A) Multnomah Falls pair 1 and (B) Multnomah Falls pair 3. Solid red lines represent uncompensated TDG values for hyporheic sensors, and dashed blue lines represent uncompensated TDG values for river sensors. Solid black lines represent river depth at the hyporheic sensor.

\section{Depth-Compensated Total Dissolved Gas}

Multnomah Falls 1 river was the only Multnomah Falls site above 100\% depth-compensated TDG and was above that level for only 3 hours. Multnomah Falls 1 river did not exceed 103\% depthcompensated TDG. Similar to the Ives Island area, changes in river stage between the 2006 and 2007 incubation seasons influenced depth-compensated TDG. Early in the study period, river stage in 2006 and 2007 was similar. From March 13 through April 4, river stage in 2007 was higher, and from April 5 through May 15, river stage in 2006 became higher (Figure 1.20). When the river stage was similar in 2006 and 2007, depth-compensated TDG values were similar. Because depth-compensated TDG is a function of river depth, when the river stage was lower in 2006 than in 2007, depth-compensated TDG values were higher. Data were insufficient to compare long-term TDG records from Multnomah Falls 3. However, we were able to compare data from Multnomah Falls 1 for both years (Figure 1.20).

\section{Dissolved Oxygen}

River values were highly variable over short time scales (e.g., days) during the first deployment at Multnomah Falls 1 and the first two deployments at Multnomah Falls 3. During subsequent deployments, the response at both locations decreased rapidly over a period of approximately 5-10 days and then gradually began to increase (Figure 1.21). This began to occur at the beginning of the second deployment on March 21 at Multnomah Falls 1 river and at the beginning of the third deployment on April 13 at Multnomah Falls 3 river. Hyporheic dissolved oxygen values were stable throughout the study, with a slight downward trend and a maximum of $90.0 \%$ at Multnomah Falls 1 hyporheic and a minimum of $56.1 \%$ at Multnomah Falls 3 hyporheic (Figure 1.21). 


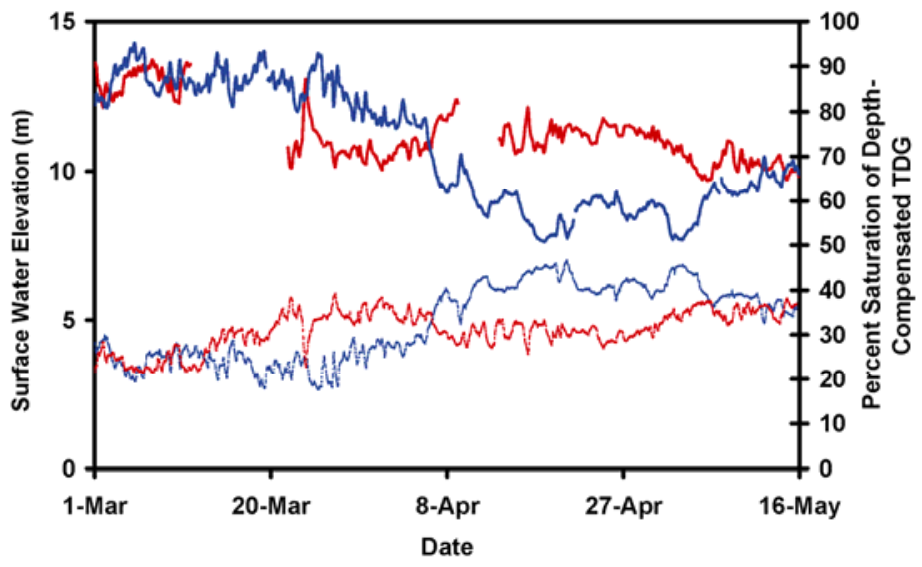

Figure 1.20. Hyporheic depth-compensated TDG at Multnomah Falls 1. Solid blue lines represent depth-compensated TDG during incubation year 2006. Dashed blue lines represent river elevations during 2006. Solid red lines represent depth-compensated TDG during incubation year 2007. Dashed red lines show river depth during 2007.
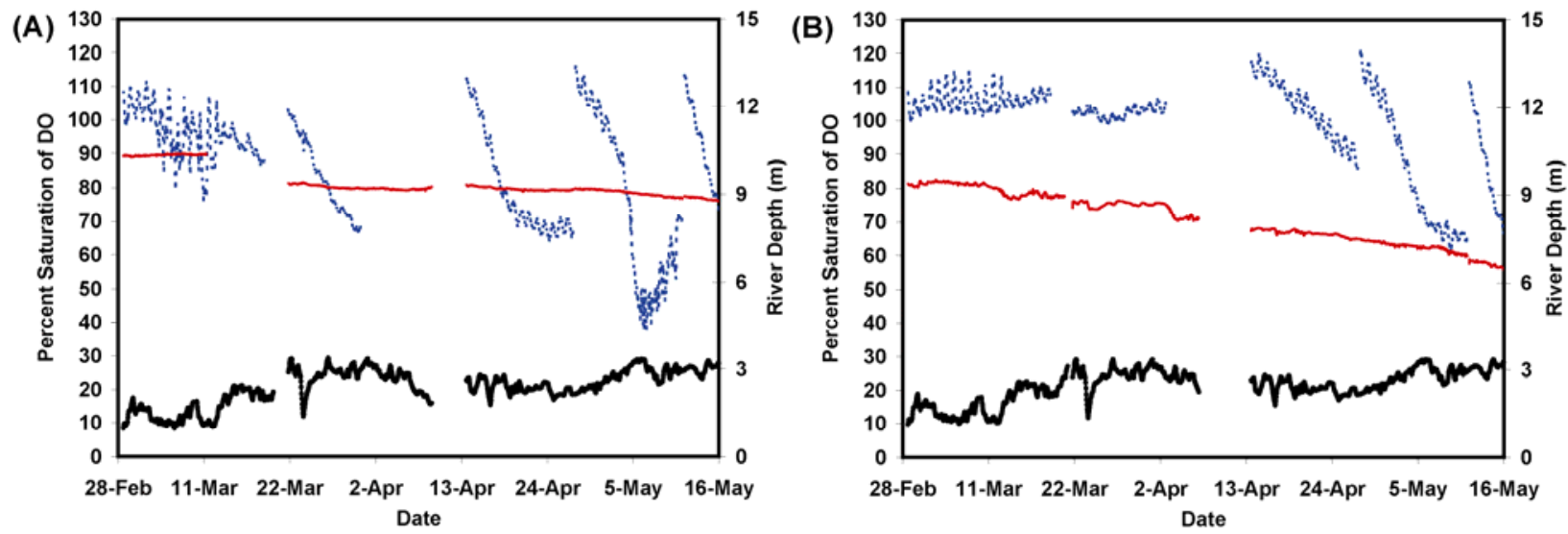

Figure 1.21. Multnomah Falls dissolved oxygen values. (A) Multnomah Falls pair 1 and (B) Multnomah Falls pair 3. Solid red lines represent dissolved oxygen values for hyporheic sensors, and dashed blue lines represent dissolved oxygen for river sensors. Solid black lines represent river depth at the hyporheic sensor.

\section{Temperature}

River temperature at both sites displayed a typical spring warming trend, gradually increasing from February through May starting at approximately $4^{\circ} \mathrm{C}$ and rising to $13.5^{\circ} \mathrm{C}$ (Figure 1.22 ). Hyporheic temperatures were very stable throughout the study period, with a slight upward trend at Multnomah Falls 3 (Figure 1.22). Multnomah Falls 1 hyporheic was warmer, with an average of $7.3^{\circ} \mathrm{C}$ compared to $6.0^{\circ} \mathrm{C}$ at Multnomah Falls 3 hyporheic. The stable nature of hyporheic temperatures in the Multnomah Falls area suggests relatively constant groundwater or spring water discharge there (Shepherd et al. 1986; Crisp 1990). 

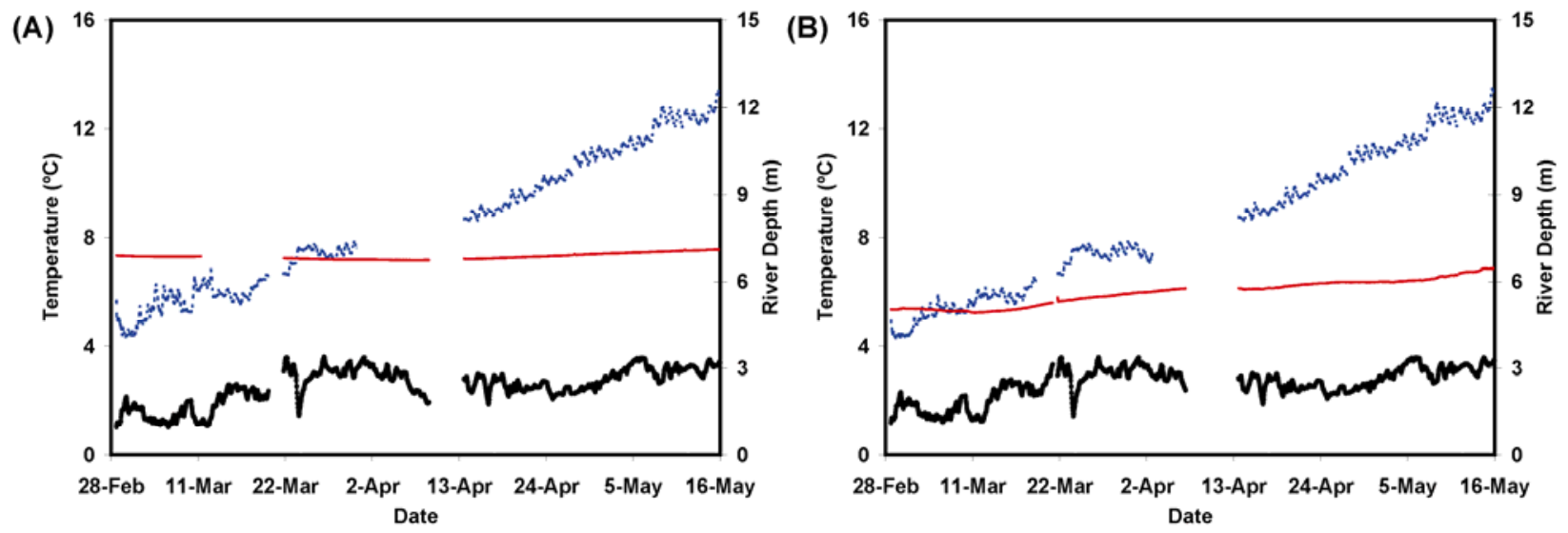

Figure 1.22. Multnomah Falls temperature values. (A) Multnomah Falls pair 1 and (B) Multnomah Falls pair 3. Solid red lines represent temperature values for hyporheic sensors, and dashed blue lines represent temperature values for river sensors. Solid black lines represent river depth at the hyporheic sensor.

\section{Specific Conductance}

Specific conductance values measured by the river piezometers varied more during the first two deployments and became more stable during the last part of the monitoring period (Figure 1.23). River values were very similar; the averages were $149.7 \mu \mathrm{S} / \mathrm{cm} \pm 0.21 \mu \mathrm{S} / \mathrm{cm}$ at Multnomah Falls 1 and $148.4 \mu \mathrm{S} / \mathrm{cm} \pm 0.39 \mu \mathrm{S} / \mathrm{cm}$ at Multnomah Falls 3. Hyporheic specific conductance values were much lower and more stable than those recorded in the Ives Island area, indicative of a hyporheic environment in which groundwater discharges into the river and the water quality is not significantly affected by fluctuations in river discharge. Hyporheic values ranged from $29 \mu \mathrm{S} / \mathrm{cm}$ to $54 \mu \mathrm{S} / \mathrm{cm}$.
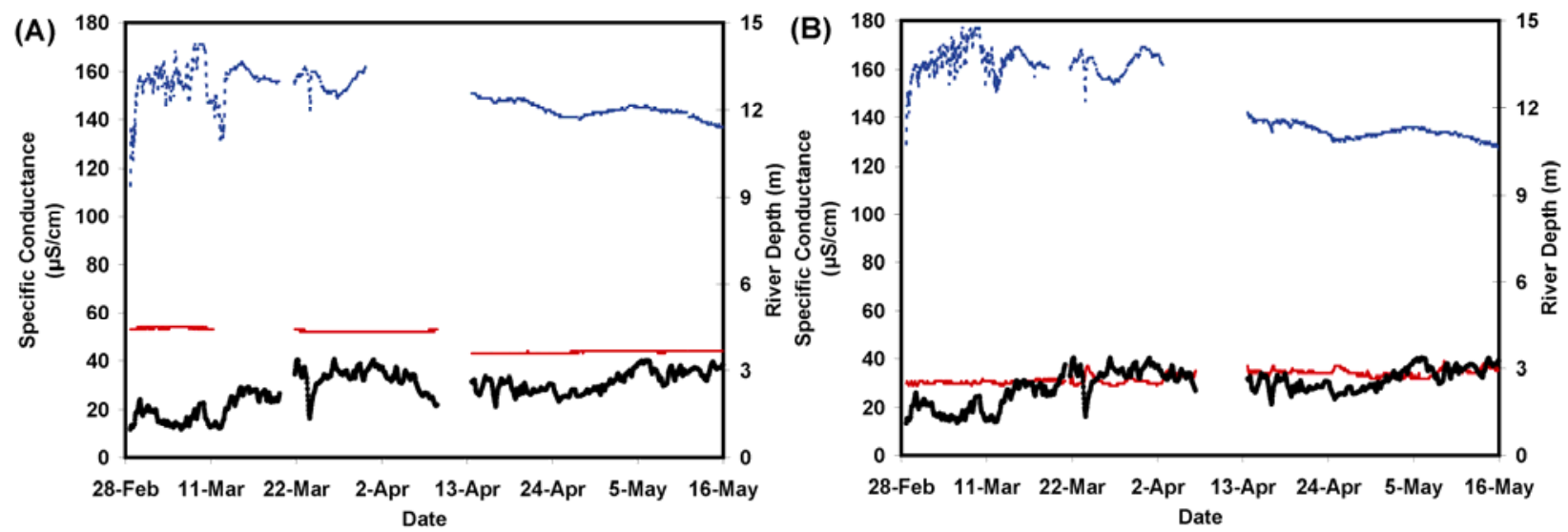

Figure 1.23. Multnomah Falls specific conductance values. (A) Multnomah Falls pair 1 and (B) Multnomah Falls pair 3. Solid red lines represent temperature values for hyporheic sensors, and dashed blue lines represent temperature values for river sensors. Solid black lines represent river depth at the hyporheic sensor. 
$\mathrm{O}_{2} / \mathrm{N}_{2}$

Ratios of $\mathrm{O}_{2}$ to $\mathrm{N}_{2}$ were calculated for Multnomah Falls hyporheic data (Figure 1.24). Multnomah Falls 1 hyporheic averaged $0.778 \pm 0.001$, and Multnomah Falls 3 averaged $0.644 \pm 0.002$. The minimum hourly ratio was at Multnomah Falls 3 and was 0.510 . The maximum hourly ratio was at Multnomah Falls 1 and was 0.867.
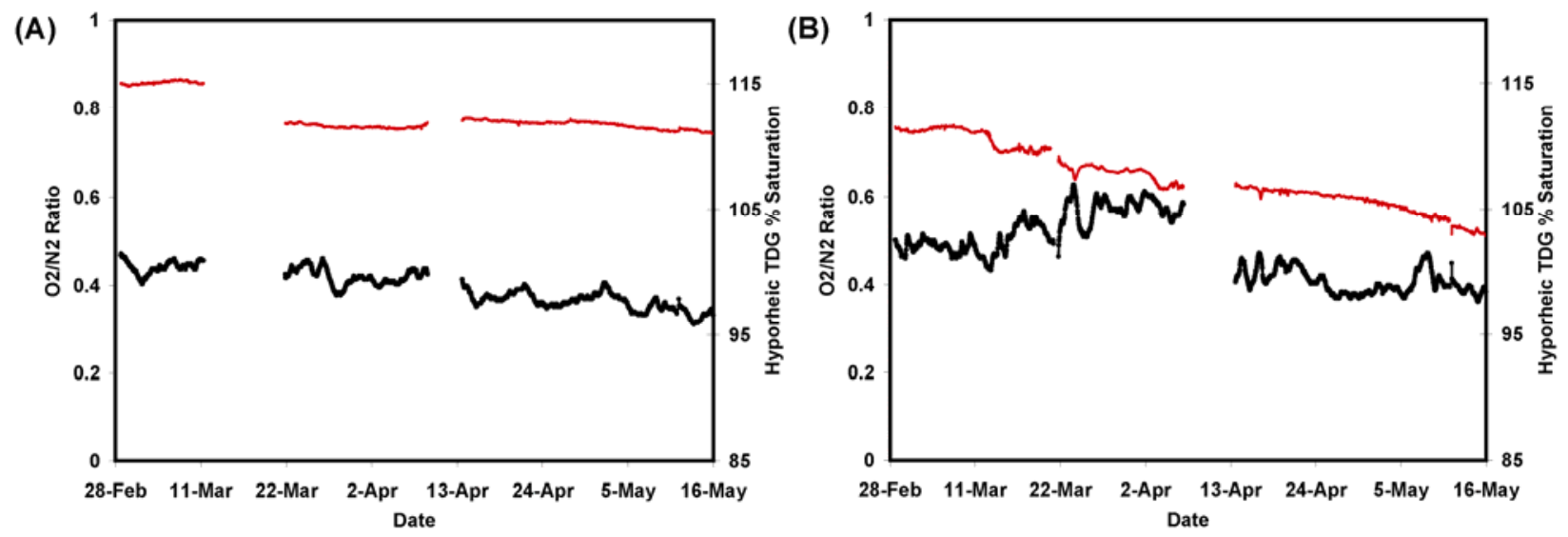

Figure 1.24. Multnomah Falls $\mathrm{O}_{2} / \mathrm{N}_{2}$ ratios and TDG values. (A) Multnomah Falls 1 hyporheic and (B) Multnomah Falls 3 hyporheic. Solid red lines represent $\mathrm{O}_{2} / \mathrm{N}_{2}$ ratios, and black lines represent TDG values.

\section{Estimated Exposure of Chum Salmon Redds to Total Dissolved Gas}

The extent to which chum salmon redds are exposed to potentially toxic depth-compensated TDG concentrations is controlled largely by the concentration of TDG in the water surrounding the egg pocket and the depth of the water column above the egg pocket that is available to provide depth compensation. Redds constructed at relatively shallow riverbed elevations are provided less depth compensation then redds constructed at deeper riverbed elevations. To estimate chum salmon redd exposure to TDG in the Ives Island and Multnomah Falls areas, we first evaluated the elevation distribution of the redds constructed there during the 2005 and 2006 spawning years (we monitored TDG during the incubation season following each of those years. Thus, our TDG monitoring data from 2006 correspond to 2005 redds, and TDG monitoring data from 2007 correspond to 2006 redds). During 2006, chum salmon redds generally were constructed at much higher elevations on the south side of Ives Bar compared to lower elevations on the north side of Ives Bar during previous years (e.g., 2000-2005; Figure 1.25). This was likely the result of extremely high volumes of rain that fell during the 2006 spawning season, creating usable spawning habitat in areas on the south side of Ives Bar but significantly increasing the water depth and velocity on the north side of Ives Bar. 


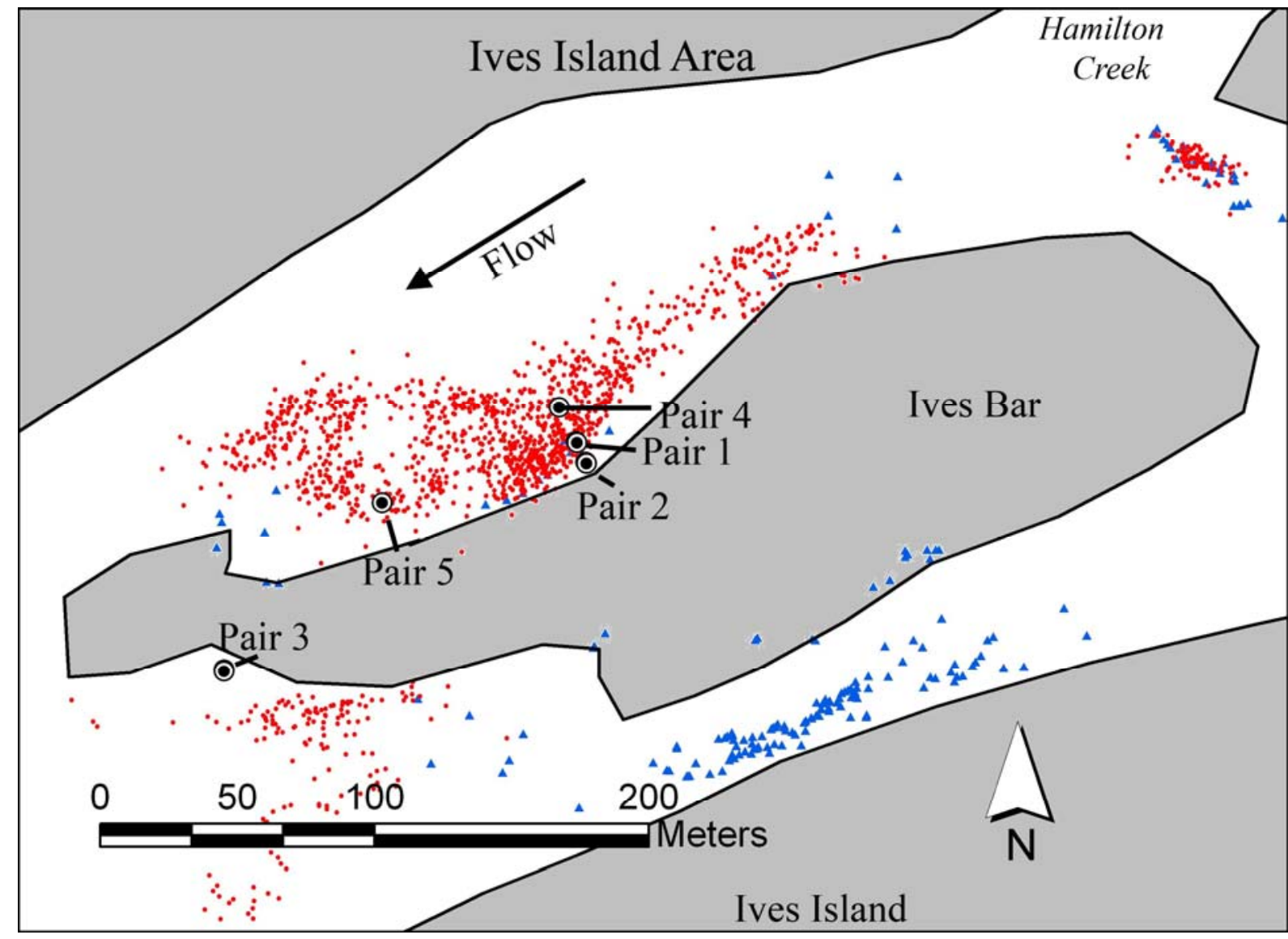

Figure 1.25. Ives Island area chum salmon redd locations for spawning years 2000-2006. Red circles represent chum salmon redds marked from spawning years 2000 through 2005. Blue triangles represent chum salmon redds marked during 2006.

We evaluated the elevation distribution of 2005-2006 Ives area chum salmon redds by comparing their locations (as determined by the ODFW) to a digital elevation model constructed by the USGS (Tiffan et al. 2004). Comparison of the 2006 chum redd elevation distribution to our sensor pairs shows that the vast majority of 2006 spawning occurred at elevations higher than our 2007 monitoring locations (Table 1.2). This is in contrast to the elevations of redds in 2005, which were generally lower than our subsequent monitoring locations (Table 1.2).

Table 1.2. Percentage of chum salmon redds constructed at riverbed elevations higher than Ives Island area monitoring locations for total dissolved gas, 2005 and 2006 spawning years

\begin{tabular}{lccc}
\hline $\begin{array}{l}\text { Monitoring } \\
\text { Location }\end{array}$ & $\begin{array}{c}\text { Elevation } \\
\text { (NGVD 29 feet) }\end{array}$ & $\begin{array}{c}\text { Percentage of 2006 chum redds } \\
\text { at a higher elevation }\end{array}$ & $\begin{array}{c}\text { Percentage of 2005 chum redds } \\
\text { at a higher elevation }\end{array}$ \\
\hline Pair 1 & 8.2 & 98.9 & 25 \\
Pair 2 & 9.2 & 91.7 & 4 \\
Pair 3 & 9.5 & 91.3 & 0 \\
Pair 4 & 7.8 & 100 & $\mathrm{NA}^{\text {(a) }}$ \\
Pair 5 & 8.1 & 99.2 & $\mathrm{NA}^{\text {(a) }}$ \\
\hline
\end{tabular}

(a) Pair 4 and pair 5 were installed during the 2007 incubation year to monitor 2006 redds. 
Our monitoring results suggest depth-compensated TDG seldom exceeds $100 \%$ at the riverbed elevations where our sensors were installed. However, during some years (e.g., the 2006-2007 spawning and incubation season), chum redds were constructed at riverbed elevations higher than our monitoring locations. It is thus possible that although river depths were high enough to sufficiently compensate for TDG levels at the riverbed elevation of our monitoring locations, river depths were not deep enough to sufficiently compensate for TDG levels at riverbed locations where most of the Ives Island area redds were constructed.

In the Multnomah Falls area, 2006 chum salmon redds were found within the same area they had been during 2003-2005 (Figure 1.26).

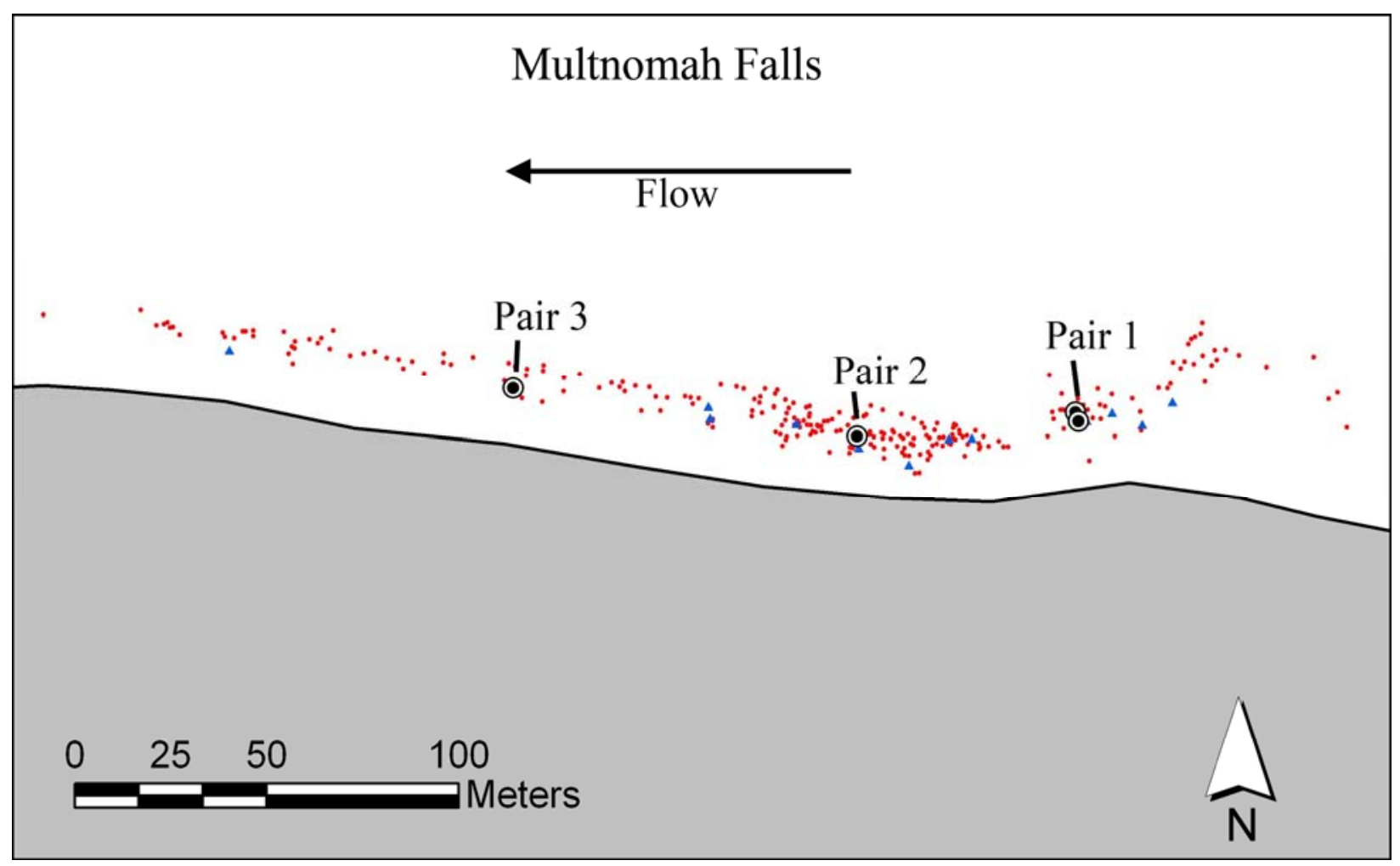

Figure 1.26. Multnomah Falls area chum salmon redd locations for spawning years 2003-2006. Red circles represent chum salmon redds marked from spawning year 2003 through 2005. Blue triangles represent chum salmon redds marked during 2006.

Chum salmon redd elevations were not recorded in the Multnomah Falls area. However, their elevation distribution appears to be relatively uniform for all the years in which redd locations were marked (Figure 1.26). In the Multnomah Falls spawning area, the riverbed is relatively flat; little range in the elevation distribution of redds is expected there. Because our sensors were installed within the area of the flat riverbed where most of the redds were constructed, and because depth-compensated TDG was never appreciably greater than $100 \%$ saturation at the elevation of our sensors, we expect there is little chance chum salmon redds are being negatively affected by TDG there. Consequently, we estimated exposure of Ives Island area chum salmon redds to depth-compensated TDG during the 2006 and 2007 incubation seasons but did not do so in the Multnomah Falls area. 
During the 2005 spawning year, only 25 redds were mapped within our Ives Island assessment area (Figure 1.27). The redds were distributed at relatively uniform elevations, ranging from $7.5 \mathrm{ft}$ to $8.8 \mathrm{ft}$ above mean sea level (MSL; NGVD 29). Fifty percent were at an elevation below $8.1 \mathrm{ft} \mathrm{MSL,} \mathrm{and} 80 \%$ of redds were below $8.3 \mathrm{ft}$ MSL. All of the redds were found on the north side of Ives Bar, in areas where chum redds typically have been found since annual chum counts began in that area during 1998 (Figure 1.27). The 2005 redds were in areas with low riverbed elevations where depth compensation was generally available during the 2006 incubation season, resulting in low exposure times to elevated TDG. There was little difference between exposure time estimates based on hyporheic monitoring results compared to estimates from surface water monitoring results.
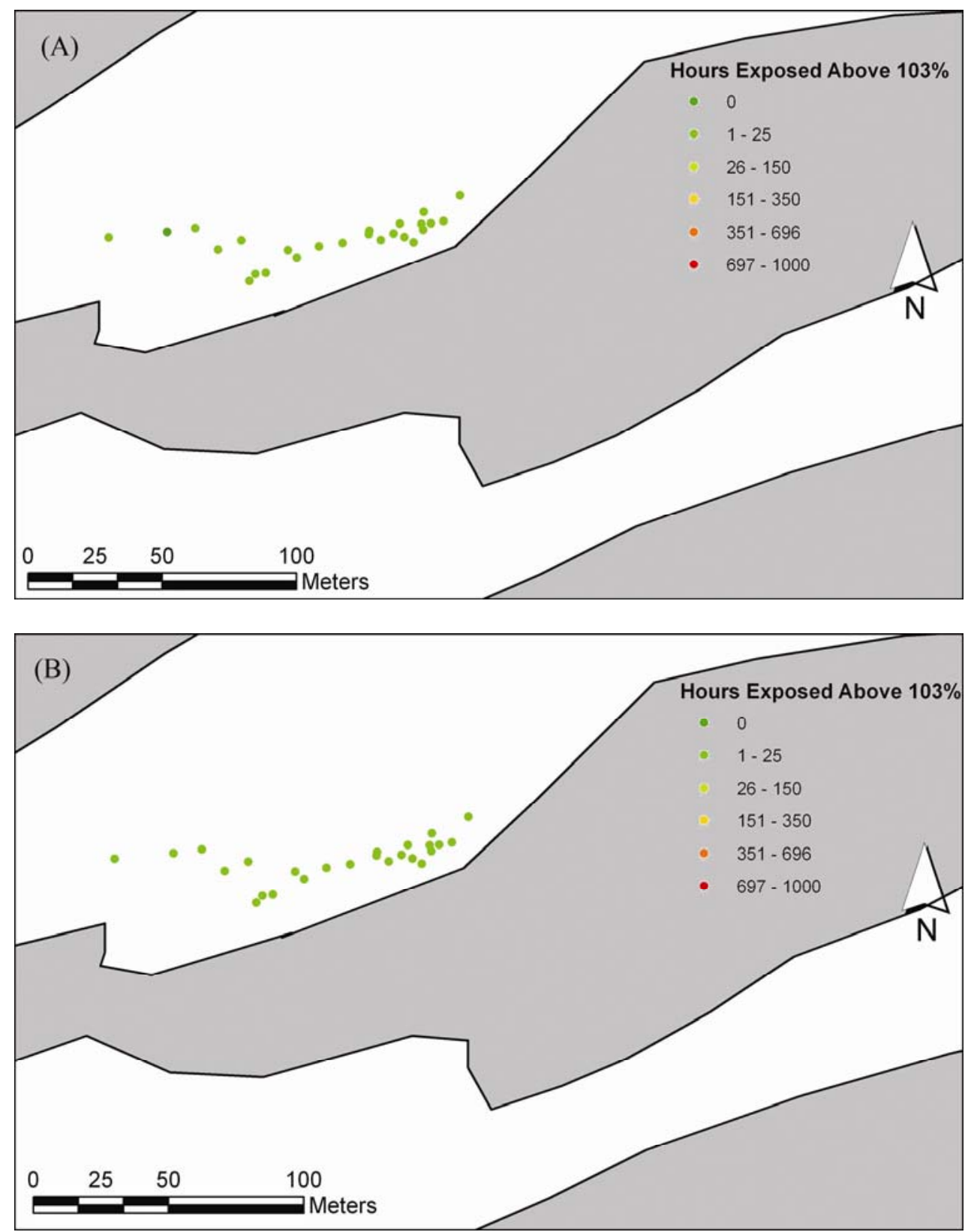

Figure 1.27. Estimated TDG exposure to chum salmon sac fry. (A) Incubation year 2006 hyporheic water monitoring results; (B) incubation year 2006 surface water results. 
At the shallowest redd in the distribution, estimated exposure time to depth-compensated TDG greater than $100 \%$ was 60 hours based on hyporheic monitoring TDG and 38 hours based on surface water TDG. Hyporheic monitoring estimates suggest redds shallower than the 50th elevation percentile were exposed to depth-compensated TDG greater than 100\% for 32 hours (Figure 1.28). Hyporheic estimates for exposure times to TDG levels of $103 \%$ and $105 \%$ were 9 hours and zero hours, respectively. Exposure times based on surface water TDG monitoring and estimated for the 50th depth percentile were 23 hours at 100\% TDG, 11 hours at 103\% TDG, and 4 hours at 105\% TDG (Figure 1.29). At higher riverbed elevations (e.g., the 80th elevation distribution percentile), exposure times based on hyporheic results were 35 hours at 100\% TDG, 11 hours at 103\% TDG, and 3 hours at 105\% TDG (Figure 1.28). Similar estimates based on surface water TDG monitoring were obtained with exposure times of 26 hours at 100\% TDG, 12 hours at 103\% TDG, and 6 hours at 105\% TDG (Figure 1.29). No dewatering of redds in our assessment area occurred during incubation year 2006.

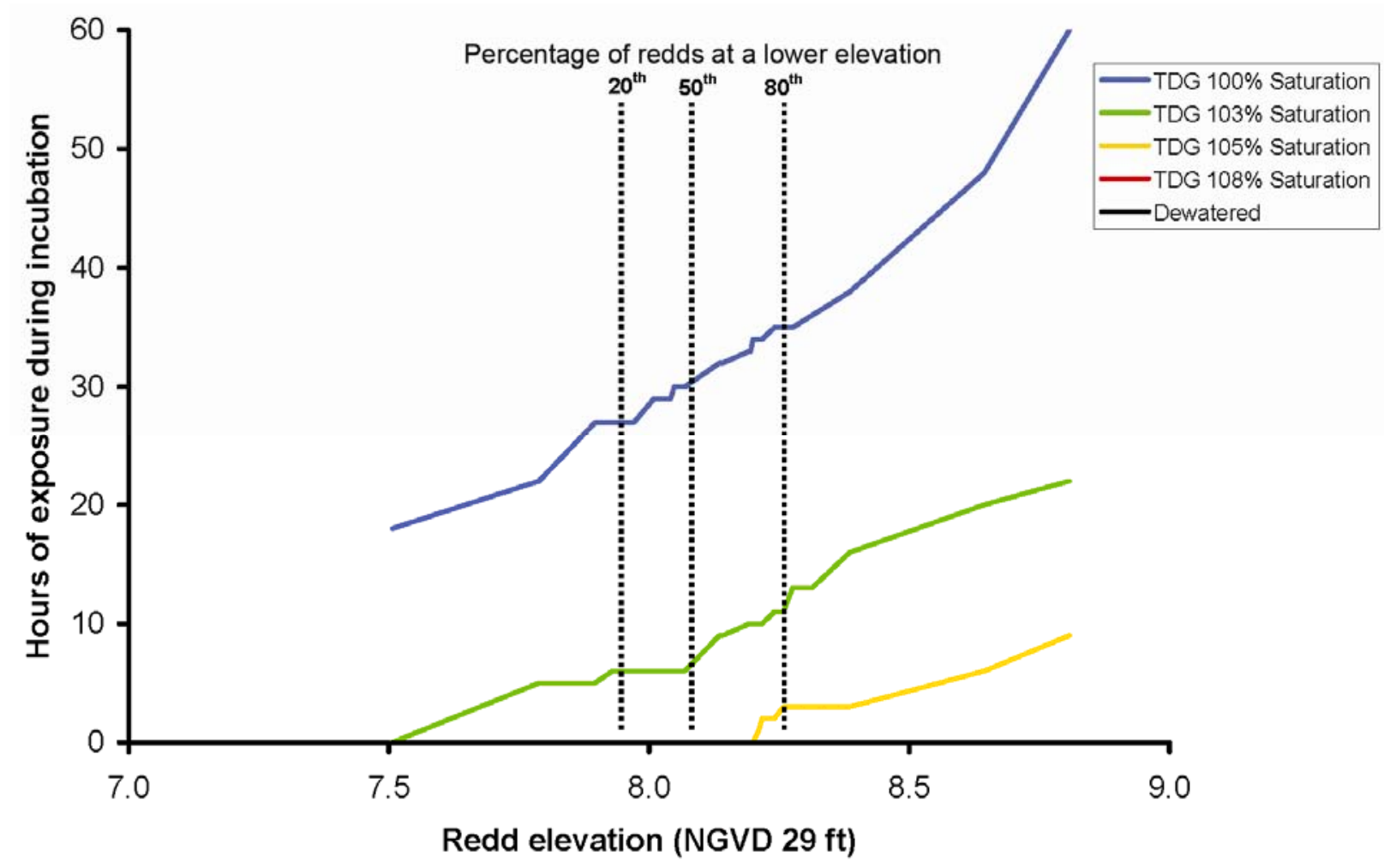

Figure 1.28. Estimated hours of TDG exposure and dewatering to chum salmon sac fry based on hyporheic results from incubation year 2006. Dashed lines show the 2005 chum salmon redd elevation distribution percentiles. 


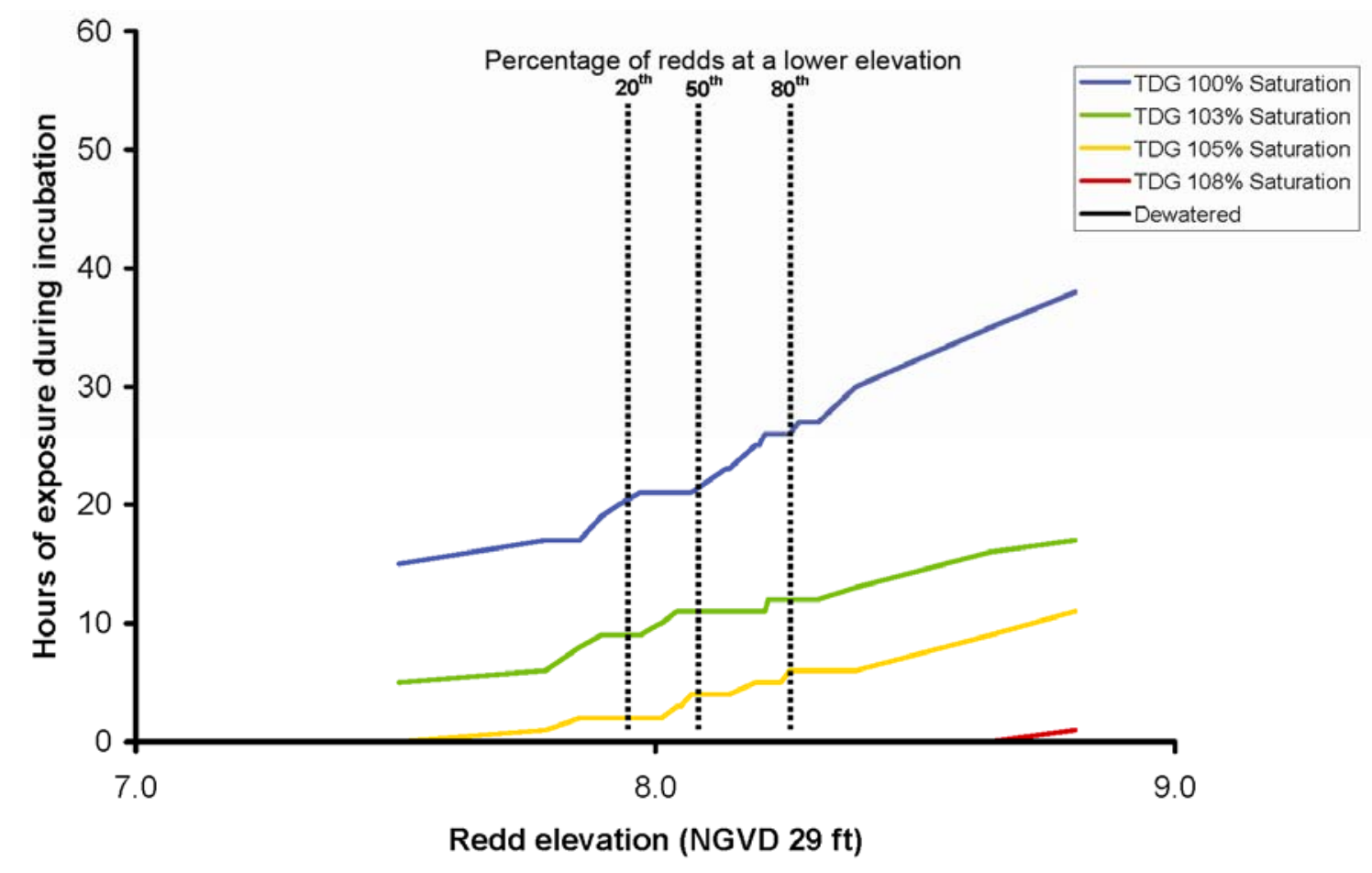

Figure 1.29. Estimated hours of TDG exposure and dewatering to chum salmon sac fry based on surface water results from incubation year 2006. Dashed lines show the 2005 chum salmon redd elevation distribution percentiles.

During the 2006 spawning year, 137 chum redds were distributed within our Ives Island assessment area at riverbed elevations ranging from $7.93 \mathrm{ft}$ to $13.9 \mathrm{ft}$ (NGVD 29). The greater range in the elevation distribution is due to relatively high water levels that were present during the previous spawning season, which allowed chum salmon to spawn in higher-elevation habitat on the south side of Ives Bar (Figure 1.30). The larger number of redds and wider elevation distribution also increased exposures to elevated TDG compared to incubation year 2006. During incubation year $2007,50 \%$ of the redds were located below $10.87 \mathrm{ft}$ MSL and 80\% were below $12 \mathrm{ft}$ MSL. Chum redds constructed in deeper water on the north side of Ives Bar were exposed to very little elevated TDG. However, on the south side of the bar, redds constructed at higher riverbed elevations were exposed to TDG greater than $103 \%$ for up to 330 hours based on hyporheic monitoring results and up to 600 hours based on surface monitoring results (Figure 1.30). Redds in areas exposed to the high TDG concentrations for the longest periods were in areas that also were dewatered more often (Figure 1.30).

Based on estimated exposures to redds at the 50th elevation percentile and shallower, surface water monitoring produced longer exposures to TDG greater than $100 \%$. However, exposure time estimates based on hyporheic monitoring were greater at TDG concentrations above $103 \%$ and $105 \%$. The hyporheic estimates suggested redds at the 50th elevation percentile were exposed to TDG concentrations greater than $100 \%$ for at least 240 hours from March 1 through May 15. The same redds were exposed to TDG greater than $103 \%$ for 103 hours and TDG greater than $105 \%$ for 86 hours (Figure 1.31). Based on surface water monitoring results, redds at the 50th elevation percentile were exposed to TDG concentrations greater than $100 \%$ for 340 hours (significantly longer than for hyporheic estimates). However, estimated exposures to $103 \%$ TDG were 47 hours and to $105 \%$ TDG for 11 hours (Figure 1.32). 

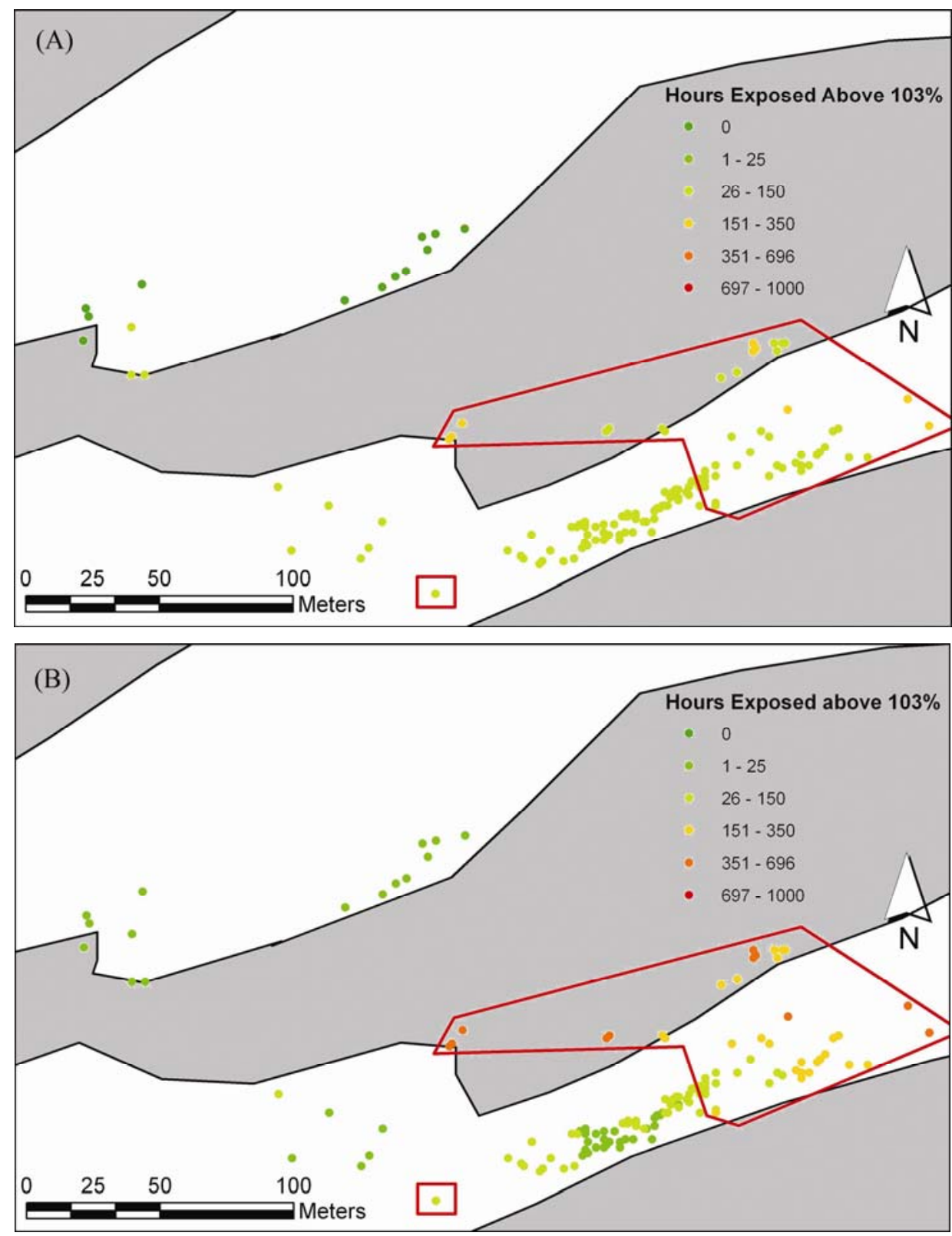

Figure 1.30. Estimated TDG exposure to chum salmon sac fry. (A) Incubation year 2007 hyporheic water monitoring results and (B) incubation year 2007 surface water results. Red lines outline areas where redds were dewatered for more than 103 hours.

At the 80th elevation percentile (elevation at which $80 \%$ of the redds were deeper), estimates based on hyporheic water monitoring produced shorter exposure times in all TDG categories compared to results based on surface water TDG monitoring. Based on hyporheic monitoring at the 80th elevation percentile, redds were exposed to TDG greater than $100 \%$ for 264 hours, 103\% TDG for 97 hours, and $105 \%$ TDG for 37 hours (Figure 1.31). Based on surface water monitoring results for redds at the 80th elevation percentile, redds were exposed to 100\% TDG for 465 hours, 103\% TDG for 240 hours, and 105\% TDG 85 hours (Figure 1.32). 


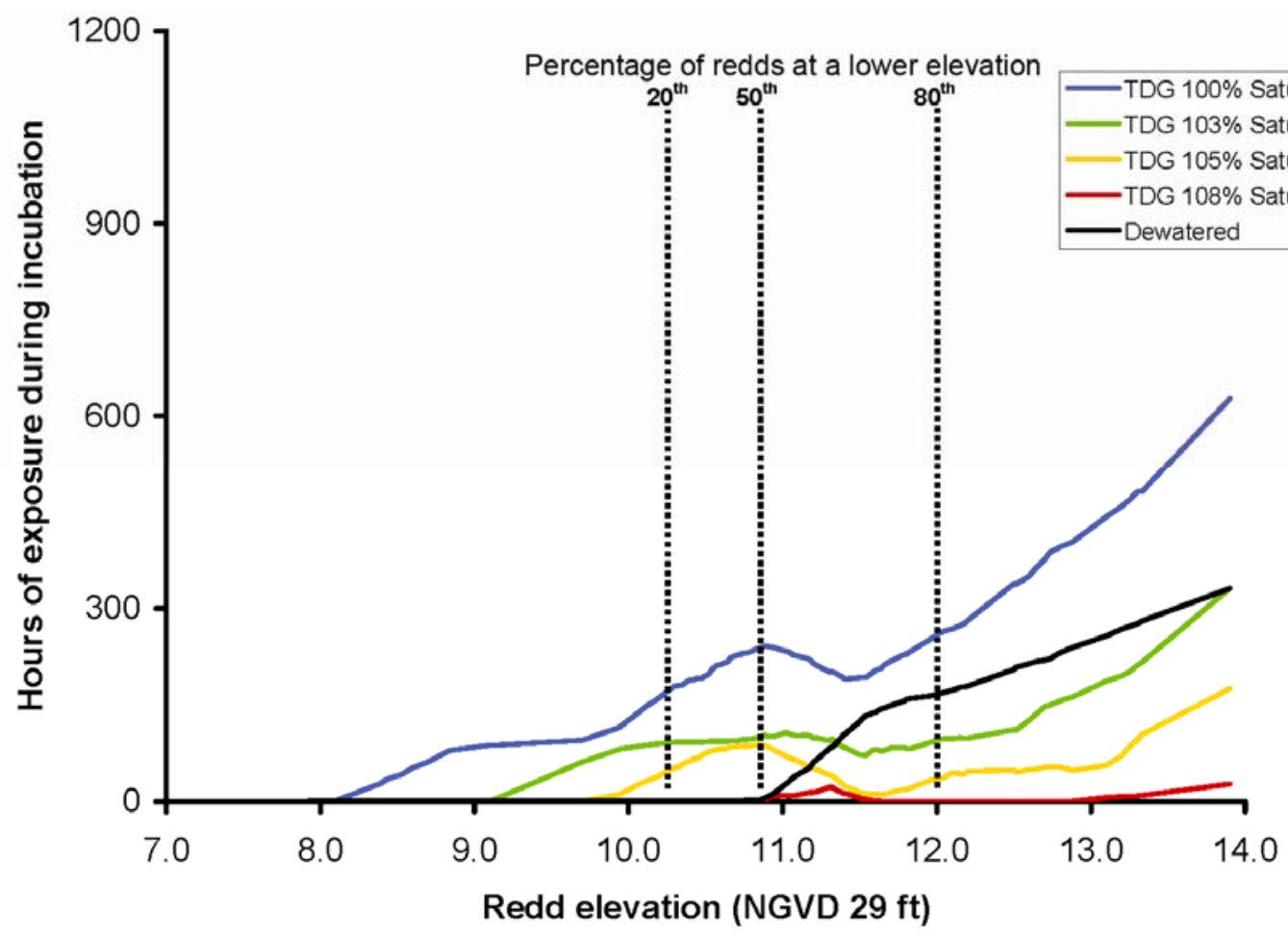

Figure 1.31. Estimated hours of TDG exposure and dewatering to chum salmon sac fry based on hyporheic results from incubation year 2007. Dashed lines show the 2006 chum salmon redd elevation distribution percentiles.

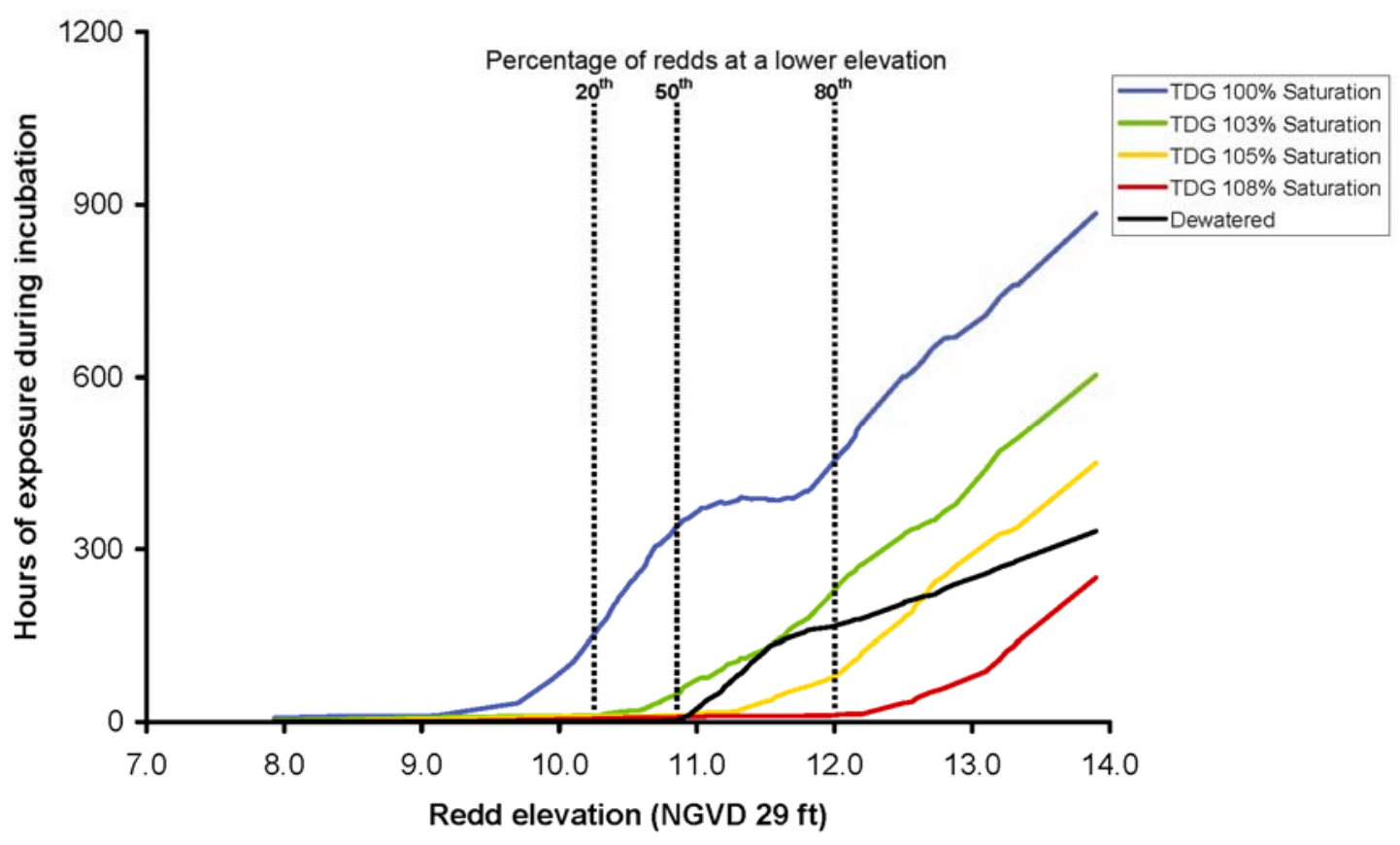

Figure 1.32. Estimated hours of TDG exposure and dewatering to chum salmon sac fry based on surface water results from incubation year 2007. Dashed lines show the 2006 chum salmon redd elevation distribution percentiles. 


\section{Discussion}

In 2006, we assessed TDG levels during times of voluntary and involuntary spill. We found no statistical difference between TDG during voluntary versus involuntary spill $(\alpha=0.05)$. Mean uncompensated TDG was $109.9 \%$ during voluntary spill and $110.2 \%$ during involuntary spill (Arntzen et al. 2007b). In 2007, the hydrosystem operator rules for spill were the same as in 2006. Daily target spills ranged from 70 to $150 \mathrm{kcfs}$ (data provided to us by the USACE). Involuntary spill did not occur during 2007.

\section{Water Quality}

Similar to our 2006 results, the response of water quality to fluctuation in river stage was significantly different at the Ives Island site compared to the Multnomah Falls site. At Multnomah Falls, hyporheic responses were relatively stable despite significant daily fluctuations in river concentrations of TDG, dissolved oxygen, and temperature (Figures 1.19, 1.21, and 1.22). In contrast, Ives hyporheic values fluctuated more than river values in response to daily changes in river stage (Figures 1.11, 1.13, and 1.15). The differences between hyporheic water and river water suggest a groundwater influence at both locations, which is not surprising - chum salmon spawn at both sites, and chum salmon generally select spawning areas where relatively warm water upwells into the river (Geist et al. 2002). The relative stability of hyporheic water quality characteristics at Multnomah Falls suggests that river discharge fluctuations have little effect on water quality at egg pocket depth there. The stable water quality signature suggests a relatively constant source of local groundwater or spring water discharge (Shepherd et al. 1986; Crisp 1990). This is supported further by similarities between the water chemistry of Multnomah Creek upstream from our study site and the hyporheic zone at our study site (Arntzen et al. 2007b). In contrast, the relative instability of hyporheic water quality characteristics near Ives Island suggests that the direction of flux between hyporheic water and the river is reversed with river stage fluctuations. This condition has been observed before in the Columbia River associated with large and frequent fluctuations in river stage (Arntzen et al. 2006a; Geist et al. in press). The hyporheic response to river stage changes in the Ives area varied by location, a result more noticeable during 2007 than during 2006 because of increased monitoring stations in 2007. For example, while Ives pairs 2, 3, 4, and 5 show less stable hyporheic responses than Multnomah Falls locations, they do not fluctuate as widely as at Ives pair 1. This is evident in the temperature response at Ives 1 (Figures 1.15 and 1.16).

Although hyporheic temperatures were most variable at Ives 1, an inverse relationship between temperature and river stage was apparent at several of the locations, especially at Ives 1, 4, and 5 (Figure 1.15). This pattern suggests that groundwater-surface-water interaction is occurring. The extent of riverbed permeability at these locations could control this pattern of interaction. For example, if the riverbed is highly permeable there, river water could easily be forced below the riverbed surface into the hyporheic zone, especially when the river stage is higher (Vaux 1968; White 1993; Arntzen et al. 2006a). Ives 1 appeared to be influenced the most by changes in river depth. At this station, mean hyporheic temperatures were closest to those of the river, and temperature fluctuations there varied more than at the other Ives site monitoring stations (Figure 1.15). Variability in riverbed permeability and small-scale variation in the location of groundwater upwelling areas likely affect the response of water quality to river stage changes in the Ives Island area.

Temperature fluctuations at the Ives Island site are most evident when there is a significant difference between hyporheic and river temperature, which occurs early during the record. Within the Ives study site, most of the monitoring locations show a seasonal warming trend (both river and hyporheic); at 
approximately the time spring spill began, the temperature difference between the hyporheic zone and the river approached zero. When this occurred, the hyporheic temperatures no longer were affected by river stage fluctuations.

Temperature affects dissolved gas solubility. At higher temperatures, total dissolved gas levels increase. This effect may contribute toward elevated hyporheic TDG levels found within the Ives study site early in the season when hyporheic temperatures were elevated relative to the river. At Ives pairs 1 , 4, and 5, TDG was higher in the hyporheic zone from the onset of the study through the first one-third of March (Figure 1.11). During this period, water depths were sufficient to compensate for elevated TDG where our sensors were located. However, chum redds constructed at elevations higher than those at which our sensors were installed (e.g., during 2007) were likely exposed to elevated TDG.

Other indicators of groundwater-surface-water mixing are the total dissolved gas and dissolved oxygen signatures. In general, at a seasonal time scale (e.g., weeks to months), surface water results for both parameters are inversely correlated with river stage (Figures 1.11 and 1.13). Presumably, this correlation is related to the distance over which spilled water plunges into the Bonneville Dam tailrace (water spilled either at the dam or from the B2 corner collector outfall). The lower the Bonneville tailwater elevation, the farther the water plunges, increasing dissolved gas levels, and vice versa. However, during short-term fluctuation in river stage, hyporheic water quality is immediately affected by changes in river stage. For example, at Ives pairs 1, 2, and 5, dissolved oxygen changes appear to be positively correlated with river stage fluctuations (Figure 1.14). Dissolved oxygen generally is higher in the river than in the adjacent hyporheic zone. When river stage increased at these locations, it is likely that more river water flowed into the hyporheic zone, and dissolved gas levels increased as the composition of the hyporheic water became similar to that of the river.

Compared to 2006, dissolved oxygen in Multnomah Falls river sensors responded very differently during 2007. After April 13, both river sensors at Multnomah Falls 1 and 3 showed high levels of dissolved oxygen at the beginning of each deployment, which gradually decreased over 5-11 days before increasing again (Figure 1.21). It is unknown whether or not this response represents naturally changing river conditions on the margins of the river in the Multnomah Falls area. It is unlikely these levels represent a sensor calibration problem because they were observed in two different sensors simultaneously. Further, the period over which the changes took place precludes the idea that the trends are related to the timing of sensor recovery (the changes occurred over days to weeks; sensor recovery occurred over a period of hours). This response deviates significantly from the surface water dissolved oxygen response observed in the Ives Island area and needs to be verified using chemical reagent tests to validate dissolved oxygen concentrations during future monitoring.

Hyporheic dissolved oxygen fluctuations have the potential to affect chum alevin negatively, both directly by lowering dissolved oxygen levels below thresholds that cause harm and indirectly by altering $\mathrm{O}_{2} / \mathrm{N}_{2}$, which can increase mortality during periods of elevated TDG (Rucker 1975). Chum salmon have a very low rate of survival to emergence when dissolved oxygen is less than $1.67 \mathrm{mg} / \mathrm{L}$ (Wickett 1954), which is similar to what was found for steelhead trout and Chinook salmon (Silver et al. 1963). We are seeing dissolved oxygen levels this low in the Ives Island area. For a short time (15 hours) at Ives 3 hyporheic, dissolved oxygen levels were less than $1.67 \mathrm{mg} / \mathrm{L}$. At Ives 5 hyporheic, the overall dissolved oxygen averaged $( \pm \mathrm{SE}) 4.3 \mathrm{mg} / \mathrm{L} \pm 0.09 \mathrm{mg} / \mathrm{L}$. Dissolved oxygen was less than $1.67 \mathrm{mg} / \mathrm{L}$ for a total of 249 hours and was as low as $0.4 \mathrm{mg} / \mathrm{L}$. These drops in dissolved oxygen occurred between March 17 and April 13. Low dissolved oxygen for that extended length of time is a concern for the redds near Ives 5. Ives 5 is not in an area spawned as heavily as 4, 1, and 2; nevertheless, quite a few redds are in the area 
(Figure 1.2). Dissolved oxygen did not drop below $3 \mathrm{mg} / \mathrm{L}$ at any of the other sites. The ratio of oxygen to dinitrogen $\left(\mathrm{O}_{2} / \mathrm{N}_{2}\right)$ becomes very important when TDG supersaturation is high and $\mathrm{O}_{2} / \mathrm{N}_{2}$ ratios are low, raising the lethality of total dissolved gas (Rucker 1975). Although most of the areas in which we have sampled TDG can be depth-compensated to safe levels, we are concerned that very low $\mathrm{O}_{2} / \mathrm{N}_{2}$ occurs where groundwater-surface-water interaction occurs in the Ives area, and that shallow redds at elevations well above our monitoring stations could be exposed to dangerously low $\mathrm{O}_{2}$ or $\mathrm{O}_{2} / \mathrm{N}_{2}$. Nebeker et al. (1985) demonstrated a significant decrease in mortality when the ratio of oxygen to nitrogen was increased while holding the total percentage saturation constant. After 71 hours at $120 \%$ TDG, 50\% of the fish died when the $\mathrm{O}_{2} / \mathrm{N}_{2}$ ratio was 0.966 . Only $7 \%$ of the fish died after 167 hours when the $\mathrm{O}_{2} / \mathrm{N}_{2}$ ratio was changed to 1.593. We estimated average ratios in the Ives area from 0.177 at Ives 3 to 0.698 at Ives 1 . The ratios in the Ives area were very low, indicating that there could be high mortalities if TDG levels were sufficiently high. The $\mathrm{O}_{2} / \mathrm{N}_{2}$ ratios we measured are typical of those found in groundwater. Mookherji et al. (2003) performed a dissolved gas analysis in a riparian wetland with nested piezometers in upwelling regions and found ratios ranging from 0.038 to 0.444. Blicher-Mathiesen et al. (1998) measured denitrification and degassing in groundwater in a Danish riparian wetland. They sampled groundwater from four piezometers and found ratios ranging from 0.011 to 0.125 .

\section{Total Dissolved Gas Exposure Estimates}

Our estimates of redd exposure to TDG showed that there was little or no relevant exposure during 2006 but that 2007 redds at the 50th elevation percentile were exposed to depth-compensated TDG greater than $100 \%$ saturation for 240 hours and depth-compensated TDG greater than $103 \%$ for 103 hours. We searched for available water surface elevation, redd elevation distribution, and surface water TDG concentration for the Ives Island areas to estimate TDG exposure from previous years and place our 2006-2007 study in context as the data allowed. We utilized water surface elevations for 2003-2005, collected by PNNL as part of a Bonneville Power Administration fish and wildlife project; redd locations compiled for the same years by ODFW; and TDG surface water concentrations from the USACE Bonneville Dam station. In general, during our study period (March 1-May 15), water surface elevations in the Ives area were very high during 2006 and 2007 compared to the other years (this was especially the case during 2006; Figure 1.33).

Our study, thus far conducted during the 2006-2007 emergence seasons, represents a very high water year (2006) and a medium to high water year (2007) compared to the water surface elevation during emergence from 2003-2007 (Figure 1.33). The potential exposure of chum redds to TDG during these years is a function of how much water was available during incubation and emergence, the elevation distribution of the redds for the specific spawning year, and where the TDG measurement was made to estimate exposure (i.e., the river or hyporheic zone; Figure 1.34). A detailed description of estimated exposure to chum salmon redds to TDG for incubation years 2003-2005 is provided in Appendix C. This evaluation is directly comparable to exposure estimated made using surface water TDG monitoring results for incubation years 2006-2007 in this report (Appendix C). In general, our results show that, during low water years (e.g., 2004-2005), TDG exposures will be higher. However, during medium to high water years (e.g., 2003 and 2007), TDG exposures are dependent on the redd elevation distribution during the previous fall spawning season. For example, estimated exposures were very low during 2003. However, during 2007, which was a similar water year during the emergence season, redds at the 50th elevation percentile were exposed to more than 100 hours of TDG higher than 103\% (based on hyporheic estimates; Figure 1.34). The year 2006 represented a very high water year (during the emergence period), during which depth compensation was available to redds most of the time (Figure 1.34). 


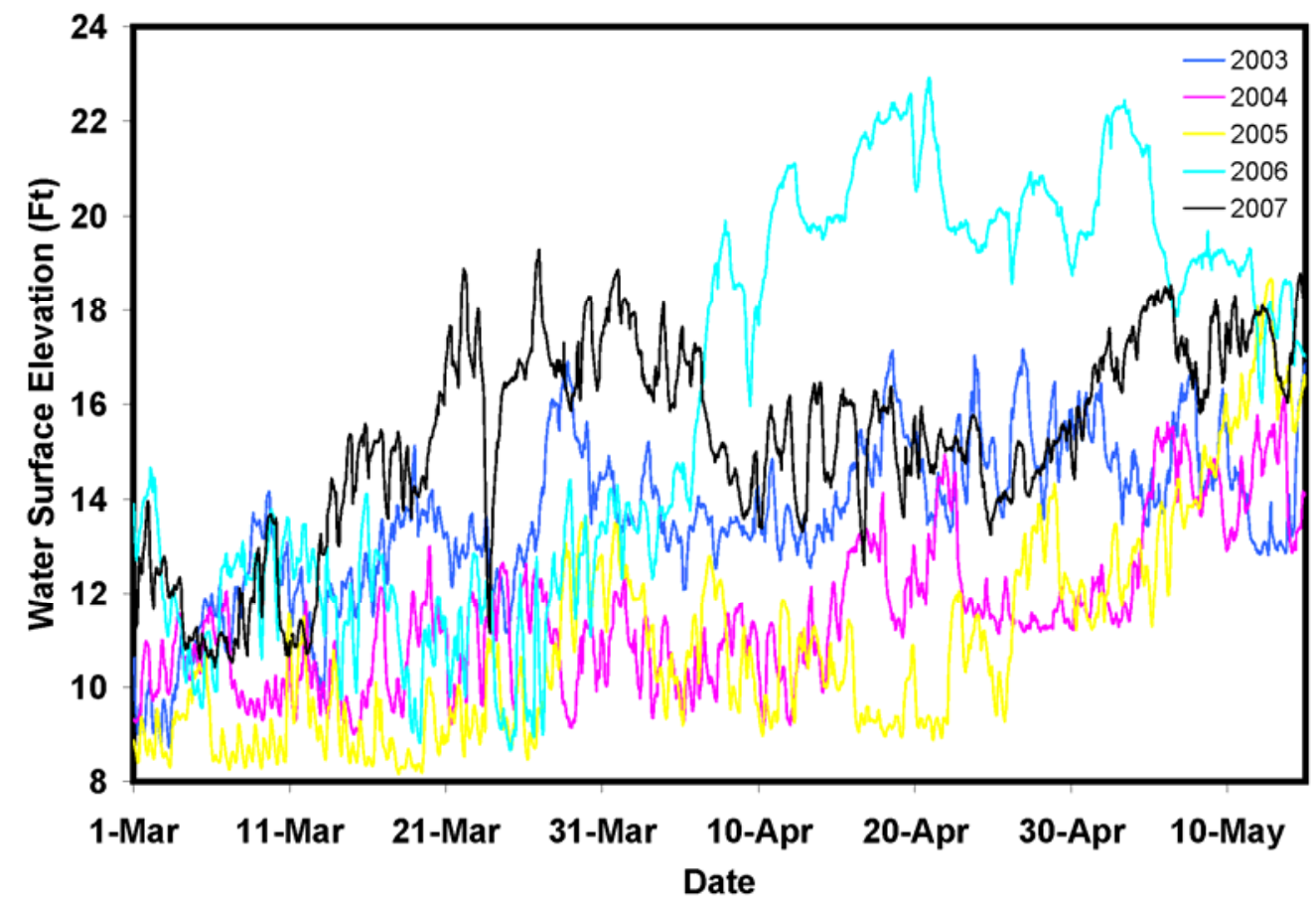

Figure 1.33. Water surface elevations during chum emergence (our study period) for the Ives Island area, 2003-2007

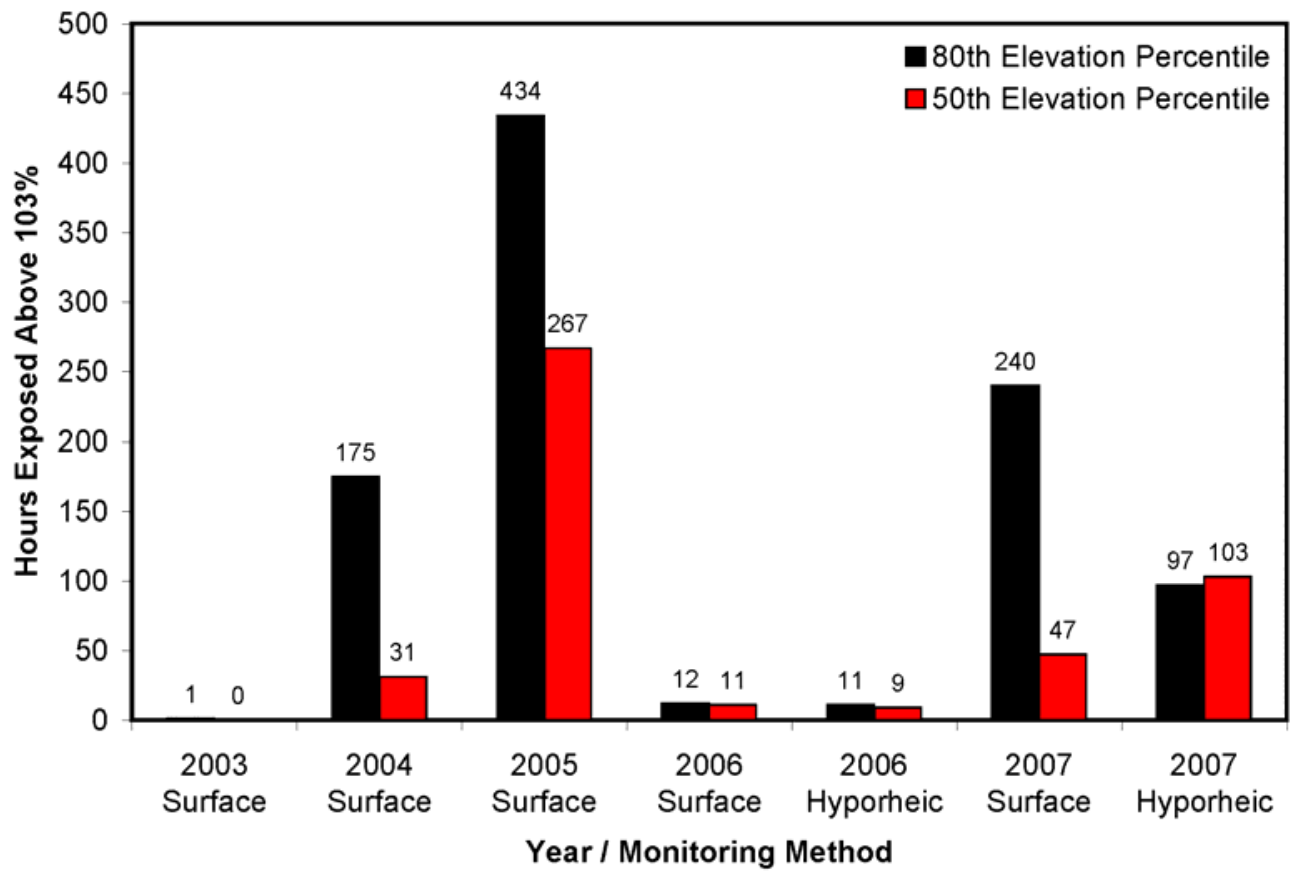

Figure 1.34. Estimated exposure time of Ives Island site chum salmon redds to depth-compensated total dissolved gas above $103 \%$, 2003-2007 
For our Ives Island area evaluation, hyporheic sensors recorded higher TDG early in the season (prior to spring spill) than surface water sensors. This occurred when surface water levels were lower. Because we assumed exposure times to TDG concentrations were zero during periods of dewatering, dewatering that occurred during the early record when hyporheic sensors recorded higher TDG concentrations than the adjacent surface water tended to lower overall exposure estimates to high elevation redds (e.g., redds above the 70th elevation percentile; Figure 1.31). This explains why the number of hours to which the 80th elevation percentile is exposed to levels above 103\% TDG based on 2007 hyporheic monitoring exposure estimates is lower than the estimated exposure at the 50th elevation percentile (Figure 1.34).

One by-product of our TDG exposure estimates was the construction of detailed dewatering histories for chum redds in the Ives Island study site for each year 2003-2007 (Appendix D). We found they were exposed to dewatering from as few as zero hours in all of 2005 to as high as 1824 hours in 2003. According to McMichael et al. (2005), for fall Chinook salmon downstream of Wanapum Dam at 103 hours of dewatering, survival ranged from $16.9 \%$ to $66.6 \%$ and averaged $29.2 \%$. In laboratory experiments, Becker et al. (1982) found that at 77 hours of dewatering (1 hour/day), nearly all preemergent alevins (advanced yolk-sac alevins to emergence from gravel) had died. At 308 hours of dewatering (4 hours/day), 50\% of eleutheroembryos ( 24 hours before hatch to advanced yolk-sac alevins) had died (Becker et al. 1982). The results from Becker et al. (1982) were acquired via a laboratory experiment in which dewatering was rapid (less than 1 minute) and no still water or excess bank storage flow was present to keep the redds moist. Therefore, the McMichael et al. results (2005) are a more appropriate comparison to our dewatering exposure results. One important difference between our study and that of McMichael et al. (2005) is that we considered redds dewatered when the water surface was below the estimated top of the egg pocket $(10 \mathrm{~cm}$ depth below the riverbed), not the riverbed surface. Because of this, our dewatering estimates should be considered conservative. In addition, for our Ives area study the differences between exposure estimates using hyporheic versus surface water monitoring data were most apparent in high-elevation redds that were frequently dewatered (it is unknown what fraction of the redds that were frequently dewatered remained viable). During the 2007 incubation year, redds above the 70th percentile elevation were dewatered for at least 103 hours, a time threshold over which negative impacts have been observed in naturally occurring salmon redds (McMichael et al. 2005). Our estimates of dewatering were made assuming dewatering occurred when water surface elevations dropped more than $10 \mathrm{~cm}$ below the riverbed surface. We have thus conservatively estimated the incidence of dewatering, compared to other evaluations in which dewatering is usually defined as occurring when the water surface meets the riverbed (McMichael et al. 2005). 


\title{
Chapter 2
}

\section{Bioassays on the Formation of Gas Bubble Disease in Chum Salmon Fry at Total Dissolved Gas Levels Ranging up to $113 \%$ Saturation}

\author{
K. D. Hand, D. R. Geist, V. I. Cullinan, R. A. Elston
}

Introduction

Few studies have been directed at the response of chum salmon sac fry and alevins to total dissolved gas (TDG) supersaturation. Birtwell et al. (2001) reported signs of gas bubble disease (GBD) in juvenile chum salmon exposed to TDG levels of $120 \%$ and $130 \%$. No information exists regarding the effects of gas supersaturation on incubating life stages of chum salmon (McGrath et al. 2006). Comparative studies of adult salmonids indicate variation in sensitivity to effects of TDG supersaturation, with Backman et al. (2002) reporting that steelhead (O. mykiss) and sockeye (O. nerka) salmon were more sensitive than Chinook salmon (O. tshawytscha) to GBD. Because of this variability in sensitivity to TDG supersaturation, studies of other salmonid species have only limited applicability to chum salmon (Weitkamp and Katz 1980).

Larval fish exhibit different signs of GBD than do juvenile and adult fish. Coho (O. kisutch) and Chinook salmon sac fry developed bubbles between the yolk sac and perivitelline membrane, causing the fry to swim in an abnormal position (head up or tail up); mortality occurred when the membrane ruptured (Rucker and Kangas 1974). Zirges and Curtis (1975) also reported mortality from gas bubbles within the yolk sac of Chinook salmon sac fry. Lake trout (Salvelinus namaycush) sac fry (Krise and Herman 1989) and larval herring (Dannevig and Dannevig 1950; Henly 1952) developed gas bubbles within the intestinal tract. Rucker and Kangas (1974) found that coho and Chinook salmon sac fry also developed free bubbles in the digestive tract, but noted further that control groups did so as well, and those bubbles did not affect swimming behavior or mortality. Hyperinflation of the air bladder was reported in lake trout sac fry (Krise and Herman 1989) and was indicated as a concern for juvenile salmonids in a data and literature review by Fidler and Miller (1997). Other signs of GBD in larval fish include the formation of bubbles under the skin, in the mouth, in the eye, and in the cardiovascular system (Rucker and Kangas 1974; Weitkamp and Katz 1980).

The objective of the laboratory study was to evaluate lethal and sublethal effects of TDG on chum salmon embryos and sac fry at gas levels ranging up to $113 \%$ saturation. A description of methods, the results of research, and a discussion of findings follows.

\section{Methods}

We examined the effects of 29 -day exposure to $100 \%, 103 \%, 108 \%$, and $113 \%$ TDG supersaturation at a constant water temperature of $9.5^{\circ} \mathrm{C}$ on direct mortality, sublethal tissue damage, delayed mortality due to gas bubble disease injury, and abnormal behavior. Two developmental stages of chum salmon (approximately two weeks pre-emergence and emergence) were sacrificed for histopathological 
examination. Incubating sac fry were monitored daily during the exposure to document mortality and developmental differences between treatments.

\section{Egg Source, Egg and Alevin Incubation}

For this task, approximately 8,000 fertilized chum salmon eggs were obtained from the Washington Department of Fish and Wildlife Minter Creek Hatchery, Gig Harbor, Washington. The eggs were spawned on December 4, 2006, and had reached a development stage of 408 accumulated thermal units (ATU) when transferred to the PNNL Aquatic Research Laboratory on January 18, 2007. The eggs were maintained in incubation trays at $5^{\circ} \mathrm{C}$ until just prior to hatch, when the temperature was raised to $9^{\circ} \mathrm{C}$.

Upon hatching February 2, hatchlings were divided into treatment groups; 300 hatchlings were placed into each of 24 egg baskets. Six replicate egg baskets were deployed in each of four stainless steel troughs; the troughs were assigned separately to each of the three treatment groups $(103 \%, 108 \%$, and $113 \%$ TDG) and to the control group ( $<100 \%$ TDG). Egg baskets were constructed of 23 -cm-high $\mathrm{x}$ 15-cm-diameter PVC pipe sections capped on the bottom, with sections of the walls and cap removed, leaving only a rigid frame. The frame was lined with fine mesh screen to allow water flow through the resulting basket. The hatchlings were distributed by volume (approximately 300 alevins per $70 \mathrm{~mL}$ ) into the egg baskets on February 5 (replicates 1-3) and February 9 (replicates 4-6).

\section{Supersaturated Gas and Temperature Control}

Gas supersaturated water was produced by a gas supersaturation column. The 9-ft-high $\mathrm{x}$ 6-in.diameter PVC pipe column has inflow hoses for both gas and water. A centrifugal pump maintains inflow water pressure. Water enters at the top of the column; a gate valve controls flow rate. Compressed air is injected to either the top or bottom of the column. A sight glass at the side of the column has a proximity meter that can be adjusted up or down to control the injected air supply. Outflow occurs from the bottom of the column. The desired saturation level produced by the column can be maintained by manipulating the combination of water inflow, water outflow, and column water level.

The exposure to four levels of gas supersaturation took place in the four stainless steel troughs $(30 \times 305 \times 13 \mathrm{~cm})$ arranged side by side on an elevated platform. The gas supersaturation column provided water to head tanks supplying three of the troughs (Figure 2.1). In the head tanks, supersaturated and control water were mixed via both manual and computerized solenoid valves to achieve the 103, 108, and $113 \%$ exposure levels. Water was piped by gravity flow from the head tanks into PVC manifolds. Ball valves on the manifolds were used to adjust flow volume. From each manifold, 12 individual sections of 1/8-in.-inside diameter tubing supplied water to emergence tubes and baskets. Water flow through each section of tubing was approximately $700 \mathrm{~mL} / \mathrm{min}$. The emergence tubes received treated water directly in a closed system. The baskets received a smaller percentage directly; the remaining water in the trough supplying the baskets came from the outflow of the emergence tubes. Due to gas loss at the exposed water surface of the trough and baskets, the total dissolved gas levels of water in the baskets for the 103, 108, and 113\% TDG levels averaged $0.7-0.9 \%$ less than in the emergence tubes. Gas levels were monitored in-line using TDG sensors (Model T507, In-Situ Inc., Fort Collins, Colorado) which were connected to a data logger (Model CR23X Micrologger, Campbell Scientific, Inc., Logan, Utah) and personal computer. The control trough was supplied with chilled well water to which no manipulation of gas levels was made, which resulted in concentrations less than $100 \%$ TDG. 


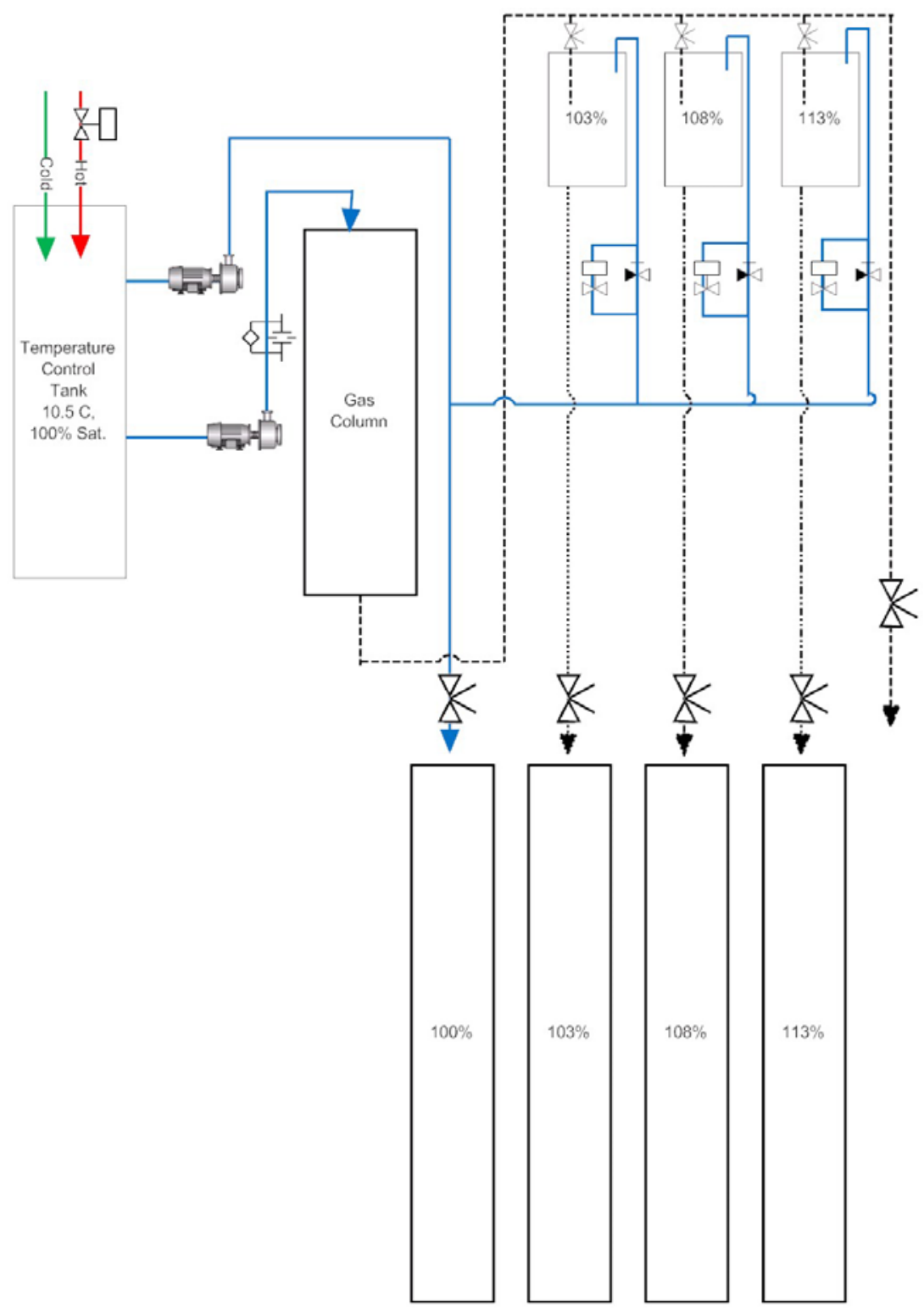

Figure 2.1. Total dissolved gas experimental system

Daily adjustments were made to the gas column during periods of unstable weather to decrease or increase percentage saturation of output as needed to maintain 103, 108, and 113\% TDG treatment water. Water temperature was maintained at an average of $9.5^{\circ} \mathrm{C}$ from hatching until termination of the experiment. Temperature control was achieved using the chilled water system supplying the Aquatic Research Laboratory.

\section{Alevin Exposure to Supersaturated Gas}

For the exposure, alevins were housed in both egg baskets and emergence tubes. On March 1, at approximately $750 \mathrm{ATU}$, a subset of alevins from each basket was transferred to a corresponding emergence tube. The transfer was accomplished by placing the alevins in a shallow water-filled tray 
where the number of normal and abnormal alevins was recorded. Abnormal alevins were removed and euthanized, and 100 normal alevins were placed into each of 24 emergence tubes. The remaining alevins were placed back into the egg baskets. Upon completion of the transfer, the six egg baskets assigned to each TDG level and their corresponding emergence tubes were distributed among the four treatment troughs, and exposure to TDG supersaturation began. The exposure period lasted 29 days, from March 1 through March 30, 2007.

Emergence tubes consisted of a light and dark chamber connected to each other via a clear tube. They were constructed of 17-cm-long sections of 5-cm-diameter white and 6.5-cm-diameter clear PVC pipe. Water flow (approximately $700 \mathrm{~mL} / \mathrm{min}$ ) was directed such that it upwelled through gravel in the bottom of the dark (white) chamber, across the clear tube, and into the light (clear) chamber. Fry emergence occurred when the alevins followed the flow of water toward the light and moved across to the clear chamber of the emergence tube.

On March 8 (108\% and 113\% TDG treatment levels) and March 9 (control and 103\% TDG treatment levels), alevins in the baskets were treated in a formalin bath to control fungus. The baskets were transferred (in-water technique) to a large tub $(\sim 150 \mathrm{~L})$ equipped with a mechanical chiller and containing a 1:6,000 ratio of Parasite-S formalin (Western Chemical Inc., Ferndale, Washington) to water. Treatment lasted 1 hour, after which the baskets were returned to their appropriate treatment trough.

\section{Survival and Development}

The date of $50 \%$ hatch was determined from daily observations of the eggs in the incubation trays. On the day of $50 \%$ hatch, a sample of 360 alevins was taken from the population, euthanized, measured for weight and length, and preserved in a $10 \%$ solution of neutral buffered formalin (NBF).

During the exposure period, alevins in the baskets and the clear portion of the emergence tubes were monitored daily. Emergent fry were counted and removed. Dead alevins were counted, removed, and examined for GBD. Also, live samples were taken from both the baskets and emergence tubes and immediately examined for signs of GBD.

Alevins that moved to the clear side of the emergence tubes within 24 hours of being placed there were removed and eliminated from the trial. After 24 hours, fry found in the clear tube were recorded as emerged for purposes of documenting the dates of first, $50 \%$, and $100 \%$ emergence. Within \pm 1 day of $50 \%$ emergence, 15 emergent fry from each emergence tube were euthanized, measured for weight and length, and preserved in a $10 \%$ solution of NBF.

Various developmental data were recorded and calculated from the samples taken at $50 \%$ hatch and $50 \%$ emergence, including wet weight, fork length, dry tissue and yolk weight, and a developmental index. After at least 80 days in a $10 \%$ solution of NBF, the preserved samples from $50 \%$ hatch and $50 \%$ emergence were processed for dry weight ratios. The body tissue and yolk tissue were dissected, combined according to treatment and replicate, and dried in an oven at $60^{\circ} \mathrm{C}$ for 2 days. After drying, the body tissue and yolk tissue of each group were weighed. A development index $\left(k_{\mathrm{D}}\right)$ was calculated as described in Bams (1970) using the following equation:

$$
k_{\mathrm{D}}=\frac{10 \sqrt[3]{\text { weight in } \mathrm{mg}}}{\text { length in } \mathrm{mm}}
$$


At the end of the exposure period, alevins remaining in the baskets were transferred to a Living Stream system (Frigid Units Inc., Toledo, Ohio; $60 \times 274$ × $55 \mathrm{~cm}$; 700-L capacity) supplied with control water for a 30-day observation period. The fish were combined by treatment level and placed in one of four floating baskets $(30 \times 43 \times 45 \mathrm{~cm})$ within the Living Stream tank. Feeding was initiated the day before the transfer. Once fish began actively feeding, they were fed four to five times daily. General observations of swimming behavior were noted, but no formal examinations were conducted. Fish were euthanized at the end of the 30-day holding period.

\section{Gross Examination}

Attempts were made during the 29-day treatment period to subsample from the baskets or emergence tubes and to conduct gross examinations for GBD on an every-other-day basis. Examinations actually occurred less regularly due to time constraints. Dead and moribund fish were examined immediately upon discovery. Live fish were euthanized in a solution of trichane methanesulfonate (MS-222) prior to examination. Alevins were examined using a variable magnification $(5 x-52 x)$ dissecting scope (Model SZH10, Olympus America, Inc., Melville, New York) for signs of gas bubble disease externally (gas bubbles in nares, mouth, and fins) and internally (gas bubbles in eyes, gills, swim bladder, and intestinal tract).

\section{Necropsy and Histology}

On exposure day 7 (March 8), alevins from each basket were euthanized and preserved in a 10\% solution of NBF. On exposure day 19 (March 20), emerged alevins from each emergence tube were similarly euthanized and preserved. These samples were stored in fixative at the Aquatic Research Laboratory until they were submitted to Dr. Ralph Elston, AquaTechnics, Inc. (Sequim, Washington) for histopathological examination.

\section{Necropsy}

The sample fish were received at AquaTechnics on June 20, 2007 and assigned case number AQ07-127. Upon receipt, each preserved fish was place whole into separate coded histology cassettes. The fish were oriented so that sagittal (longitudinal or anterior to posterior) histology sections would result. Thus, the cut fish sections are viewed from the side from anterior to posterior. A spreadsheet was created that identified the fish treatment and identity for each histology cassette. The cassettes containing fish were then re-immersed in fixative.

\section{Histology Processing}

Histology processing was performed by a subcontractor to AquaTechnics, Inc. Routine methods of dehydration, embedding, sectioning, and staining tissue sections with hematoxylin and eosin (H\&E) were used (Luna 1968). A set of subcontractor histology processing protocols approved by AquaTechnics is on file at AquaTechnics. The cassettes and resulting histology blocks and slides carried the coded case number unique to each specimen and histology cassette. The coded identification information did not contain any reference to the specific treatment the specimen received during the experiment that produced the fish. The resulting embedded tissue block for each fish was cut at nine approximately evenly spaced levels, utilizing about $75 \%$ of the thickness of each fish. Each of the nine levels was numbered sequentially with each section cut at approximately $5 \mu \mathrm{m}$ thickness. Thus, each fish resulted in nine 
tissue sections that, in total, represented a range of the organs and tissues present in each fish. The objective was to obtain all types of organs or tissue that were thought to be potentially affected by gas supersaturation.

\section{Histology Interpretation}

The histology sections were examined by light microscopy using an Olympus BX40 microscope equipped with 4x,10x, 20x, 40x, and 100x objective lenses. The sections were examined without knowledge of the treatment group to which the specimen belonged. Each organ of interest was examined, and lesions were recorded in two Excel spreadsheets. The spreadsheet organization and key to the lesion codes used in the spreadsheets were provided in an explanatory text. Because the first reading of all slides indicated that significant lesions in the gill tissues occurred at an apparent high prevalence, the gill tissues were re-examined and results entered in the second spreadsheet. Lesions in the secondary lamellae of the gills were graded as follows: grade $0=$ lesion not present; grade $1=$ very rare/very mild; grade 2 = few/mild; grade $3=$ many/moderate; and grade $4=$ too many to count $/$ severe.

\section{Special Stains}

Due to the finding of an unknown structure (apparently a protistan parasite) in epithelium of the gills and adjacent tissues, special staining studies were conducted to attempt to elucidate the nature of this structure. To implement these special staining studies, the sections were recut from several representative blocks containing the unknown structures and stained with the following special stains: periodic acidSchiff (PAS), Giemsa, Gomori methenamine silver (GMS), Gram, and mucicarmen (Luna 1968).

\section{Statistical Analysis}

Descriptive statistics, including the coefficient of variation (CV \%) and histograms, were used to evaluate the variability in exposure concentrations and water temperature. Analysis of variance (ANOVA) was used to compare average water temperature, accumulated thermal units (ATU), and fish response among exposure concentrations. The nonparametric alternative, the Kruskal-Wallis test, was used when sample sizes were small or when transformation of the response variable did not satisfy parametric assumptions.

Box plots visually characterize the effect of each treatment. A box plot portrays the data as a rectangle bounded by the first and third quartiles of the data and separated by a horizontal line at the median value. Mean responses are indicated by solid circles. Whiskers, or lines above and below the rectangle, indicate a nonparametric distributional upper and lower limits based on the quartiles. Extreme values are represented as an asterisk and are values outside these limits.

Separate analyses were performed on the histology results. The severity of each type and the sum of all gill lesions were analyzed to test the null hypothesis of equal proportional occurrence among percentage TDG levels for each sample ( 7 and 19 days TDG exposure). When expected frequencies were too low to meet the assumptions of a chi-square analysis, a binomial exact test of goodness of fit was used. The severity of gill lesions (ranked between $0=$ no lesion, and 1 to 4 indicating increasing severity) were pooled into two categories (low $=0+1$, and moderate $=2+3+4$ ) to meet the assumptions of both the chi-square and the binomial exact goodness-of-fit test using the marginal frequencies of occurrence as the expected proportions. When a dose-response was exhibited by the data, a probit analysis was 
conducted on the proportion of moderate lesions as a function of TDG. An effective concentration that causes 50\% response (i.e., lesion formation; EC50) and the $95 \%$ confidence interval were calculated when appropriate. Because of the small number of treatments (4), a simple linear regression also was employed.

The maximum number and proportional occurrence of parasites in the tissues of the thymus, gills, and skin also were evaluated. A full generalized linear model was used to evaluate the main effects of sampling period and TDG exposure level and their interaction.

\section{Results}

\section{Gas and Temperature Levels}

Actual dissolved gas levels followed very closely the experimental targets (Table 2.1) and varied very little. The coefficient of variation $(\mathrm{CV})$ values for all treatments were less than $1 \%$; the largest variability $(\mathrm{CV}=0.74 \%)$ occurred in the control group (Figure 2.2$)$.

Table 2.1. Total dissolved gas levels used in the exposure experiments and measured in 10-minute increments between March 1 and March 30, 2007

\begin{tabular}{ccccccc}
\hline & & & \multicolumn{5}{c}{ Standard } \\
Treatment & $N$ & Mean & Median & Deviation & Minimum & Maximum \\
\hline Control & 4087 & $93.9 \%$ & $93.9 \%$ & 0.00695 & $92.3 \%$ & $97.9 \%$ \\
$103 \%$ & 4114 & $103.0 \%$ & $103.0 \%$ & 0.0027 & $102.0 \%$ & $105.4 \%$ \\
$108 \%$ & 4114 & $107.9 \%$ & $108.0 \%$ & 0.0016 & $107.1 \%$ & $109.2 \%$ \\
$113 \%$ & 4114 & $112.9 \%$ & $112.9 \%$ & 0.0015 & $112.2 \%$ & $113.3 \%$ \\
\hline
\end{tabular}

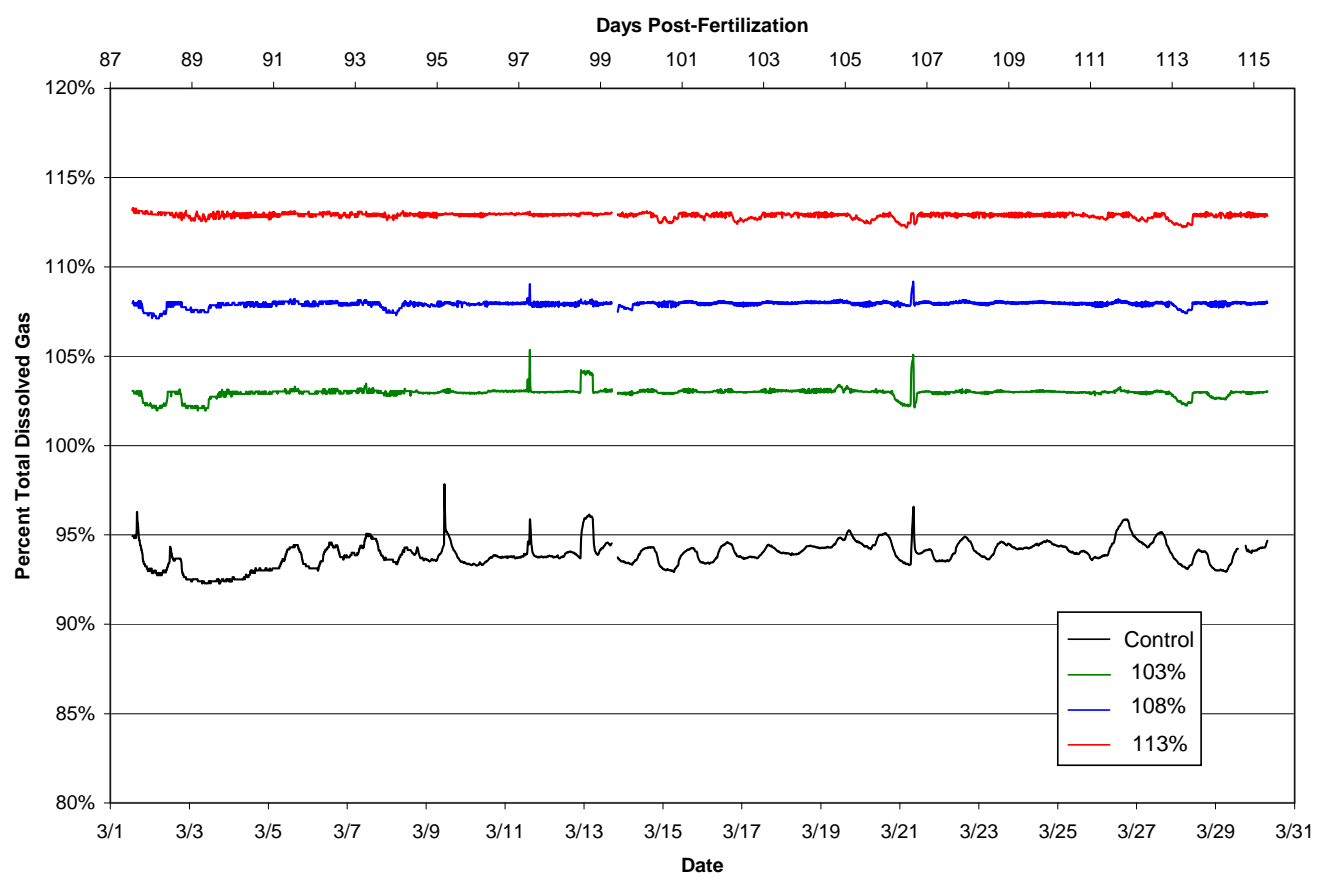

Figure 2.2. Total dissolved gas (\%) levels throughout exposure period for control (black), 103\% (green), $108 \%$ (blue), and 113\% (red) treatments. Data from a 2-hour 30-minute period on March 13 during which a power outage occurred are excluded from this view. 
A brief power outage on March 13, 2007 caused TDG levels to drop an average of 7\%, 11\%, and $12 \%$ from the target concentrations for the $103 \%, 108 \%$, and $113 \%$ TDG treatment groups, respectively. The minimum concentration for the treatments occurred at the end of the outage, which lasted a total of 2 hours and 30 minutes. The control increased to a maximum of $96.6 \%$ TDG and then declined to an average of 95.2\% TDG (Figure 2.3). The power outage also caused water temperatures in all four treatment troughs to rise. The water for the control, $103 \%, 108 \%$, and $113 \%$ treatment groups rose to maximum temperatures of $11.1,12.5,12.7$, and $13.4^{\circ} \mathrm{C}$, respectively, during the outage (Figure 2.3 ).

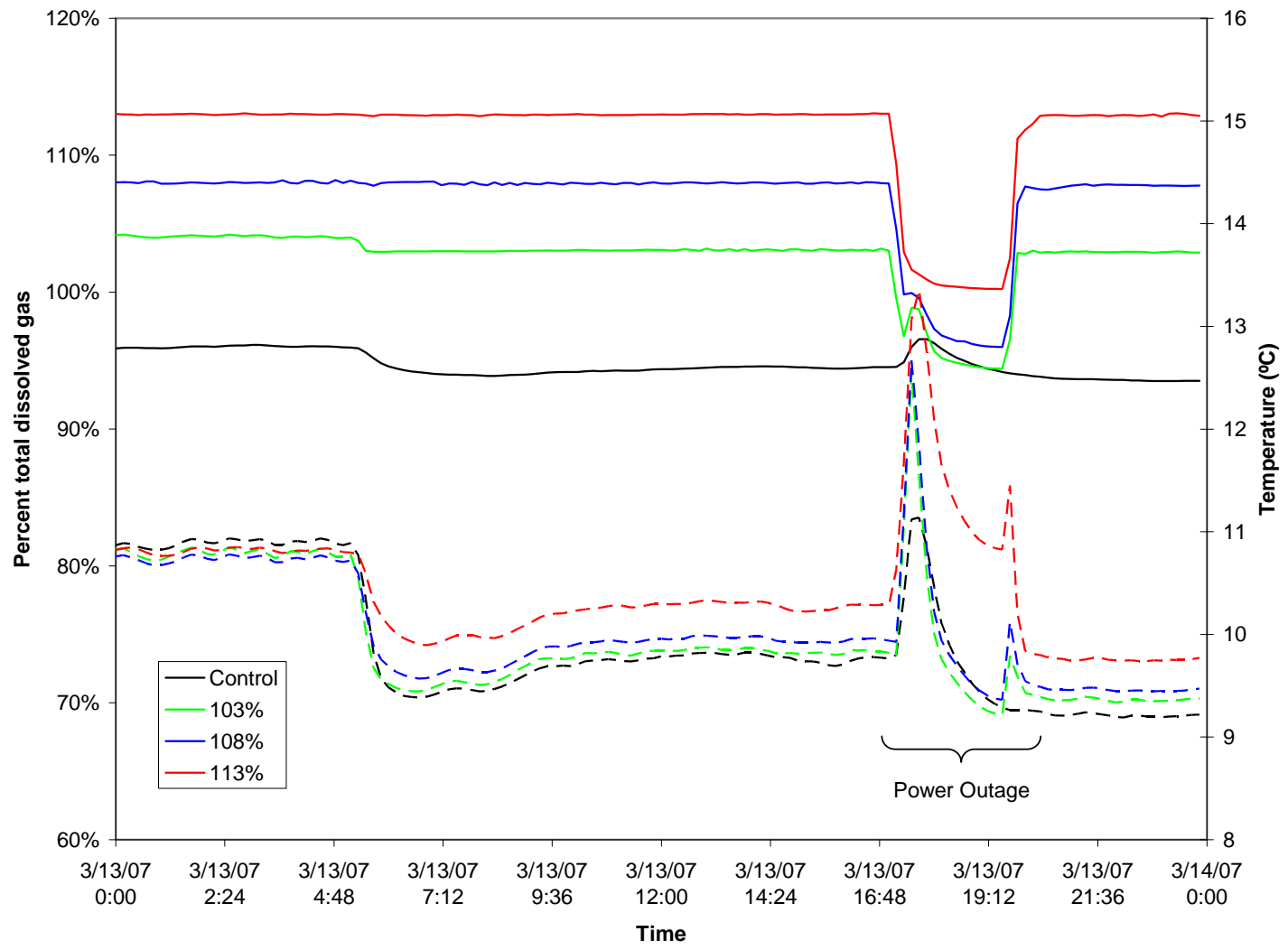

Figure 2.3. Total dissolved gas (\%; solid lines) and temperature $\left({ }^{\circ} \mathrm{C}\right.$; dashed lines) on March 13,2007 , during a power outage between 1700 and 1930 hours

The water temperature over the study period from hatching (February 2) until termination (April 30) averaged 9.3 to $9.9^{\circ} \mathrm{C}$ (daily means ranged from 9.1 to $10.9^{\circ} \mathrm{C}$ ) (Figure 2.4). During the 29-day exposure period, mean water temperatures in the control and three treatment groups ranged from $9.3^{\circ} \mathrm{C}$ in the control to $9.9^{\circ} \mathrm{C}$ in the $113 \%$ TDG treatment group (Table 2.2); the mean daily temperature was highly related to treatment group (ANOVA: $F=74 ; \mathrm{df}=3$ and 112; $P<0.001$ ). A two-sample t-test showed that the difference between the control group and $113 \%$ TDG treatment group was significant during the exposure period (two-sample t-test): $t$-value $=-12 ; \mathrm{df}=55 ; P<0.001$ ). 


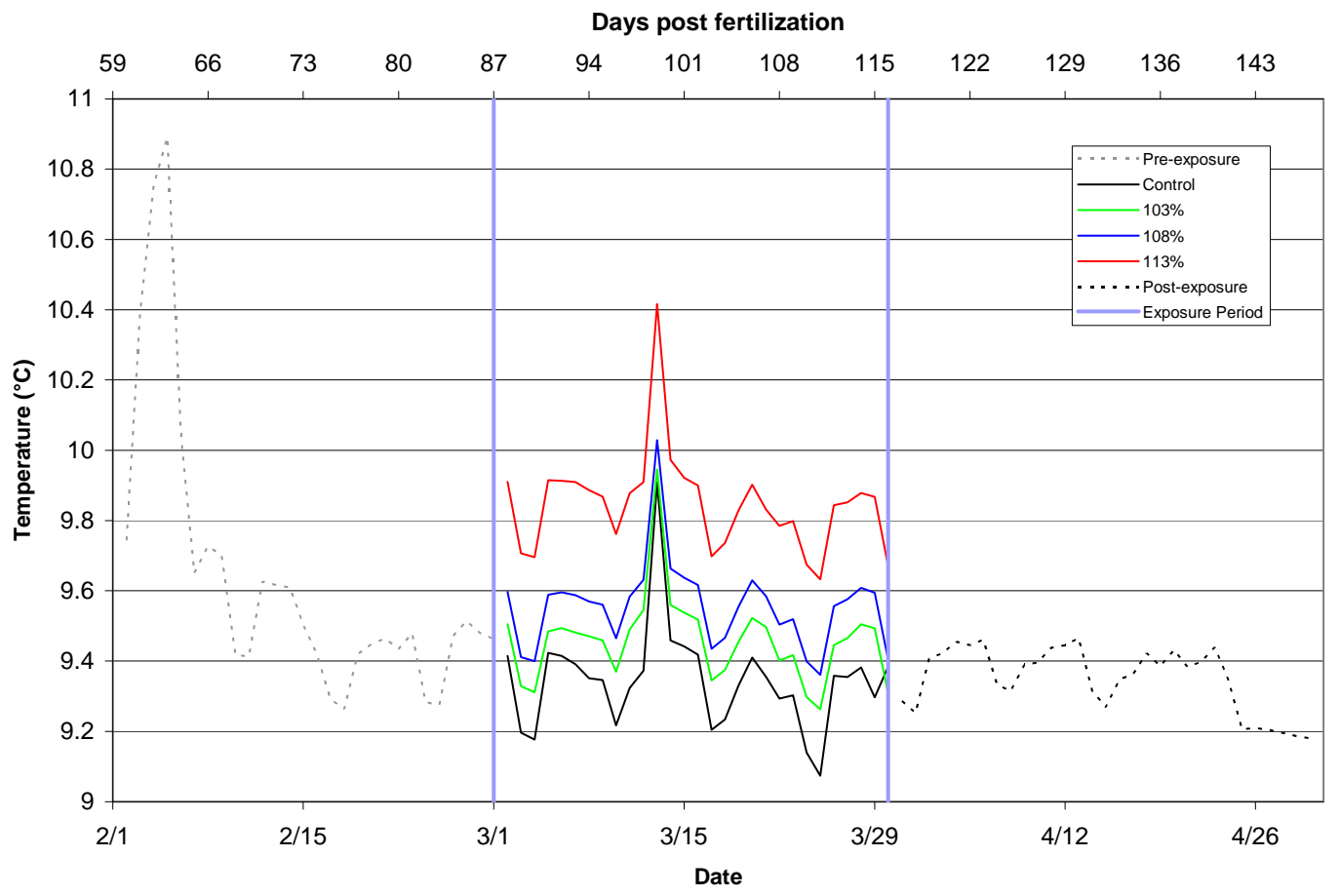

Figure 2.4. Daily mean temperatures for the study period

Table 2.2. Mean daily temperature $\left({ }^{\circ} \mathrm{C}\right)$ during the 29-day exposure period

\begin{tabular}{lcccccc}
\hline $\begin{array}{c}\text { Treatment } \\
\text { Group }\end{array}$ & $N$ & Mean & Median & $\begin{array}{c}\text { Standard } \\
\text { Deviation }\end{array}$ & Minimum & Maximum \\
\hline Control & 29 & 9.34 & 9.35 & 0.15 & 9.07 & 9.91 \\
$103 \%$ & 29 & 9.46 & 9.47 & 0.13 & 9.26 & 9.95 \\
$108 \%$ & 29 & 9.56 & 9.58 & 0.12 & 9.36 & 10.03 \\
$113 \%$ & 29 & 9.85 & 9.87 & 0.14 & 9.63 & 10.42 \\
\hline
\end{tabular}

\section{Survival and Development}

Survival from hatch to emergence equaled or exceeded $88 \%$ in all gas treatments. There was a significant difference among treatment groups in the proportion of fish that survived to emergence; survival of fish from hatch to $50 \%$ emergence in the $113 \%$ TDG treatment group was significantly less than the other groups (Kruskal-Wallis test: $H=10.25$; $\mathrm{df}=3 ; P=0.017$ ). Emergence occurred significantly earlier in the $113 \%$ TDG treatment group (by about 5 to 7 days) than in other treatments (ANOVA: $F=15.99 ; \mathrm{df}=3$ and $20 ; P<0.001$ ).

The results in the $113 \%$ TDG treatment group appeared to be affected by the power outage (Figure 2.5). For example, coincident to the power outage on March 13, emergence occurred on March 14 in three of the six replicates $(1,4$, and 6 ); these same replicates suffered $25 \%, 15 \%$, and $16 \%$ mortality, respectively. No mortality or atypical emergence was recorded at this time in replicates 2,3 , and 5 in the $113 \%$ TDG treatment group or in any of the other treatment groups. Based on these results, we decided to remove from further analysis replicates 1, 4, and 6 from the $113 \%$ TDG treatment group. Subsequent results reported here do not include these replicates unless otherwise noted. 


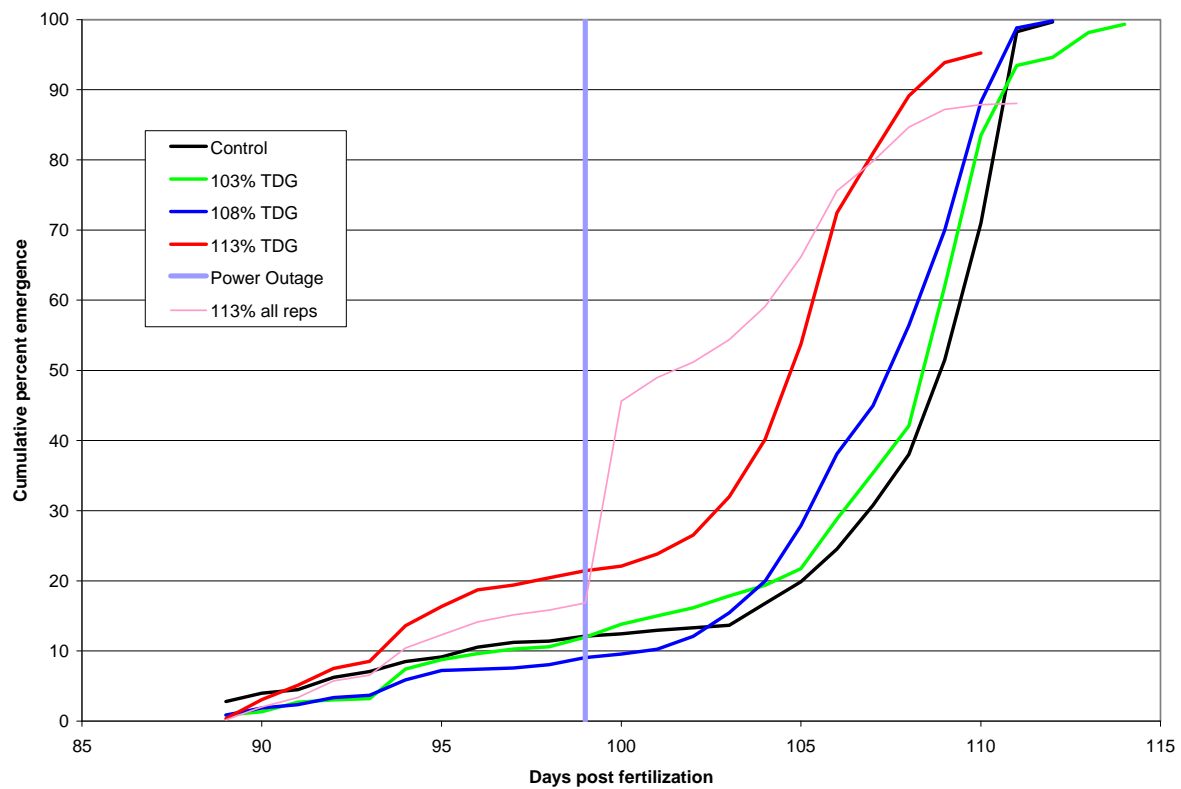

Figure 2.5. Days to $50 \%$ emergence for each treatment group. Note: only replicates 2, 3, and 5 were used in the cumulative emergence plot for the $113 \%$ TDG treatment group.

When the three replicates were removed from the survival analysis, the results showed that the proportion that survived to emergence did not differ among the treatment groups (Kruskal-Wallis test: $H=4.31 ; \mathrm{df}=3 ; P=0.230$; Table 2.3). The removal of these replicates reduced the average difference in emergence timing among the treatment groups, but the control group still took about 4 days longer to emerge than did the 113\% TDG treatment group (Figure 2.6); this result was statistically significant (Kruskal-Wallis test: $H=10.10 ; \mathrm{df}=3 ; P=0.018$ ). The date of $50 \%$ emergence ranged from March 19 to March 23, and the accumulated thermal units at the time of 50\% emergence ranged from 927 to 959 (Table 2.3). The thermal units accumulated at the time of 50\% emergence were significantly different among the treatment groups (ANOVA: $F=54.89 ; \mathrm{df}=3$ and $311 ; P<0.001$ ).

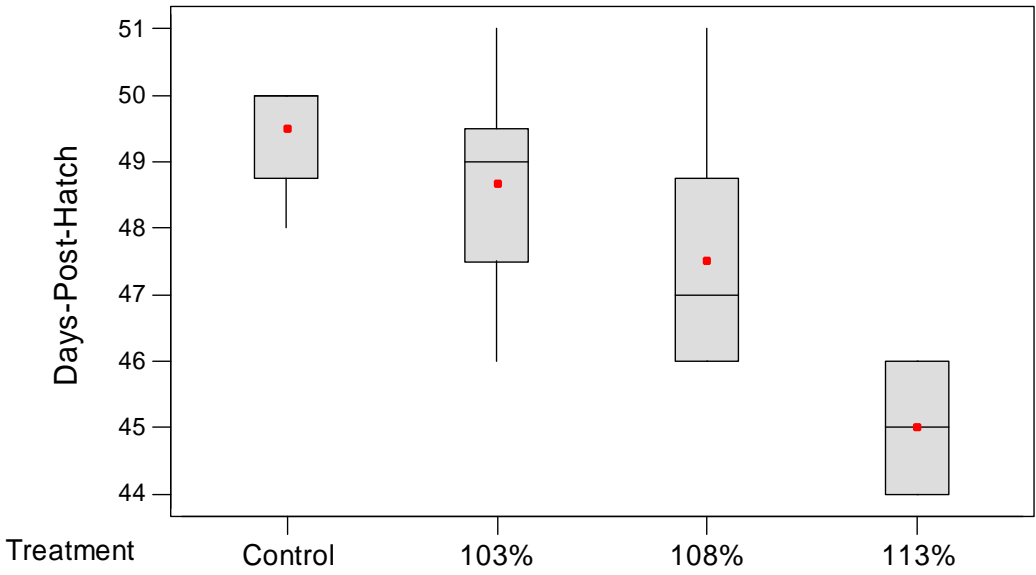

Figure 2.6. Number of days post-hatch that emergence occurred plotted against the control and three treatment levels 
Table 2.3. Mean (and range) survival, days post-fertilization (DPF), date, and accumulated thermal units (ATU) at 50\% emergence

\begin{tabular}{ccccc}
\hline Treatment Group & Survival & DPF & Date & ATU \\
\hline \multirow{2}{*}{ Control } & $99.7 \%$ & 109 & $3 / 23$ & 959 \\
& $(99-100 \%)$ & $(108-110)$ & $(3 / 22-24)$ & $(943-965)$ \\
$103 \%$ TDG & $99.3 \%$ & 108 & $3 / 22$ & 954 \\
& $(98-100 \%)$ & $(106-111)$ & $(3 / 20-25)$ & $(930-974)$ \\
$108 \%$ TDG & $99.8 \%$ & 107 & $3 / 21$ & 945 \\
& $(99-100 \%)$ & $(106-111)$ & $(3 / 20-25)$ & $(929-980)$ \\
$113 \%$ TDG & $95.2 \%$ & 105 & $3 / 19$ & 927 \\
& $(90-100 \%)$ & $(104-106)$ & $(3 / 18-20)$ & $(918-934)$ \\
\hline
\end{tabular}

\section{Alevin and Fry Size}

The mean wet weight of alevins at 50\% hatch (February 2, 2007) was $188 \mathrm{mg}$, while the mean fork length was $21.5 \mathrm{~mm}$ (Table 2.4). At the time the alevins were transferred to the emergence tubes on March 2, 2007, their average wet weight had increased to $283 \mathrm{mg}$ and their mean fork length had increased to $33.3 \mathrm{~mm}$ (Table 2.4). There was no difference in either wet weight or fork length among treatment groups at the time the alevins were transferred to emergence tubes (ANOVA - weight: $F=0.35 ; \mathrm{df}=3$ and $92 ; P=0.792$. ANOVA - length: $F=0.21 ; \mathrm{df}=3$ and $92 ; P=0.889)$.

Table 2.4. Size of chum salmon sampled at 50\% hatch (February 2, 2007) and at time of transfer to emergence tubes (March 1, 2007)

\begin{tabular}{cccccccc}
\hline $\begin{array}{c}\text { Development } \\
\text { Stage }\end{array}$ & Variable & $\mathrm{N}$ & Mean & Median & $\begin{array}{c}\text { Standard } \\
\text { Deviation }\end{array}$ & Minimum & Maximum \\
\hline \multirow{2}{*}{$50 \%$ hatch } & Wet weight $(\mathrm{mg})$ & 360 & 188 & 190 & 20 & 110 & 239 \\
& Fork length $(\mathrm{mm})$ & 360 & 21.5 & 22.0 & 0.7 & 20.0 & 23.0 \\
Transfer to & Wet weight $(\mathrm{mg})$ & 96 & 283 & 284 & 28 & 222 & 338 \\
emergence tubes & Fork length $(\mathrm{mm})$ & 96 & 33.3 & 33.0 & 1.0 & 30.0 & 35.0 \\
\hline
\end{tabular}

The mean wet weight of alevins at 50\% emergence ranged from $296 \mathrm{mg}$ in the $113 \%$ TDG treatment group to $311 \mathrm{mg}$ in the $103 \%$ TDG treatment group, while the mean fork length ranged from $36.2 \mathrm{~mm}$ in the $113 \%$ TDG treatment group to $36.7 \mathrm{~mm}$ in the control and $103 \%$ TDG treatment groups (Table 2.5). Because the ATUs were significantly different at emergence (see previous section), ATUs were used as a covariate to analyze size at emergence. Linear regression analysis showed that wet weight at $50 \%$ emergence was related to ATU (ANOVA: $F=6.72, P=0.010$ ) but not TDG level (ANOVA: $F=0.51$, $P=0.676$ ). Weight was lower (and ATUs lower) in the $113 \%$ TDG treatment group because alevins emerged earlier than they did in the other treatment groups. The fork lengths of alevins were not related to either ATUs (ANOVA: $F=0.0, P=0.963)$ or treatment $(F=1.97, P=0.118)$.

The mean development index $\left(k_{\mathrm{D}}\right)$ ranged from 1.84 to 1.86 and was significantly different among the treatment groups (ANOVA: $F=5.80, P=0.001$ ) and co-varied significantly with ATUs (ANOVA: $F=13.63, P<0.001)$. Even though statistical significance was detected, the large degrees of freedom (error $\mathrm{df}=310$ ) and the small differences between the least square means suggest that the differences are not biologically significant. 
Table 2.5. Size of chum salmon sampled at 50\% emergence

\begin{tabular}{lccccccc}
\hline \multicolumn{1}{c}{ Variable } & Treatment & $\mathrm{N}$ & Mean & Median & $\begin{array}{c}\text { Standard } \\
\text { Deviation }\end{array}$ & Minimum & Maximum \\
\hline \multirow{3}{*}{ Wet weight (mg) } & Control & 90 & 308 & 312 & 31 & 227 & 379 \\
& $103 \%$ & 90 & 311 & 313 & 31 & 237 & 398 \\
& $108 \%$ & 90 & 309 & 307 & 31 & 240 & 386 \\
& $113 \%$ & 45 & 296 & 290 & 34 & 230 & 369 \\
& Control & 90 & 36.7 & 37.0 & 1.2 & 33.0 & 39.0 \\
Fork length (mm) & $103 \%$ & 90 & 36.7 & 37.0 & 1.4 & 34.0 & 40.0 \\
& $108 \%$ & 90 & 36.4 & 36.5 & 1.3 & 33.0 & 39.0 \\
& $113 \%$ & 45 & 36.2 & 36.0 & 1.3 & 34.0 & 39.0 \\
Development & Control & 90 & 1.84 & 1.84 & 0.04 & 1.76 & 1.99 \\
index $\left(k_{\mathrm{D}}\right)$ & $103 \%$ & 90 & 1.84 & 1.84 & 0.04 & 1.76 & 1.98 \\
& $108 \%$ & 90 & 1.86 & 1.85 & 0.05 & 1.73 & 2.01 \\
& $113 \%$ & 45 & 1.84 & 1.83 & 0.04 & 1.72 & 1.92 \\
\hline
\end{tabular}

On average, alevins gained weight at approximately $10 \mathrm{mg} / \mathrm{d}$ (Figure 2.7 ) and length at approximately $1.2 \mathrm{~mm} / \mathrm{d}$ (Figure 2.8) from hatch to emergence and followed a growth curve typical of salmonid alevins. The weight gain did not differ among treatment groups and was related more to days post-hatch (see stats below). Both weight and length could be modeled as a second order polynomial function of days posthatch $\left(R^{2}=0.99\right)$. The regression equation for weight was

$$
\text { Weight }=-0.2639+0.01036(\mathrm{DPF})-0.0000471\left(\mathrm{DPF}^{2}\right)
$$

where DPF was days post-fertilization.

The length gains of the fish were represented by

$$
\text { Length }=-32.25+1.22(\mathrm{DPF})-0.005405\left(\mathrm{DPF}^{2}\right) \text {. }
$$

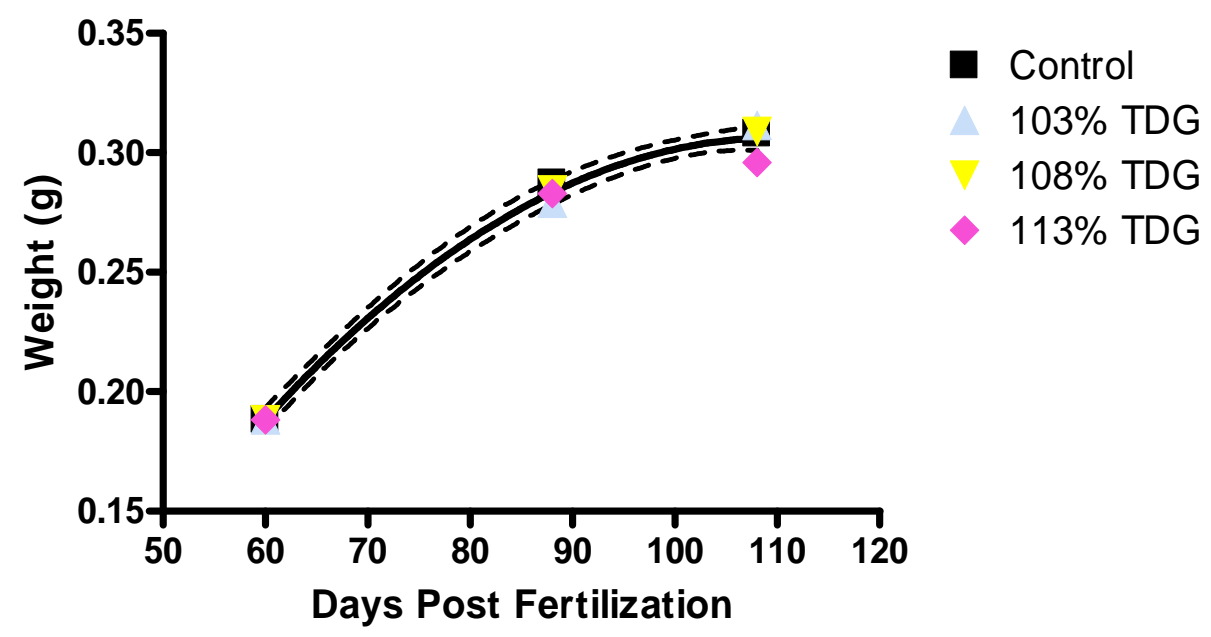

Figure 2.7. Average daily weight gain $(\mathrm{mg} / \mathrm{d})$ from $50 \%$ hatch to $50 \%$ emergence. 


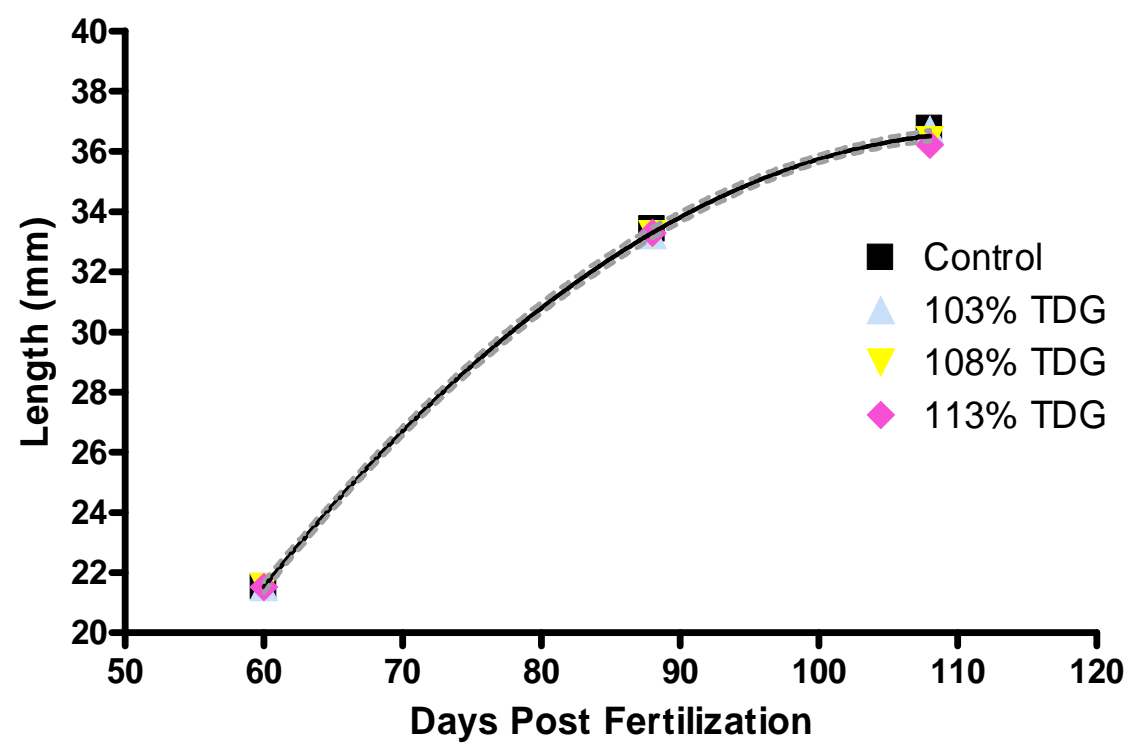

Figure 2.8. Average daily length gain $(\mathrm{mm} / \mathrm{d})$ from $50 \%$ hatch to $50 \%$ emergence.

The mean dry tissue weight of alevins at $50 \%$ hatch was $12 \mathrm{mg}$ (range 11 to $12 \mathrm{mg}$ ). At the time of $50 \%$ emergence, the mean dry tissue weight across the treatment groups ranged from $48.6 \mathrm{mg}$ in the $113 \%$ TDG treatment group to $52.9 \mathrm{mg}$ in the control group (Table 2.6); the differences among the treatment groups were not significant (Kruskal-Wallis test: $H=3.96 ; \mathrm{df}=3 ; P=0.266$ ). The mean dry yolk weight of alevins at 50\% hatch was $6.8 \mathrm{mg}$ (range 6.4 to $7.1 \mathrm{mg}$ ). At $50 \%$ emergence, the mean dry yolk weight across treatment groups ranged from $1.8 \mathrm{mg}$ in the control group to $4.8 \mathrm{mg}$ in the $113 \%$ TDG treatment group (Table 2.6). There was a significant difference in dry yolk weight among groups at $50 \%$ emergence (Kruskal-Wallis test: $H=8.03 ; \mathrm{df}=3 ; P=0.045$ ). Finally, the total dry weight of alevins at $50 \%$ emergence ranged from $5.33 \mathrm{mg}$ in the $113 \%$ TDG treatment group to $5.48 \mathrm{mg}$ in the control group (Table 2.6); the differences among groups were not significant (Kruskal-Wallis test: $H=0.52$; $\mathrm{df}=3$; $P=0.916)$.

Table 2.6. Tissue, yolk, and total dry weights of emergent fry

\begin{tabular}{cccccccc}
\hline Variable & Treatment & $N$ & Mean & Median & $\begin{array}{c}\text { Standard } \\
\text { Deviation }\end{array}$ & Minimum & Maximum \\
\hline Tissue & Control & 6 & 52.9 & 52.4 & 1.4 & 51.5 & 55.2 \\
dry wt & $103 \%$ & 6 & 52.4 & 53.0 & 2.0 & 48.8 & 54.0 \\
(mg) & $108 \%$ & 6 & 52.3 & 52.2 & 2.4 & 49.7 & 56.5 \\
& $113 \%$ & 3 & 48.6 & 47.2 & 3.5 & 46.0 & 52.5 \\
Yolk dry & Control & 6 & 1.80 & 1.75 & 0.60 & 1.12 & 2.46 \\
wt & $103 \%$ & 6 & 1.86 & 1.54 & 0.088 & 1.04 & 2.97 \\
(mg) & $108 \%$ & 6 & 2.15 & 2.14 & 0.059 & 1.32 & 3.07 \\
& $113 \%$ & 3 & 4.78 & 5.37 & 1.38 & 3.21 & 5.77 \\
Total dry & Control & 6 & 54.8 & 54.6 & 1.5 & 52.8 & 56.5 \\
wt & $103 \%$ & 6 & 54.2 & 54.3 & 1.8 & 51.7 & 57.0 \\
(mg) & $108 \%$ & 6 & 54.5 & 54.4 & 2.0 & 51.9 & 57.8 \\
\hline
\end{tabular}




\section{Gross Examination of Gas Bubble Disease}

At least half of all fish examined in all treatment groups appeared to have bubbles present in the eyes (Table 2.7). The bubbles were found in the epithelial tissue around the margin of the eye, as well as behind the eye in the orbital cavity; bubbles observed behind the eye in the orbital cavity were pronounced. The proportion of samples where bubbles in the eyes were observed was higher in the $113 \%$ TDG treatment group, but bubbles were observed also in the control group, leading us to believe that some of the bubbles were likely due to the probing technique. Bubbles in the nares were more common in the 108\% and $113 \%$ TDG treatment groups but were observed also in the 103\% TDG treatment group and the control group (Table 2.7). Overinflated swim bladders were first observed in fry swimming in the egg baskets in the $113 \%$ TDG treatment group. Some fish were unable to maintain buoyancy and were floating on the surface. This condition was more pronounced in the $103 \%$ and $108 \%$ TDG-level groups than in the highest-level and control groups when viewed under the scope; it is not clear why this is the case. Bubbles were observed in the intestinal tract (stomach and/or gut) in all but the 108\% TDG group.

Table 2.7. Results of gross examinations of sac fry sampled during the exposure period

\begin{tabular}{ccccc}
\hline Treatment Group & Bubbles in eyes & Bubbles in nares & $\begin{array}{c}\text { Overinflated air } \\
\text { bladder }\end{array}$ & $\begin{array}{c}\text { Bubbles in intestinal } \\
\text { tract }\end{array}$ \\
\hline $\begin{array}{c}\text { Control } \\
(n=7)\end{array}$ & $57 \%$ & $14 \%$ & $43 \%$ & $14 \%$ \\
$103 \%$ TDG & & & & \\
$(n=7)$ & $57 \%$ & $14 \%$ & $100 \%$ & $50 \%$ \\
$108 \%$ TDG & & & $100 \%$ & $0 \%$ \\
$\quad(n=4)$ & $50 \%$ & $31 \%$ & $46 \%$ & $39 \%$ \\
\hline $\begin{array}{c}113 \% \mathrm{TDG} \\
(n=13)\end{array}$ & $69 \%$ & & & \\
\hline
\end{tabular}

\section{Histology}

A histological finding in many fish was the presence of crenated erythrocytes (also referred to as echinocytes). This lesion was limited to the capillaries in the secondary lamellae. A second finding was the dilation of secondary lamellar tips. This involved only the distal tip of the filament, usually with congestion. A mild distal filament epithelial separation coupled with a mild epithelial hypertrophy of secondary lamellae also was present in many fish. This condition was characterized by the presence of a pink-brown, somewhat granular thickened cytoplasm of epithelial cells lining the filaments. The cells were only slightly enlarged and could be classified as low cuboidal. Normally, the cytoplasm of the epithelial cells was extremely thin and appeared as a thin, solid line.

The most significant histological findings were observed in the secondary lamellae of some fish and included epithelial cell separation and vacuolar swelling and/or fragmentation with possible separation of the basement membrane from the pillar cell cytoplasm. This was characterized by observation of a clear empty space between the epithelial cell and basement membrane or cytoplasm of the pillar cell. In the most severe cases (grade 4), a separation of approximately 5 to $6 \mu$ was noted. The separation was so severe that the pillar cell cytoplasm that forms the lamellar blood channels was clearly isolated from the epithelium. This gave the impression of a tube within a blood-filled tube. This is a unique lesion and most probably represents edema. No proteinaceous exudate was present, but this may have been removed by the flushing action of the water through the filaments. 
Hepatic glycogen depletion was present in some fish but did not appear to be a significant problem. The individual cases of a fungal infection and a widespread thrombotic event were significant to those individuals but, based on the relatively few numbers affected, did not appear to be significant as a group problem.

The severity of lesions was greater in fish from the 19-day sample than in fish from the 7-day sample, and only the severity of epithelial hypertrophy and epithelial separation and swelling exhibited a potential dose response with TDG (Figure 2.9). When the severity levels were pooled, epithelial hypertrophy in fish from the 19-day sample had a significantly smaller than expected proportion of moderate lesions in the control group (i.e., 100\% TDG) and significantly larger proportion in the $108 \%$ and $113 \%$ TDG exposures (binomial exact test: $P<0.05$ ). In other words, moderate lesions were significantly more prevalent in the two highest gas concentrations than in the control group. A probit analysis of the proportion of moderate epithelial hypertrophy in fish from the 19-day sample as a function of TDG was used to estimate an EC50 of $102.8 \%$ TDG (100.5\% to 104.7\%; Figure 2.10). The proportions of moderate epithelial separation and swelling were significantly different from expected in fish from both the 7- and 19-day sample (binomial exact test: $P<0.05$ ); however, there was not an increasing proportion of moderate response with increasing TDG in the 7-day sample. For the 19-day sample, all fish exposed to the $103 \%, 108 \%$, and $113 \%$ TDG levels had moderate epithelial separation and swelling, suggesting a significant tissue response to the lowest supersaturated gas level tested; thus, the EC50 for this lesion would be less than 103\% TDG. The proportion of moderate lesions (sum of all lesions) was significantly different from expected in fish from both the 7- and 19-day samples (chi-square test: $P<0.05)$; however, there was not an increasing proportion of moderate response with increasing TDG in either sample date.

Many of the fish examined were infected also with an unidentified protozoan on the thymus, gills, and skin. However, this infection did not appear to correlate with the lesions in the secondary lamellae. Although we examined representative protozoa with several special histological stains (Giemsa, periodic acid-Schiff, Gomori methenamine silver, Gram, and mucicarmen), it was not possible to identify the protozoan. All of the special stains were negative. The maximum count and proportion occurrence of parasites per nine possible tissue samples per fish suggests that the skin had the greatest infection and that the count of parasites and the proportion of occurrence of infection increased between the 7- and 19-day samples (Table 2.8). For the maximum count of parasites, the interaction of the sampling date and TDG exposure level in the full two-way ANOVA was not significant for any of the tissue types (ANOVA: $P>0.54$ ). The main effect of TDG also was not significant for any of the tissue types (ANOVA: $P>0.57$ ). However, the main effect of sampling date was significant (ANOVA: $P<0.007$ ) for all tissue types, with an increase in counts for the 19-day sample. The proportion of occurrence showed a similar response; the interaction effect and the main effect of TDG were not significant for all tissues (ANOVA: $P>0.23$ ). The main effect of sample date was significant (ANOVA: $P<0.01$ ) for infection on the thymus and gills, with an increase in proportion occurrence for the 19-day sample. The main effect of sample date was only nearly significant, however, for infection on the skin (ANOVA: $P=0.065$ ). 

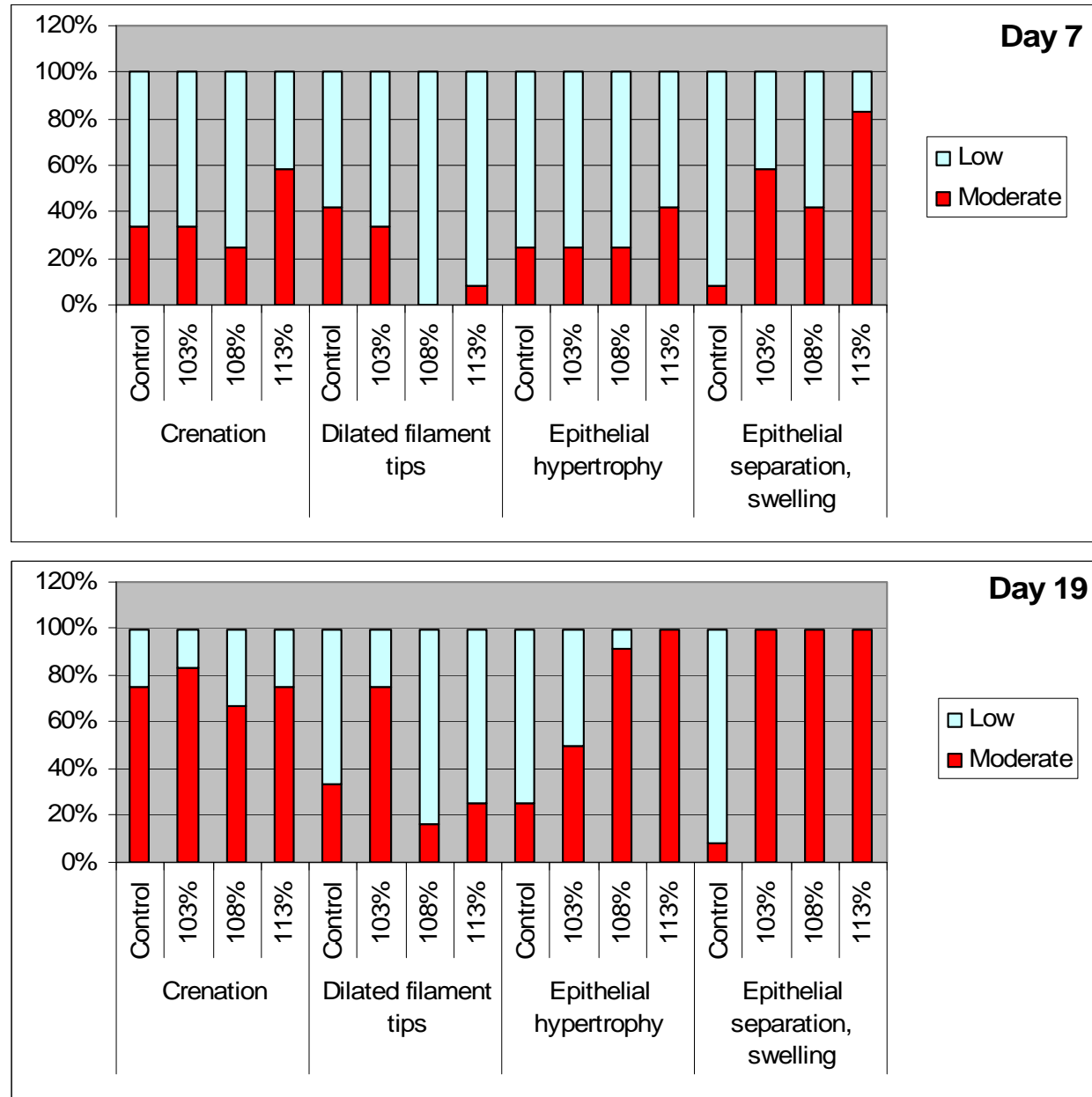

Figure 2.9. The proportion of tissue samples from day 7 and day 19 of the gas exposure that exhibited lesions. Low represents lesions that were coded as 0 or 1 , while Moderate represents lesions that were coded as 2,3 , or 4 .

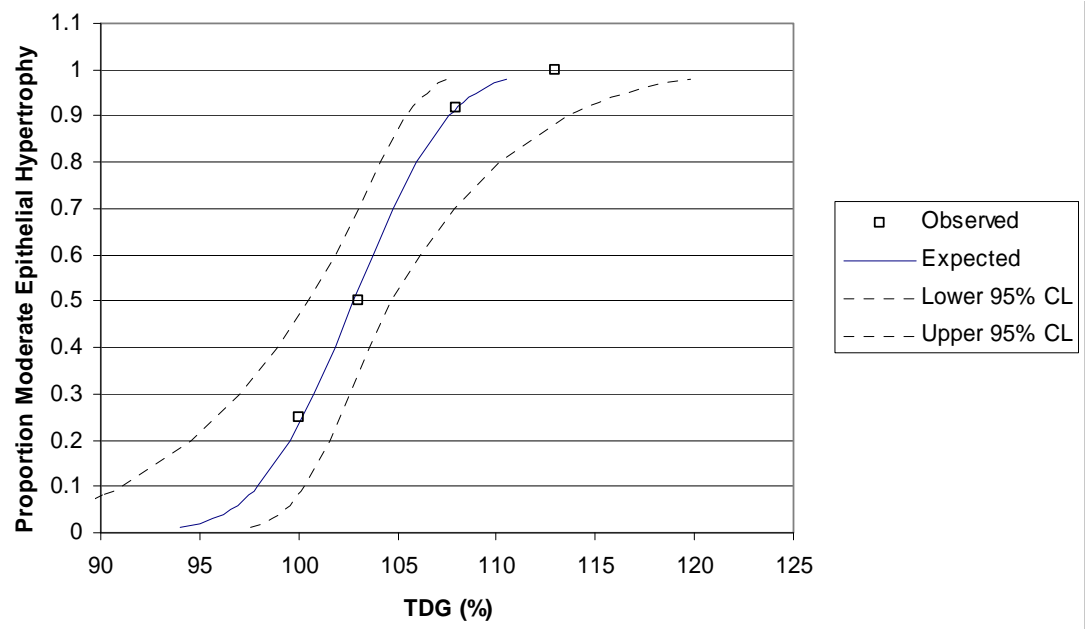

Figure 2.10. Dose response of the proportion of moderate epithelial hypertrophy in the 19-day sample as a function of total dissolved gas (\%) 
Table 2.8. Maximum count and proportion (Pr) occurrence of parasites per nine possible tissue samples per fish

\begin{tabular}{llllllllllll}
\hline Variable & Treatment & $N$ & Mean & Median & $\begin{array}{l}\text { Standard } \\
\text { Deviation }\end{array}$ & Minimum & Maximum & Q1 & Q3 & CV \\
\hline
\end{tabular}

7 Days Post-Exposure

\begin{tabular}{|c|c|c|c|c|c|c|c|c|c|c|}
\hline \multirow{4}{*}{ Thymus } & $100 \%$ & 12 & 2.92 & 5.00 & 2.58 & 0.00 & 5.00 & 0.00 & 5.00 & $88 \%$ \\
\hline & $103 \%$ & 12 & 2.50 & 2.50 & 2.61 & 0.00 & 5.00 & 0.00 & 5.00 & $104 \%$ \\
\hline & $108 \%$ & 12 & 2.92 & 5.00 & 2.58 & 0.00 & 5.00 & 0.00 & 5.00 & $88 \%$ \\
\hline & $113 \%$ & 12 & 2.08 & 0.00 & 2.58 & 0.00 & 5.00 & 0.00 & 5.00 & $124 \%$ \\
\hline \multirow{4}{*}{ Gills } & $100 \%$ & 12 & 0.00 & 0.00 & 0.00 & 0.00 & 0.00 & 0.00 & 0.00 & $0 \%$ \\
\hline & $103 \%$ & 12 & 0.50 & 0.00 & 1.17 & 0.00 & 3.00 & 0.00 & 0.00 & $234 \%$ \\
\hline & $108 \%$ & 12 & 0.50 & 0.00 & 1.17 & 0.00 & 3.00 & 0.00 & 0.00 & $234 \%$ \\
\hline & $113 \%$ & 12 & 0.25 & 0.00 & 0.87 & 0.00 & 3.00 & 0.00 & 0.00 & $346 \%$ \\
\hline \multirow{4}{*}{ Skin } & $100 \%$ & 12 & 9.17 & 7.50 & 7.02 & 5.00 & 30.00 & 5.00 & 10.00 & $77 \%$ \\
\hline & $103 \%$ & 12 & 7.92 & 7.50 & 4.98 & 0.00 & 20.00 & 5.00 & 10.00 & $63 \%$ \\
\hline & $108 \%$ & 12 & 12.50 & 10.00 & 8.39 & 5.00 & 30.00 & 5.00 & 20.00 & $67 \%$ \\
\hline & $113 \%$ & 12 & 7.50 & 5.00 & 3.37 & 5.00 & 15.00 & 5.00 & 10.00 & $45 \%$ \\
\hline \multirow{4}{*}{ Pr-Thymus } & $100 \%$ & 12 & 0.37 & 0.42 & 0.38 & 0.00 & 1.00 & 0.00 & 0.58 & $103 \%$ \\
\hline & $103 \%$ & 12 & 0.25 & 0.17 & 0.31 & 0.00 & 1.00 & 0.00 & 0.46 & $126 \%$ \\
\hline & $108 \%$ & 12 & 0.26 & 0.33 & 0.30 & 0.00 & 1.00 & 0.00 & 0.33 & $113 \%$ \\
\hline & $113 \%$ & 12 & 0.25 & 0.00 & 0.35 & 0.00 & 1.00 & 0.00 & 0.50 & $142 \%$ \\
\hline \multirow{4}{*}{ Pr-Gills } & $100 \%$ & 12 & 0.00 & 0.00 & 0.00 & 0.00 & 0.00 & 0.00 & 0.00 & $0 \%$ \\
\hline & $103 \%$ & 12 & 0.02 & 0.00 & 0.04 & 0.00 & 0.11 & 0.00 & 0.00 & $234 \%$ \\
\hline & $108 \%$ & 12 & 0.03 & 0.00 & 0.07 & 0.00 & 0.22 & 0.00 & 0.00 & $249 \%$ \\
\hline & $113 \%$ & 12 & 0.02 & 0.00 & 0.06 & 0.00 & 0.22 & 0.00 & 0.00 & $347 \%$ \\
\hline \multirow{4}{*}{ Pr-Skin } & $100 \%$ & 12 & 0.77 & 0.78 & 0.14 & 0.56 & 1.00 & 0.67 & 0.89 & $18 \%$ \\
\hline & $103 \%$ & 12 & 0.80 & 0.89 & 0.31 & 0.00 & 1.00 & 0.78 & 1.00 & $39 \%$ \\
\hline & $108 \%$ & 12 & 0.79 & 0.83 & 0.22 & 0.33 & 1.00 & 0.67 & 1.00 & $29 \%$ \\
\hline & $113 \%$ & 12 & 0.82 & 0.89 & 0.19 & 0.33 & 1.00 & 0.69 & 0.97 & $23 \%$ \\
\hline \multicolumn{11}{|c|}{19 Days Post-Exposure } \\
\hline \multirow{4}{*}{ Thymus } & $100 \%$ & 12 & 3.75 & 5.00 & 2.26 & 0.00 & 5.00 & 1.25 & 5.00 & $60 \%$ \\
\hline & $103 \%$ & 12 & 4.17 & 5.00 & 1.95 & 0.00 & 5.00 & 5.00 & 5.00 & $47 \%$ \\
\hline & $108 \%$ & 12 & 5.83 & 5.00 & 5.15 & 0.00 & 20.00 & 5.00 & 5.00 & $88 \%$ \\
\hline & $113 \%$ & 12 & 5.00 & 5.00 & 3.02 & 0.00 & 10.00 & 5.00 & 5.00 & $60 \%$ \\
\hline \multirow{4}{*}{ Gills } & $100 \%$ & 12 & 1.25 & 0.00 & 1.55 & 0.00 & 3.00 & 0.00 & 3.00 & $124 \%$ \\
\hline & $103 \%$ & 12 & 0.75 & 0.00 & 1.36 & 0.00 & 3.00 & 0.00 & 2.25 & $181 \%$ \\
\hline & $108 \%$ & 12 & 1.00 & 0.00 & 1.48 & 0.00 & 3.00 & 0.00 & 3.00 & $148 \%$ \\
\hline & $113 \%$ & 12 & 1.00 & 0.00 & 1.48 & 0.00 & 3.00 & 0.00 & 3.00 & $148 \%$ \\
\hline \multirow{4}{*}{ Skin } & $100 \%$ & 12 & 13.75 & 10.00 & 8.56 & 5.00 & 35.00 & 10.00 & 15.00 & $62 \%$ \\
\hline & $103 \%$ & 12 & 13.75 & 12.50 & 6.44 & 5.00 & 25.00 & 10.00 & 20.00 & $47 \%$ \\
\hline & $108 \%$ & 12 & 13.33 & 10.00 & 7.49 & 0.00 & 30.00 & 10.00 & 18.75 & $56 \%$ \\
\hline & $113 \%$ & 12 & 12.92 & 10.00 & 7.53 & 5.00 & 25.00 & 5.00 & 20.00 & $58 \%$ \\
\hline \multirow{4}{*}{ Pr-Thymus } & $100 \%$ & 12 & 0.43 & 0.42 & 0.34 & 0.00 & 1.00 & 0.08 & 0.63 & $80 \%$ \\
\hline & $103 \%$ & 12 & 0.40 & 0.50 & 0.23 & 0.00 & 0.75 & 0.27 & 0.50 & $57 \%$ \\
\hline & $108 \%$ & 12 & 0.71 & 0.90 & 0.38 & 0.00 & 1.00 & 0.52 & 1.00 & $54 \%$ \\
\hline & $113 \%$ & 12 & 0.50 & 0.55 & 0.35 & 0.00 & 1.00 & 0.20 & 0.75 & $71 \%$ \\
\hline \multirow{4}{*}{ Pr-Gills } & $100 \%$ & 12 & 0.07 & 0.00 & 0.11 & 0.00 & 0.33 & 0.00 & 0.11 & $148 \%$ \\
\hline & $103 \%$ & 12 & 0.05 & 0.00 & 0.10 & 0.00 & 0.33 & 0.00 & 0.08 & $212 \%$ \\
\hline & $108 \%$ & 12 & 0.14 & 0.00 & 0.28 & 0.00 & 0.89 & 0.00 & 0.20 & $193 \%$ \\
\hline & $113 \%$ & 12 & 0.06 & 0.00 & 0.10 & 0.00 & 0.25 & 0.00 & 0.12 & $162 \%$ \\
\hline \multirow{4}{*}{ Pr-Skin } & $100 \%$ & 12 & 0.94 & 1.00 & 0.11 & 0.67 & 1.00 & 0.92 & 1.00 & $12 \%$ \\
\hline & $103 \%$ & 12 & 0.97 & 1.00 & 0.07 & 0.78 & 1.00 & 1.00 & 1.00 & $7 \%$ \\
\hline & $108 \%$ & 12 & 0.76 & 0.94 & 0.36 & 0.00 & 1.00 & 0.61 & 1.00 & $47 \%$ \\
\hline & $113 \%$ & 12 & 0.84 & 0.94 & 0.20 & 0.44 & 1.00 & 0.69 & 1.00 & $23 \%$ \\
\hline
\end{tabular}




\section{Post-Treatment Observations}

No abnormal swimming behavior was noted during the post-treatment period. Upon termination, it was generally observed that fish size varied considerably. Substantial mortalities, although not quantified, also were found. However, both the size variation and mortalities are attributed to an inadequate feeding program throughout the holding period.

\section{Discussion}

Results from our study showed that direct mortality of chum salmon fry exposed to various concentrations of total dissolved gas was not influenced by levels ranging up to $113 \%$ TDG. However, sublethal tissue damage was measurable at levels of $108 \%$ and $113 \%$ TDG. Although gross examinations were inconclusive, histological examination found increased occurrence of gill lesions of the secondary lamellae in fish exposed to the two highest levels, especially epithelial hypertrophy and epithelial separation and swelling. Emergence timing was affected by the total dissolved gas concentration; fry exposed to the $113 \%$ TDG level emerged about four days earlier than those of the control group. Alevins from all four treatment groups followed a typical salmonid growth curve; dissolved gas did not affect alevin size.

Preliminary analysis indicated that survival to emergence differed between treatment groups, with fish in the 113\% TDG treatment emerging 5-7 days earlier than those in other groups. However, coincident to the power outage that occurred on March 13, a single unexpected mortality and emergence event took place within the $113 \%$ TDG treatment group. The power outage affected the survival and emergence timing of three replicates at the $113 \%$ TDG level. A temperature spike and drop in TDG levels occurred in conjunction with the power outage, and we believe that a low flow condition along with the temperature spike (up to $13.4^{\circ} \mathrm{C}$ for the $113 \%$ TDG trough) resulted in the high mortality/early emergence event. Each treatment trough was provided water from two sources at different proportions. It was likely that only the $113 \%$ TDG treatment trough was affected because it received a higher proportion of its water from the more sensitive source. It is not clear why only three of the six replicates in the 113\% TDG trough displayed such a response, but individual differences in the supply tubing configuration from the manifold may have played a role. Either way, we believe the results were spurious and decided to remove them from our analysis; the corrected proportion that survived to emergence did not differ statistically among the four treatment groups.

The most significant histological finding was that of epithelial cell separation and vacuolar swelling in the secondary lamellae of the gills, which resulted in an increase in the interstitial space. This is a unique gill lesion and most probably represents edema. Toxins can cause this lesion but usually also result in lamellar syncytia and fusion, which was not present in the affected fish. "Edema of the gills" was one of the lesions resulting from GBD in fingerling Chinook salmon (Pauley and Nakatani 1967). Their morphologic findings were very similar to that seen in this study. The lack of additional lesions in other organs in this study, compared to the findings of Pauley and Nakatani (1967), may be due to the age difference or differences in the concentration of gas supersaturation levels. Pauley and Nakatani (1967) also reported gross lesions (gas bubbles on the body, head, peritoneal lining of the body cavity, and oral cavity) associated with GBD that were not observed in our study. Pauley and Nakatani (1967) did not report the concentration of gas supersaturation in their work. Although we were unable to confirm it, there was a report (E. M. Dawley, personal communication) that other disease factors may have 
contributed in part to Pauley and Nakatani's results. Even so, we did find a probable commonality of gill lesions in fish exposed to gas supersaturation between the two studies.

Analysis demonstrated that the proportion of fish with moderate epithelial hypertrophy and moderate epithelial separation and swelling was related to the dissolved gas concentration. Larger proportions than expected of fish in the 108\% (19-day sample) and 113\% (7- and 19-day samples) TDG treatments exhibited these lesions. That survival was no different among treatment groups suggests that the presence of these lesions in the gill tissue of subyearling chum salmon does not produce an acute mortality. This is similar to findings reported in other studies of gas exposure to salmonids (Wright and McLean 1985; Krise and Meade 1988). However, it is possible that the lesions produce a sublethal and/or longer-term chronic effect that we were not able to measure in this study. Chronic effects of long-term exposure to dissolved gas concentrations similar to this study have been observed in other salmonids, but often the signs of the gas bubble disease (mortality, reduced growth, lesions) do not appear until after several weeks of exposure. Mortality of lake trout did not increase at $110 \%$ TDG until after day 28, and there was no difference in mortality after one year of exposure to 108\% TDG (Krise 1993). Our treatment period (only 29 days) and/or post-treatment observation period (30 days) may not have been long enough to elucidate a response. This may be a topic deserving of further study.

The cause of cell crenation found histologically in many fish is not known; however, certain toxins can cause this lesion. It is also possible that it could be an artifact of the methodology of fixation and/or euthanasia. Dilation of filament tips and mild epithelial separation and swelling of filament tips was present in most fish. The latter appeared to be a terminal event and may have been related to stress at euthanasia. The mild distal filament epithelial separation, coupled with a mild epithelial hypertrophy, present in many fish could be the result of poor water quality. However, no epithelial hyperplasia (only one occurrence) was present to indicate a severe water quality problem.

The infection by an unidentified protozoan merits further examination to assess the potential of this parasite for affecting experimental results. Several external protozoan parasite genera (e.g., Costia, Trichodina, and Ichthyophthirius) are known to infect juvenile salmonids, sometimes causing mild epizootics (Rucker et al. 1954). Urawa and Yamao (1992) reported mortalities in hatchery-reared juvenile cherry salmon (O. masou) and pink salmon (O. gorbuscha) in Japan due to infection by a ciliated protozoan. The infected fish in their study displayed gill epithelial hyperplasia and fusion of gill lamellae and filaments. However, the protozoan infection in our study affected the skin primarily and did not appear to correlate with lesions in the secondary lamellae of the gills. It appeared from our results that the length of exposure, rather than the concentration of the dissolved gas, was more related to the incidence of the protozoan. Examination by electron microscopy and/or molecular probe methods would be required to identify the protozoan organism. Once the organism has been identified, further literature search could provide additional insight. Of interest to note is the implication that fish weakened by other factors are more susceptible to parasitic infections (Lom and Nigrelli 1970).

The results of the gross examinations for GBD were inconclusive. We did observe newly hatched fry in the highest gas concentrations that were unable to maintain neutral buoyancy. This was likely due to an overinflated swim bladder or bubbles in the hind gut. Signs of apparent GBD were observed consistent with other researchers; such as bubbles in the eyes (Rucker and Kangas 1974; Weitkamp and Katz 1980), nares, and intestinal tract (Dannevig and Dannevig 1950; Henly 1952; Krise and Herman 1989).

Overinflated swim bladders were reported as a concern by Krise and Herman (1989) and Fidler and Miller (1997) and were observed in our study. However, these signs were observed in control groups as well as in 
the higher TDG treatment groups. Possible reasons for the inconclusive data during this first year of study include small sample sizes and preliminary examination methods. It is recommended for future efforts that the sample size be increased and that a more quantifiable examination protocol be employed.

The number of days post-fertilization to emergence was statistically different between the control group and the $113 \%$ TDG group. It is not clear why the $113 \%$ TDG group emerged earlier, even though it had a lower average ATU than the other groups. Possible reasons worth investigating are behavioral effects of increased TDG concentrations or additional effects from the power outage. All four treatment groups emerged earlier than anticipated with respect to ATU. We estimated the ATUs for emergence of chum salmon incubated at $9.5-10.0^{\circ} \mathrm{C}$ to be $1029-1049$ ATU using a computer model called IncubWin (Jensen and Jensen 1999). In our study, actual ATUs at emergence ranged from 927 to 959 . The difference may be related to differences in defining emergence. We used behavior (moving from the dark tube to the light tube) to define emergence, not maximum alevin wet weight.

In general, size of alevins at emergence was not affected by TDG level. Slight differences in mean alevin wet weight between treatments were attributed to ATU and not to TDG levels. Weight (and ATU) was lower in fry exposed to the $113 \%$ TDG level because they emerged earlier. However, fish from the highest supersaturation group had significantly larger residual yolks than all other groups at emergence. This finding, coupled with the lower ATUs, infers the possibility of premature emergence for the $113 \%$ TDG group. Whether this is related to gas bubble disease is unclear and warrants further study.

In conclusion, although direct mortality from increased gas supersaturation was not documented in our study, sublethal tissue effects and developmental differences were observed. It is not known whether these sublethal effects affect the long-term survival of chum salmon fry. Based on the field data, it is likely that concentrations of gas above $103 \%$ TDG are present downstream from Bonneville Dam during the period from hatch through emergence. Future studies of dissolved gas on fry should consider exposing fry earlier in their development to elevated dissolved gas and monitoring fry longer following exposure. 


\title{
Chapter 3
}

\section{Sampling of Chum Salmon Embryos from Natural Redds}

\author{
E. V. Arntzen, K. D. Hand, K. J. Murray, E. M. Dawley, D. R. Geist
}

\section{Introduction}

Hydropower project management agencies and Native American Tribes have questioned whether controlled laboratory studies are representative of TDG exposure in the Columbia River. Their concern led to the recommendation that pre-emergent chum salmon fry incubating in the river environment also be sampled. No previous field work has been conducted to directly evaluate the response of incubating chum salmon to actual conditions downstream of Bonneville Dam (McGrath et al. 2006). The third objective during the 2007 PNNL study was to sample chum salmon sac fry during spill operations at Bonneville Dam to determine if there is a physiological response to elevated TDG levels. This task was deemed necessary to validate any potential impacts observed during the concurrent laboratory exposure study or expected negative impacts based on results from TDG monitoring in adjacent chum salmon spawning gravels.

The objective of the field study was to sample live chum alevins from up to 10 redds from a range of riverbed elevations during a time when surface water TDG was elevated and river discharge was low enough so that depth-compensated TDG values would remain greater than $103 \%$ for an extended period. This chapter provides the details of the field sampling.

\section{Study Site}

Sac fry sampling was conducted downstream from Bonneville Dam at a site north of Ives Island, on the right bank at river kilometer 230 (Figure 3.1).

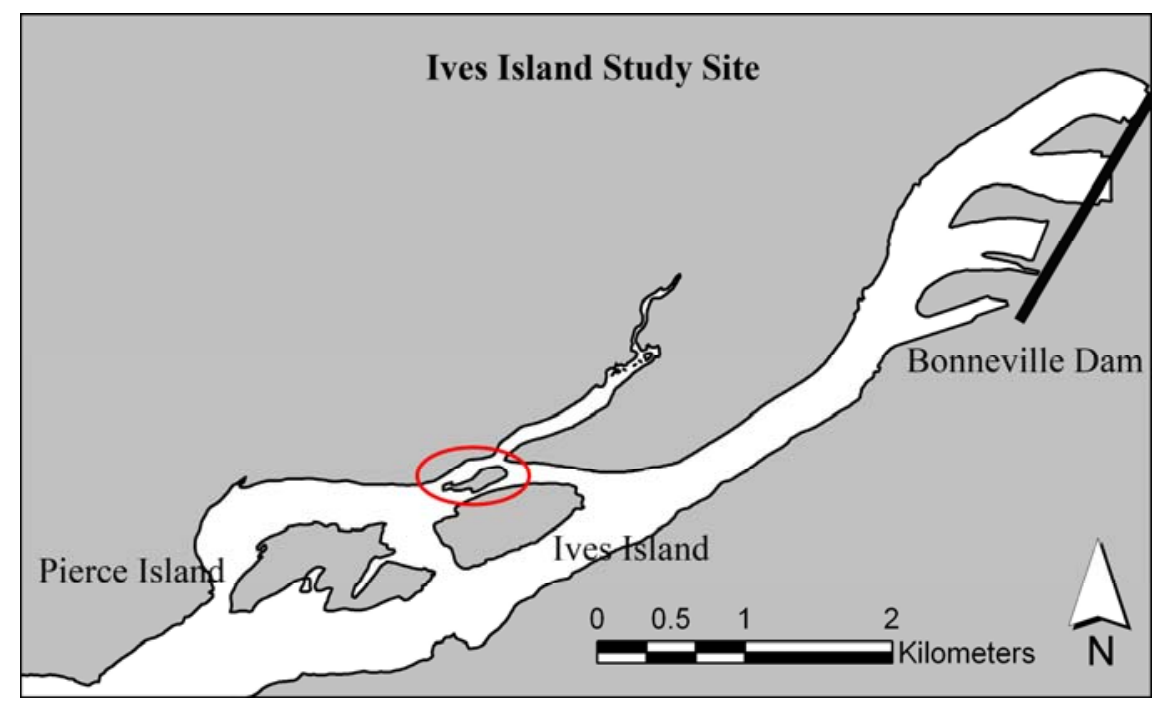

Figure 3.1. Ives Island study site 
Naturally occurring chum salmon redds considered most likely to be exposed to elevated TDG levels were targeted for sac fry sampling. The calculated compensation depth and redd elevation were considered in this evaluation. Arntzen et al. (2007b) determined that the calculated compensation depth during 2004 through 2006 ranged from approximately 0.5 to $1.0 \mathrm{~m}$ in the Ives Island area. Therefore, redds that were frequently exposed to water depths shallower than $1 \mathrm{~m}$ and exposed to supersaturated dissolved gas levels were considered vulnerable to GBD.

\section{Methods}

Because the actual water surface elevation varies in the Ives Island area, the riverbed elevations corresponding to the redd locations were used to identify the shallowest redds. Global Positioning System coordinates were known for 137 chum salmon redds spawned in 2006. These redds were grouped by riverbed elevation into five categories $(7.5-9.5,9.5-10.5,10.5-11.5,11.5-12.5$, and $12.5-14 \mathrm{ft})$, with at least 13 redds in each group. Field crews used this information to locate redds within the chosen riverbed elevation ranges during field sampling.

Our goal was to collect samples following a period when tailwater elevation was low and TDG was relatively high, maximizing the possibility for observing signs of GBD. In fact, although the TDG was elevated within potential sampling areas, the river elevation remained high, such that the compensation depth generally was exceeded. An exception occurred on March 23, 2007, when a flow modification specifying a 12.5-ft Bonneville Dam tailwater elevation allowed access to redds. Our sampling effort coincided with this flow reduction. Water levels were low enough to allow access to some of the higherelevation chum salmon redds in the Ives Island area and to provide some possibility that signs of gas bubble trauma could be identified in the field. Redds from the 12.5- to 14-ft riverbed elevation group were selected for sampling.

A trash pump (Homelite Model HTP2) fitted with $25 \mathrm{ft}$ of 2-in.-diameter inlet hose and $200 \mathrm{ft}$ of 2-in.-diameter outlet hose with an adjustable stream fire hose nozzle attached to the end was used to flush alevins from the redds. We tried various water pressures during the flushing task. Probing with a gentle stream of water was found to be the most effective method of flushing alevins from redds. Higher velocities were found to cause injury to the alevins in the form of hemorrhaging in the fins.

Eight redds were sampled, of which three contained alevins (Figure 3.2). In some locations, several redds were clustered and GPS coordinates overlapped. At these sites, the field crew navigated to the general location using the GPS, then used physical characteristics to identify an individual redd. Field crew members netted alevins with aquarium nets as they were exposed and placed them into 5-gal buckets containing river water (Figure 3.3).

Alevins were transported immediately in buckets to a mobile laboratory trailer on the adjacent river shore on the Pierce Wildlife Refuge. The mobile laboratory was equipped with a dissecting scope and associated tools (Figure 3.4). Portable aquarium air pumps and air stones were used to maintain oxygen levels for fish being held in the buckets. Temperature was monitored and ice added as necessary to maintain the water at the current river temperature of approximately $7.5^{\circ} \mathrm{C}$. 


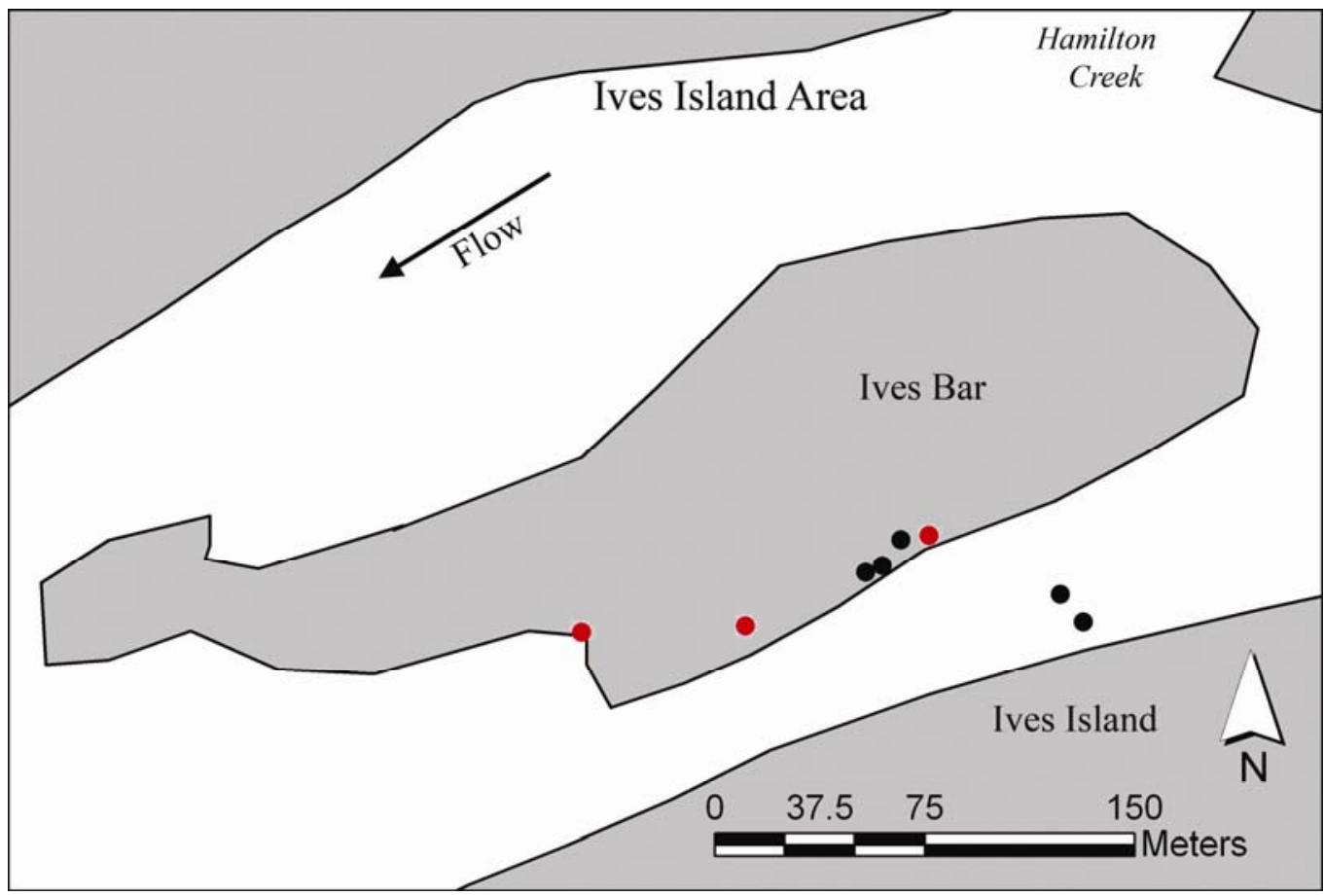

Figure 3.2. Chum salmon redds flushed in search of chum salmon sac fry. Live chum fry were found in three redds (red circles), while none was found in the other five redds (black circles).

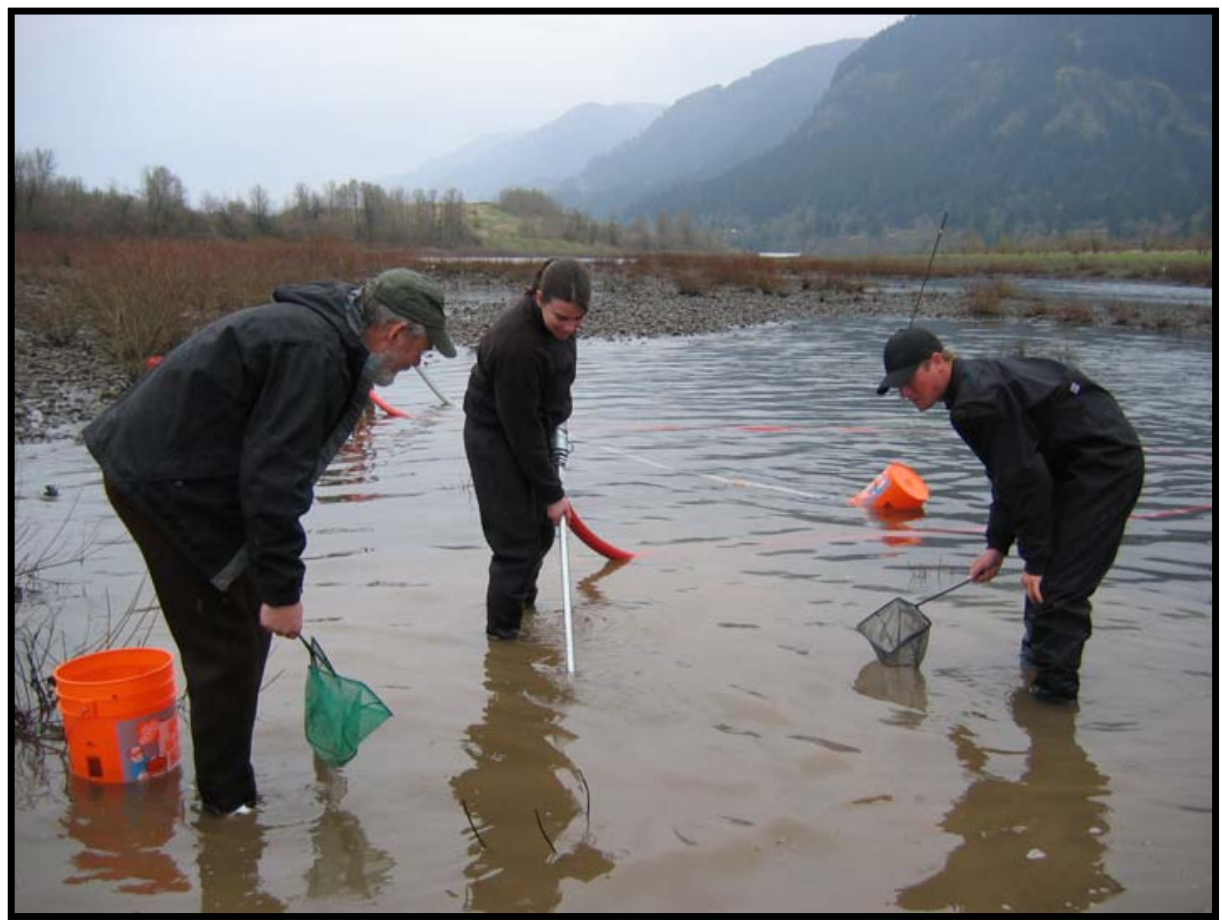

Figure 3.3. Flushing of sac fry from redds using pressurized water and sac-fry sampling using aquarium nets 


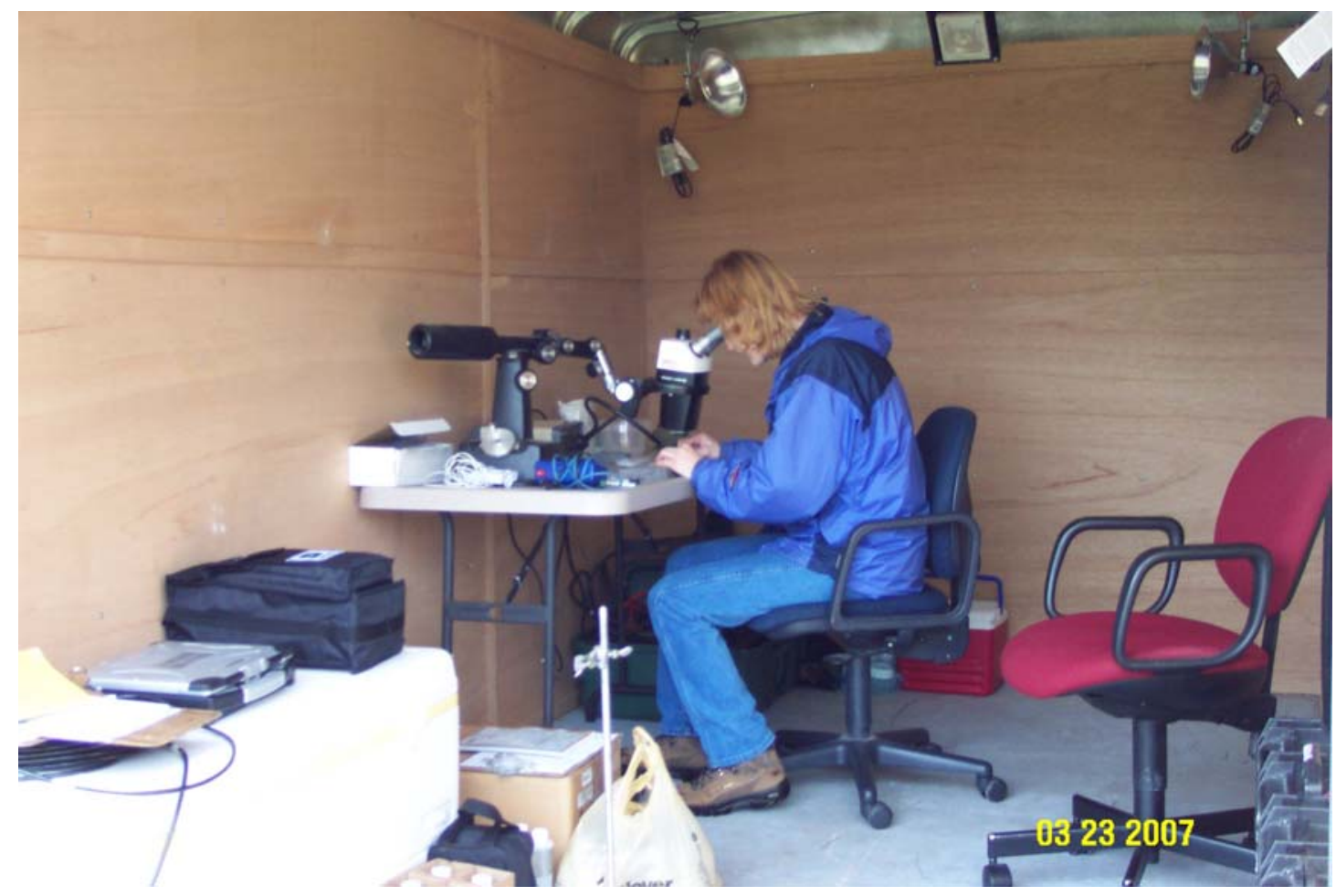

Figure 3.4. Examination of sac fry in the mobile laboratory trailer

Hans et al. (1999) suggested that signs of gas bubble trauma in live fish do not change significantly within 1 hour of removal from a supersaturated environment, so we attempted to complete all evaluations of GBD within 1 hour of sample recovery. Signs of GBD in larval fish may include air bubbles in the yolk sac or between the yolk sac and perivitelline membrane (Shirahata 1966), in the mouth (Peterson 1971), or on the body surface (Shirahata 1966). Therefore, all specimens were examined for gas bubbles in and associated with the yolk sac, mouth, and external body surface.

Alevins were anesthetized individually in an $80 \mathrm{mg} / \mathrm{L}$ solution of buffered MS-222. When active swimming had stopped and respirations had slowed, each alevin was transferred to a Petri dish with a small amount of water for examination. Alevins were examined using a Bausch \& Lomb StereoZoom 7 variable magnification (7x-70x) dissecting scope (Bausch \& Lomb, Inc., Rochester, New York). External examinations checked for air bubbles in the nares, mouth, fins, eye surfaces, caudal peduncle, and yolk sac. Lengths of the fish also were measured. As examinations were completed, each alevin was transferred to anesthetic-free water and allowed to recover fully before being released back into the river.

A small number were euthanized and examined internally. The internal examination checked for bubbles in the gills and intestinal tract and determined the degree of swim bladder inflation. Two alevins from each redd (six total) were euthanized and preserved in a $10 \%$ solution of neutral buffered formalin for possible histological examination. 


\section{Results}

Water levels were high prior to sampling, which resulted in low levels of depth-compensated TDG in the Ives Island area. From the onset of monitoring on March 4 until just prior to field sampling on March 23, depth-compensated TDG reached $103 \%$ four times, each for no more than 2 hours. For most of that time, depth-compensated TDG was $80-90 \%$. Tailwater levels for the four days prior to sampling were approximately $20 \mathrm{ft}$ or greater, and discharge levels averaged $260 \mathrm{kcfs}$. During the flow modification when sampling occurred, tailwater levels dropped to $12.6 \mathrm{ft}$ and discharge levels were at $80 \mathrm{kcfs}$ (Figure 3.5). During this time, TDG levels became elevated due to the low water levels. Depthcompensated TDG rose to approximately $105 \%$ in the sampling area (Figure 3.6).

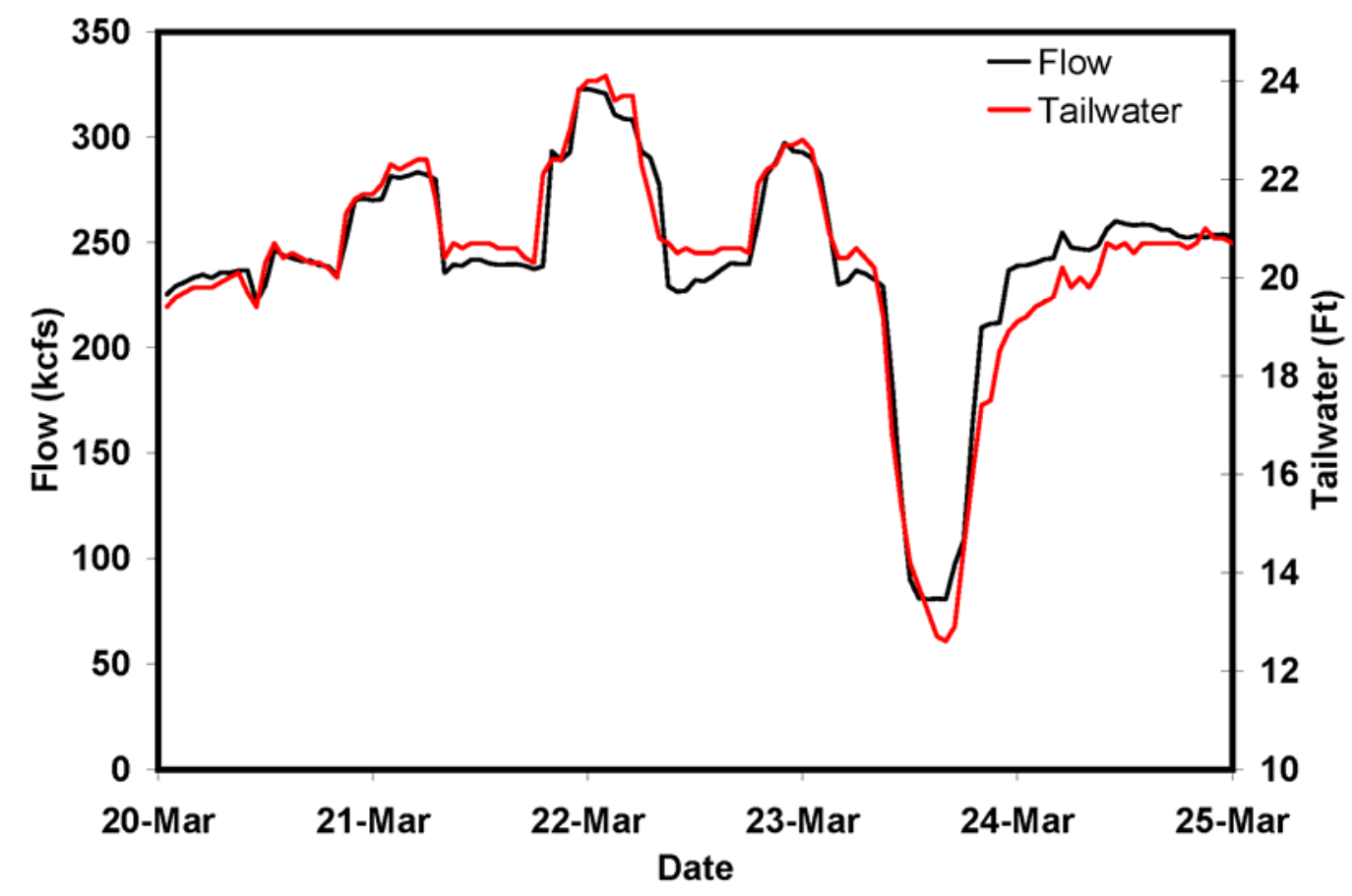

Figure 3.5. Flow and tailwater levels before, during, and after chum salmon redd flushing

Eight redds were pumped and 87 fry collected from three of the eight redds (Figure 3.2). Fifty-one fish were collected from redd 123, fifteen fish from redd 127, and twenty-one fish from redd 134 (Table 3.1). Forty-three fish were examined externally; a subset of five was also examined internally. Six other fry were euthanized and preserved in a $10 \%$ solution of NBF for possible histological examination. The fry from redd 123 were less developed than those from the other two redds. These sac fry averaged $29.2 \mathrm{~mm}$ in length. Fry from redds 127 and 134 were nearly buttoned-up and averaged $38.9 \mathrm{~mm}$ and $40.3 \mathrm{~mm}$ in length, respectively.

Table 3.2 summarizes observations made during examinations. Of the 38 fish examined externally, 2 had air bubbles in the nares; no fish had bubbles in the fins, caudal peduncle, yolk, or eyes. Of the subset of five fish also examined internally, four had partially to fully inflated swim bladders and four had bubbles in the stomach and/or hindgut. Hemorrhaging in the fins was observed in half of the fish. This injury was attributed to trauma during pumping and collection. 


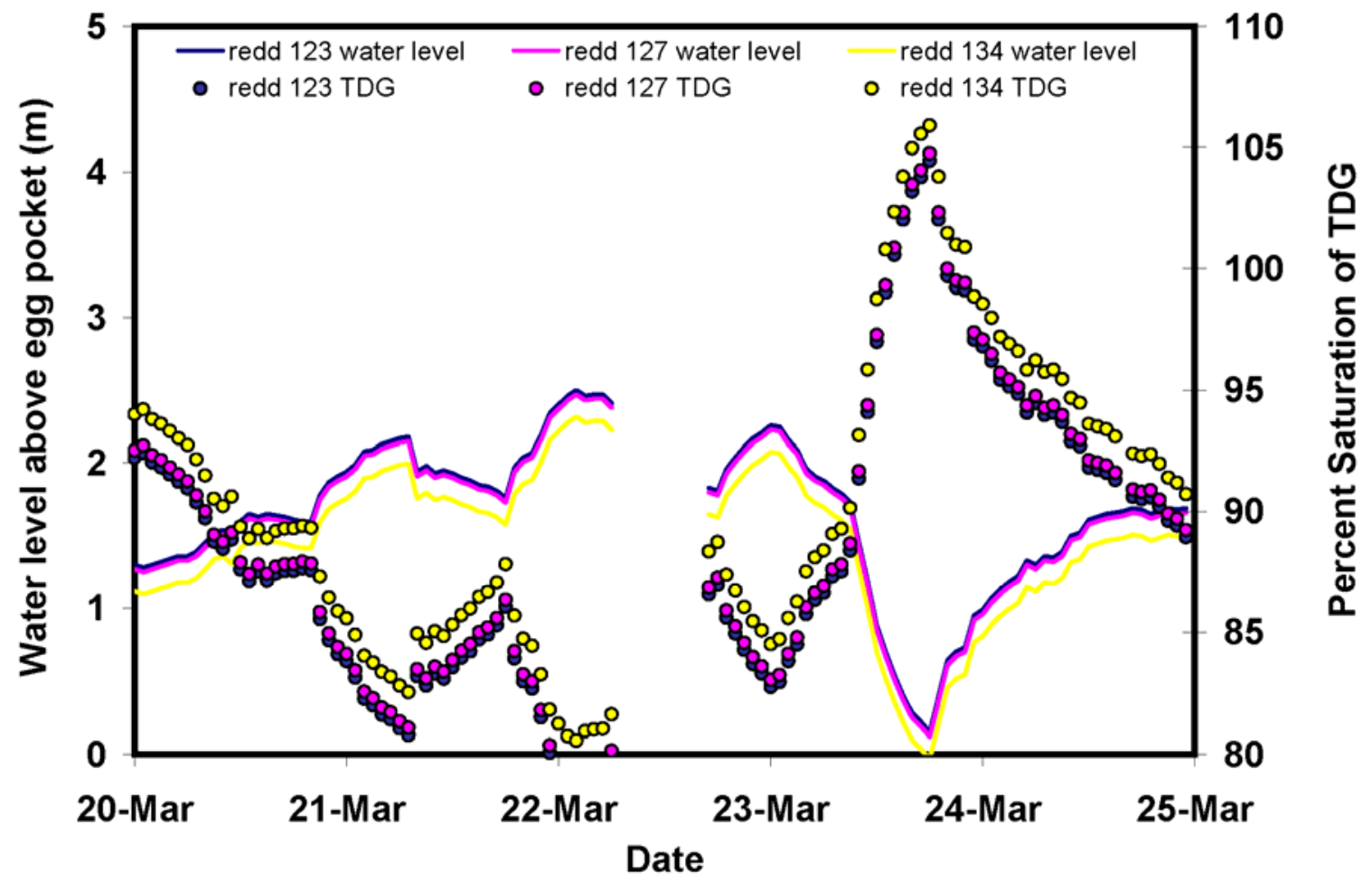

Figure 3.6. Depth-compensated TDG (circles) and water levels above the egg pocket (solid lines) at redds where live chum alevin were collected

Table 3.1. Numbers of alevins collected, examined, and released during redd sampling

\begin{tabular}{cccc}
\hline Redd No. & Fish Collected $(n)$ & Fish Examined $(n)$ & Fish Released $^{(\mathrm{a})}(n)$ \\
\hline 123 & 51 & 18 & 47 \\
127 & 15 & 13 & 10 \\
134 & 21 & 12 & 17 \\
Total & 87 & 43 & 74 \\
\hline
\end{tabular}

(a) Fish not released included mortalities and fish euthanized for lethal examination and histology samples.

Table 3.2. Results of alevin examinations

\begin{tabular}{lccc}
\hline \multicolumn{1}{c}{ External Exam } & $\begin{array}{c}\text { Redd 123 } \\
(n=18)\end{array}$ & $\begin{array}{c}\text { Redd 127 } \\
(n=13)\end{array}$ & $\begin{array}{c}\text { Redd 134 } \\
(n=12)\end{array}$ \\
\hline Bubbles on surface of eyes & 0 & 0 & 0 \\
Bubbles in nares & 0 & 2 & 0 \\
Hemorrhaging in fins & 9 & 9 & 4 \\
\hline \multicolumn{1}{c}{ Internal Exam } & Redd 123 & Redd 127 & $(n=3)$ \\
\multicolumn{1}{c}{ Inflated swim bladder } & no sample & 2 & Redd 134 \\
Bubbles in intestinal tract & no sample & 3 & 2 \\
\hline
\end{tabular}




\section{Discussion}

Very few external signs of gas bubble disease were observed. This result was not surprising, considering the relatively high river discharge during the week leading up to sac fry sampling. Depthcompensated TDG did exceed $105 \%$ at targeted redds the day sampling occurred, when river stage dropped approximately $2 \mathrm{~m}$. The drop in river stage started the morning of March 23, 2007, with river levels decreasing by approximately $3 \mathrm{ft}$ in the Ives Island area by noon (the approximate time at which sac fry sampling began). The river stage decreased approximately 3 additional $\mathrm{ft}$ from noon until sampling ended at approximately 1700 hours. Thus, the potential exposure time of alevins to elevated TDG was zero to 6 hours, depending on redd elevation. This corresponded to exposure times to depth-compensated TDG greater than $100 \%$ of approximately 9 hours at redd 134 and approximately 6 hours at redds 123 and 127. Estimated exposure times to depth-compensated TDG greater than $103 \%$ was 5 hours at redd 134 and 3 hours at redds 123 and 127 . Redd 134 was exposed to depth-compensated TDG greater than 105\% for approximately 2.5 hours. Redds 123 and 127 reached peak depth-compensated TDG concentrations of $104.5 \%$ and $104.8 \%$, respectively.

Despite the relatively low TDG concentrations and short exposure time, results from internal examinations on five specimens suggested that four out of five of them had inflated swim bladders, and four out of five had bubbles in the intestinal tract. While this represents symptoms of GBD in $80 \%$ of the fish examined, the sample size was very small. Our sample size was small because we wanted to release most alevins unharmed and also because time during the evaluation was constrained. Our internal examination procedure required approximately 10 minutes per fish, and examinations needed to be completed within 1 hour of alevin removal from the supersaturated environment o preserve signs of GBD (Hans et al. 1999). To increase the sample size, either additional redds would have to be disturbed or the examination methodology should be modified so several examinations could occur simultaneously.

Estimates of mortality and symptoms of GBD were qualitative because we did not know how many eggs were deposited in naturally occurring chum salmon redds. Future evaluations could provide a quantitative estimate of survival and GBD symptoms if they were conducted using egg baskets deployed in artificial redds placed adjacent to naturally occurring redds. This technique has been used successfully for previous fall Chinook salmon research in the Snake River (Hanrahan et al. 2004; Hanrahan 2007). We suggest this technique could be applied so that it is representative of the gravel environment within the Ives Island spawning area; replicates the depth of a natural chum salmon egg pocket; and emulates the vertical distribution of chum salmon as they respond to effects from total dissolved gas encountered during emergence.

Our results showed that the fry from redd 123 were less developed and smaller than those from the other two redds. Previous work has shown that the timing of alevin development varies widely in the Ives Island area. Geist et al (2002) documented warm areas of upwelling hyporheic water in chum spawning areas and related them to chum salmon spawning site selection. Subsequent temperature monitoring conducted by PNNL was used by the Oregon Department of Fish and Wildlife to estimate accumulated thermal units and predict a wide range of emergence times depending on site specific temperature profiles (Arntzen et al. 2005, 2006b, 2007a; Fish Passage Center 2006). The wide range of development timing indicates that some redds may be exposed to elevated TDG for longer periods than others. This has implications for chronic exposure effects, because elevated TDG may affect some redds differently than others, depending on their developmental stage. 



\section{Chapter 4}

\section{Literature Cited}

Arntzen E, D Geist, T Hanrahan, K McGrath, and S Thorsten. 2005. Summary of Temperature Data Collected to Improve Emergence Timinc Estimates for Chum and Fall Chinook Salmon in the Lower Columbia River - 1998-2004 Progress Report. DOE/BP-00000652027, Bonneville Power Administration, Portland, Oregon.

Arntzen EV, DR Geist, and PE Dressel. 2006a. "Effects of fluctuating river flow on groundwater/surface water mixing in the hyporheic zone of a regulated, large cobble bed river." River Research and Applications 22(8):937-946.

Arntzen EV, TP Hanrahan, KE McGrath, CJ Murray, Y-J Chien, and SL Thorsten. 2006b. "Summary of Temperature Data Collected to Improve Emergence Timing Estimates for Chum and Fall Chinook Salmon in the Lower Columbia River." Chapter 2 in Evaluation of Salmon Spawning Below the Four Lowermost Columbia River Dams - 2004-2005 Annual Report, DR Geist and AJ Currie (eds). DOE/BP00000652-32, Bonneville Power Administration, Portland, Oregon.

Arntzen EV, JL Panther, DR Geist, and EM Dawley. 2007a. Total Dissolved Gas Monitoring in Chum Salmon Spawning Gravels Below Bonneville Dam. PNNL-16200, Pacific Northwest National Laboratory, Richland, Washington.

Arntzen EV, RP Mueller, CJ Murray, Y-J Bott, JL Panther, DR Geist, and TP Hanrahan. 2007b. Evaluation of Salmon Spawning Below Bonneville Dam - Annual Report - October 2005September 2006. DOE/BP-00000652-35, Bonneville Power Administration, Portland, Oregon.

Backman TWH and AF Evans. 2002. "Gas bubble trauma incidence in adult salmonids in the Columbia River Basin.” North American Journal of Fisheries Management 22:579-584.

Backman TWH, AF Evans, MS Robertson, and MA Hawbecker. 2002. "Gas bubble trauma incidence in juvenile salmonids in the lower Columbia and Snake Rivers." North American Journal of Fisheries Management 22:965-972.

Bams RA. 1970. "Evaluation of a revised hatchery method tested on pink and chum salmon fry." Journal of the Fisheries Research Board of Canada 27:1429-1452.

Becker K, RP Von Herzen, TJG Francis, RN Anderson, J Honnorez, AC Adamson, JC Alt, R Emmermann, PD Kempton, H Kinoshita, C Laverne, MJ Mottl, and RL Newmark. 1982. "In situ electrical resistivity and bulk porosity of the oceanic crust Costa Rica Rift." Nature 300:594-598.

Beiningen KT and WJ Ebel. 1970. "Effect of John Day Dam on dissolved nitrogen concentrations and salmon in the Columbia River." Transactions of the American Fisheries Society 99:664-671. 
Beiningen KT and WJ Ebel. 1971. Dissolved Nitrogen, Dissolved Oxygen, and Related Water Temperatures in the Columbia and Lower Snake Rivers, 1965-69. Data Report No. 56, National Marine Fisheries Service, Seattle, Washington.

Birtwell IK, JS Korstrom, M Komatsu, BJ Fink, LI Richmond, and RP Fink. 2001. The Susceptibility of Juvenile Chum Salmon (Oncorhynchus keta) to Predation Following Sublethal Exposure to Elevated Temperature and Dissolved Gas Supersaturation in Seawater. Canadian Technical Report of Fisheries and Aquatic Sciences 2343:1-128, Fisheries and Oceans Canada, Ottawa, Ontario, Canada.

Blicher-Mathiesen G, GW McCarty, and LP Nielsen. 1998. "Denitrification and degassing in groundwater estimated from dissolved dinitrogen and argon." Journal of Hydrology 208:16-24.

Bouck GR. 1982. "Gasometer: An inexpensive device for continuous monitoring of dissolved gases and supersaturation." Transactions of the American Fisheries Society 111:505-516.

Colt J. 1983. "The computation and reporting of dissolved gas levels." Water Research 17:841-849.

Colt J. 1984. Computation of Dissolved Gas Concentrations in Water as Functions of Temperature, Salinity, and Pressure. Special Publication 14, American Fisheries Society, Bethesda, Maryland.

Crisp DT. 1990. "Water temperatures in a stream gravel bed and implications for salmonid incubation." Freshwater Biology 23:601-602.

Dannevig A and G Dannevig. 1950. "Factors affecting the survival of fish larvae." Journal du Conseil International pour l'Exploration de la Mer 15:277-283.

Dawson DK. 1986. Computer program calculation of gas supersaturation in water. The Progressive Fish-Culturist 48:142-146.

Ebel WJ. 1969. "Supersaturation of nitrogen in the Columbia River and its effect on salmon and steelhead trout." Fisheries Bulletin 68(1):1-11.

Ebel W and H Raymond. 1976. "Effects of atmosphere gas saturation on salmon and steelhead trout of the Snake and Columbia Rivers." Marine Fisheries Review 38(7):1-14.

EPA (U.S. Environmental Protection Agency). 1987. Quality Criteria for Water 1986. EPA 440/5-86001, U.S. Environmental Protection Agency, Washington, D.C.

Fidler LE and SB Miller. 1997. British Columbia Water Quality Guidelines for the Protection of Aquatic Biota from Dissolved Gas Supersaturation - Technical Report. Ministry of Environment, Lands and Parks, Environment Canada, Department of Fisheries and Oceans, Vancouver, British Columbia, Canada.

Fish Passage Center. 2006. "Spawning - Water Temperature and Emergence." Available at http://www.fpc.org/spawning/spawning_emergence.html (October 2007).

Geist DR, MC Joy, DR Lee, and T Gonser. 1998. "A method for installing piezometers in large cobble bed rivers." Ground Water Monitoring and Remediation 18(1):78-82. 
Geist DR, TP Hanrahan, EV Arntzen, GA McMichael, CJ Murray, and Y-J Chien. 2002.

"Physicochemical characteristics of the hyporheic zone affect redd site selection by chum salmon and fall Chinook salmon in the Columbia River." North American Journal of Fisheries Management 22:10771085.

Geist DR, EV Arntzen, CJ Murray, K McGrath, Y Bott, and TP Hanrahan. "Influence of river level on temperature and hydraulic gradients in chum and fall Chinook salmon spawning areas downstream of Bonneville Dam, Columbia River.” North American Journal of Fisheries Management (in press).

Hach Environmental. 2006. Hydrolab DS5X, DS5, and MS5 Water Quality Multiprobes - User Manual - February 2006, Edition 3. Hach Environmental, Loveland, Colorado.

Hans KM, MG Mesa, and AG Maule. 1999. "Rate of disappearance of gas bubble trauma signs in juvenile salmonids.” Journal of Aquatic Animal Health 11:383-390.

Henly E. 1952. "The influence of the gas content of sea-water on fish and fish larvae." Rapports et Proces-verbaux des Reunions, Conseil International pour l'Exploration de la Mer 131(3):24-27.

Jensen JOT and ME Jensen. 1999. "IncubWin: A new Windows 95/98,NT computer program for predicting embryonic stages in Pacific salmon and steelhead trout." Bulletin of the Aquaculture Association of Canada 99(4):28-30.

Knittel MD, GA Chapman, and RR Garton. 1980. "Effects of hydrostatic pressure on steelhead survival in air-supersaturated water." Transactions of the American Fisheries Society 109:755-759.

Krise WF. 1993. "Effects of one-year exposures to gas supersaturation on lake trout." The Progressive Fish-Culturist 55:159-176.

Krise WF and RL Herman. 1989. "Tolerance of lake trout (Salvelinus namaycush Walbaum) sac fry to dissolved gas supersaturation." Journal of Fish Diseases 12:269-273.

Krise WF and JW Meade. 1988. "Effects of low-level gas supersaturation on lake trout (Salvelinus namaycush)." Canadian Journal of Fisheries and Aquatic Sciences 45:666-674.

Lom J and RF Nigrelli. 1970. "Brooklynella hostilis n. g., n. sp., a pathogenic cyrtophorine ciliate in marine fishes." Journal of Protozoology 17(2):224-232.

Luna LG (ed). 1968. Manual of Histologic Staining Methods of the Armed Forces Institute of Pathology. 3rd ed. McGraw-Hill Book Company, New York.

McGrath K, E Dawley, and DR Geist. 2006. Total Dissolved Gas Effects on Fishes of the Lower Columbia River. PNNL-15525, Pacific Northwest National Laboratory, Richland, Washington.

McMichael GA, CL Rakowski, BB James, and J Lukas. 2005. "Estimated fall Chinook salmon survival to emergence in dewatered redds in a shallow side channel of the Columbia River." North American Journal of Fisheries Management 25(3):876-884. 
Meekin TK and RL Allen. 1974. "Summer Chinook and sockeye salmon mortality in the upper Columbia River and its relationship to nitrogen supersaturation." In Nitrogen Supersaturation Investigations in the Mid-Columbia, Washington Department of Fisheries Technical Report 12, pp. 127153. Washington Department of Fisheries, Olympia.

Mookherji S, GW McCarty, and JT Angier. 2003. "Dissolved gas analysis for assessing the fate of nitrate in wetlands." Journal of the American Water Resources Association 39:381-387.

NAS/NAE (National Academy of Sciences/National Academy of Engineering). 1973. Water Quality Criteria 1972. EPA-R3-73033, U.S. Environmental Protection Agency, Washington, D.C.

Nebeker AV, AK Hauck, and FD Baker. 1979. "Temperature and oxygen-nitrogen gas ratios affect fish survival in air-supersaturated water." Water Research 13:299-303.

Nebeker TE, JD Hodges, BL Karr, and DM Moehring. 1985. Thinning Practices in Southern Pines With Pest Management Recommendations. Technical Bulletin 1703, U.S. Department of Agriculture, Washington, D.C.

NMFS (National Marine Fisheries Service). 1999. "Listing Endangered and Threatened Species and Designating Critical Habitat: Petition to List Eighteen Species of Marine Fishes in Puget Sound, Washington." Federal Register, 21 June 1999, 64(118):33037-33040.

NOAA (National Oceanographic and Atmospheric Administration). 1995. Item 2. Pages 104-110 in Endangered Species Act - Section 7, Consultation, Biological Opinion, Federal Columbia River Power System (FCRPS). National Oceanic and Atmospheric Administration, National Marine Fisheries Service, Northwest Regional Office, Seattle, Washington.

NOAA (National Oceanographic and Atmospheric Administration). 2000. "Risk Assessment for Spill Program Described in 2000 Draft Biological Opinion." Appendix E in Endangered Species Act - Section 7, Biological Opinion on the Reinitiation of Consultation on Operation of the Federal Columbia River Power System, Including the Juvenile Fish Transportation Program, and 19 Bureau of Reclamation Projects in the Columbia Basin. National Oceanic and Atmospheric Administration, National Marine Fisheries Service, Northwest Regional Office, Seattle, Washington.

Pauley GB and RE Nakatani. 1967. "Histopathology of "gas-bubble" disease in salmon fingerlings." Journal of the Fisheries Research Board of Canada 24(4):867-871.

Peterson H. 1971. Smolt rearing methods, equipment and techniques used successfully in Sweden. In Atlantic Salmon Workshop, WM Carter (ed), Atlantic Salmon Foundation Special Publication Series 2(1), pp. 32-62. International Atlantic Salmon Foundation, Fredericton, Nova Scotia, Canada.

Rucker RL. 1975. The home range of the coyote (Canis latrans) and its method of calculation. Masters thesis, Idaho State University, Pocatello.

Rucker RR and PM Kangas. 1974. "Effect of nitrogen supersaturated water on coho and Chinook salmon.” The Progressive Fish-Culturist 36(3):152-156. 
Rucker RR, BJ Earp, and EJ Ordal. 1954. "Infectious diseases of Pacific salmon." Transactions of the American Fisheries Society 83(1):297-312.

Ryan BA and EM Dawley. 1998. Effects of Dissolved Gas Supersaturation on Fish Residing in the Snake and Columbia Rivers, 1997. Bonneville Power Administration, Portland, Oregon. Available at http://pisces.bpa.gov/release/documents/documentviewer.aspx?doc=93605-2 (October 2007).

Ryan BA, EM Dawley, and RA Nelson. 2000. "Modeling the effects of dissolved gas supersaturation on resident aquatic biota in the mainstem Snake and Columbia Rivers." North American Journal of Fisheries Management 20:192-204.

Shepherd BG, GF Hartman, and WJ Wilson. 1986. "Relationships between stream and intra-gravel temperatures in coastal drainages, and some implications for fisheries workers." Canadian Journal of Fisheries and Aquatic Sciences 43:1818-1822.

Shirahata S. 1966. "Experiments on nitrogen gas disease with rainbow trout fry." Bulletin of the Freshwater Fisheries Research Laboratory (Tokyo) 15:197-211.

Silver SJ, CE Warren, and P Doudoroff. 1963. "Dissolved oxygen requirements of developing steelhead trout and Chinook salmon embryos at different velocities." Transactions of the American Fisheries Society 92(4):327-343.

Tanner DQ and MW Johnston. 2001. Data-Collection Methods, Quality-Assurance Data, and Site Considerations for Total Dissolved Gas Monitoring, Lower Columbia River, Oregon and Washington, 2000. Water Resources Investigations Report 01-4005, U.S. Geological Survey, Portland, Oregon.

Tiffin K, R Garland, D Rondorf, and J Skalicky. 2004. Juvenile and Adult Fall Chinook and Chum Salmon habitat Studies below Bonneville Dam on the Columbia River - 2002-2003 Annual Report. DOE/BP-00004701-2, Bonneville Power Administration, Portland, Oregon.

Toner MA and EM Dawley. 1995. Evaluation of the Effects of Dissolved Gas Supersaturation on Fish and Invertebrates Downstream from Bonneville Dam, 1993. U.S. Army Corps of Engineers, Portland District, Portland, Oregon.

USACE (U.S. Army Corps of Engineers), U.S. Bureau of Reclamation, and Bonneville Power Administration. 2004. Final updated proposed action for the FCRPS biological opinion remand. November 24, 2004. Available at http://www.salmonrecovery.gov/biological_Opinions/FCRPS/biop_remand_2004/update (October 2007).

Urawa S and S Yamao. 1992. "Scanning electron microscopy and pathogenicity of Chilodonella piscicola (Chiliophora) on juvenile salmonids.” Journal Aquatic Animal Health 4:188-197.

Vaux WG. 1968. "Intragravel flow and interchange of water in a streambed." U.S. Fish and Wildlife Service Fishery Bulletin 66:479-489.

Weitkamp DE and M Katz. 1980. “A review of dissolved gas supersaturation literature.” Transactions of the American Fisheries Society 109:659-702. 
Weitkamp DE, RD Sullivan, T Swant, and J DosSantos. 2003. "Gas bubble disease in resident fish of the Lower Clark Fork River." Transactions of the American Fisheries Society 132:865-876.

White DS. 1993. "Perspectives on defining and delineating hyporheic zones." Journal of the North American Benthological Society 12(1):61-69.

Wickett P. 1954. "The oxygen supply to salmon eggs in spawning beds." Journal of the Fisheries Research Board of Canada 116:933-953.

Wright PB and WE McLean. 1985. "The effects of aeration on the rearing of summer Chinook fry (Onchorhunchus tshawytscha) at the Puntledge Hatchery." Canadian Technical Report of Fisheries and Aquatic Sciences 1390.

Zirges MM and LD Curtis. 1975. "An experimental heated-water incubation system for salmonid eggs." The Progressive Fish-Culturist 37(4):217-218. 


\section{Appendixes}

Supplemental information is included in the following appendixes, which are on the CD that accompanies this report:

Appendix A - Membrane Tests

Appendix B - Water Quality Data

Appendix C - Total Dissolved Gas Exposure Estimates at Ives Island, Spawning Years 2002-2004

Appendix D - Ives Area Redd Dewatering 